\title{
Um auxílio à navegação acessível na web para usuários cegos
}

\author{
Rafael José Geraldo
}



Data de Depósito:

Assinatura:

\title{
Rafael José Geraldo
}

\section{Um auxílio à navegação acessível na web para usuários cegos}

\author{
Tese apresentada ao Instituto de Ciências \\ Matemáticas e de Computação - ICMC-USP, \\ como parte dos requisitos para obtenção do título \\ de Doutor em Ciências - Ciências de Computação e \\ Matemática Computacional. VERSÃO REVISADA \\ Área de Concentração: Ciências de Computação e \\ Matemática Computacional \\ Orientadora: Profa. Dra. Renata Pontin de \\ Mattos Fortes
}

\section{USP - São Carlos}

Novembro de 2016 
Ficha catalográfica elaborada pela Biblioteca Prof. Achille Bassi e Seção Técnica de Informática, ICMC/USP, com os dados fornecidos pelo(a) autor(a)

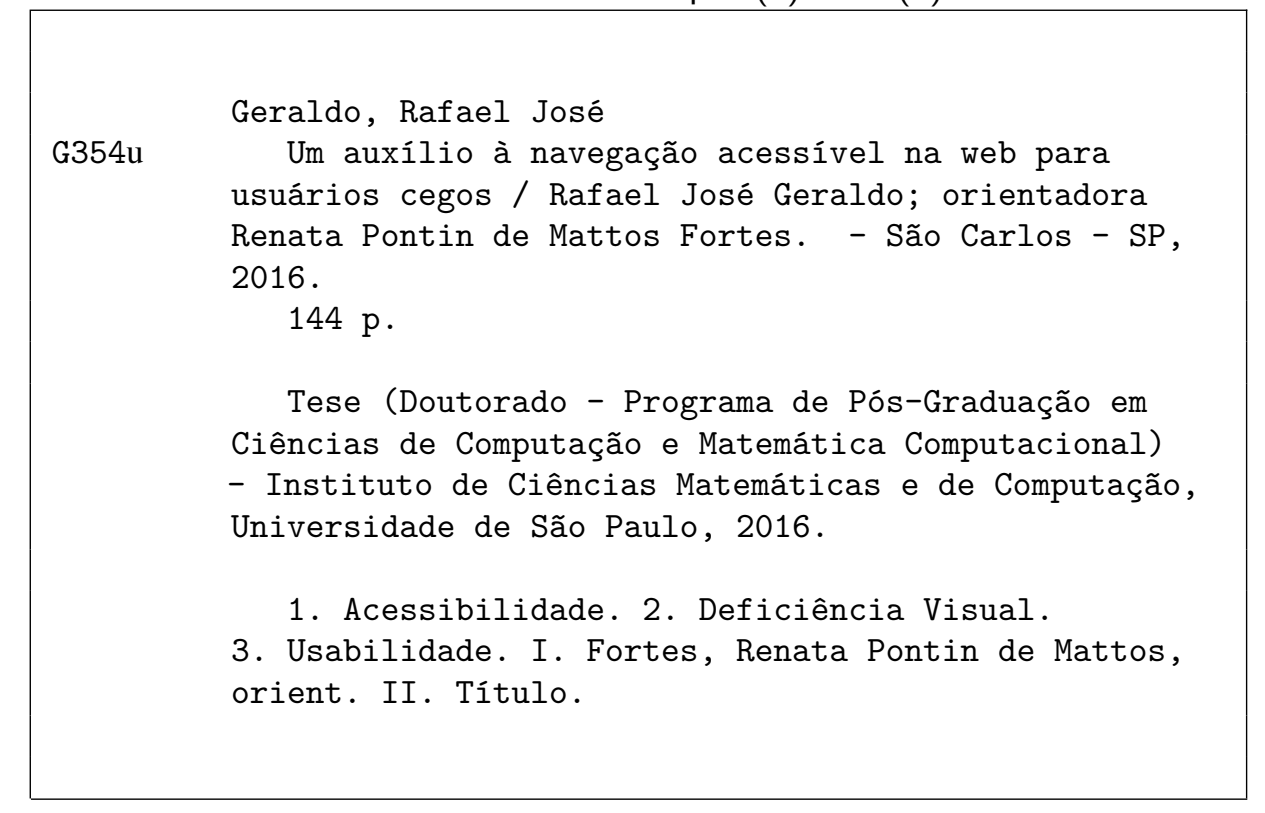




\section{Rafael José Geraldo}

\section{An accessible web navigation aid for blind users}

Doctoral dissertation submitted to the Instituto de Ciências Matemáticas e de Computação - ICMC-USP, in partial fulfillment of the requirements for the degree of the Doctorate Program in Computer Science and Computational Mathematics. FINAL VERSION

Concentration Area: Computer Science and Computational Mathematics

Advisor: Profa. Dra. Renata Pontin de Mattos Fortes 

Aos meus pais, que sempre me estimularam a dar esse grande passo. Estas duas pessoas com muita sabedoria, discernimento e dedicação estiveram ao meu lado encorajando-me nas horas difíceis e aplaudindo-me nos momentos de glória, portanto têm minha eterna gratidão.

À minha esposa Márcia, pelo incentivo, amor, compreensão e atenção. Agradeço por sempre ter uma palavra de conforto e estímulo nos momentos difíceis. Obrigado também por toda a ajuda nas correções e, acima de tudo, por estar sempre ao meu lado.

À professora Dra Renata Pontin de Mattos Fortes, pela orientação dessa tese. Obrigado por todo seu empenho, dedicação, sabedoria e compreensão com que me conduziu durante todo esse tempo. Agradeço ainda por ter acreditado em mim, pelo conhecimento que adquiri com você e por todo incentivo no decorrer do trabalho.

A todos os meus amigos, pelo companheirismo e pelos momentos compartilhados.

A todos aqueles que, direta ou indiretamente, tive o prazer de trocar conhecimentos para que essa tese atingisse seus objetivos.

Finalmente, agradeço aos professores do Departamento de Ciências de Computação pelas contribuições na minha formação e à CAPES pelo apoio financeiro durante o desenvolvimento desse trabalho. 

"We ourselves feel that what we are doing is just a drop in the ocean. But the ocean would be less because of that missing drop."

(Madre Teresa de Calcuta) 



\section{RESUMO}

GERALDO, R. J.. Um auxílio à navegação acessível na web para usuários cegos. 2016. 144 f. Tese (Doutorado em Ciências - Ciências de Computação e Matemática Computacional) Instituto de Ciências Matemáticas e de Computação (ICMC/USP), São Carlos - SP.

Acessibilidade na Web tem como objetivo possibilitar que qualquer pessoa possa entender e interagir com o conteúdo de uma página Web, independente de deficiências ou outros fatores. Embora exista uma grande quantidade de trabalhos realizados na área, pode-se ainda perceber que pessoas com alguns tipos específicos de deficiências encontram mais dificuldades ao navegar na Web, como no caso dos usuários cegos. Com intuito de minimizar os problemas enfrentados por esses usuários cegos ao navegar na Web, foi proposta nesta tese uma abordagem que consiste em extrair automaticamente o conhecimento de navegação implícito na apresentação visual de uma página Web e alterar o design dessa navegação de uma maneira otimizada a esses usuários. Com esse objetivo, primeiramente foram estudados os trabalhos relacionados aos principais problemas enfrentados pelos usuários cegos ao interagir com a Web, assim como os conjuntos de diretrizes de acessibilidade e usabilidade específicos para minimizar esses problemas, fundamentados em um mapeamento sistemático conduzido sobre o tema.

Após a identificação dos problemas e diretrizes, foi desenvolvido um classificador baseado no método Naïve Bayes, considerando-se três características comumente encontradas nos padrões de design de menus de navegação, com intuito de classificar automaticamente os links contidos nesta página em diferentes classes referentes às estruturas de navegação. Após desenvolvido, o método foi testado e avaliado em sites governamentais por meio de uma análise estatística, apresentando um boa taxa de acerto em suas classificações.

Com base nas dificuldades encontradas na primeira etapa de pesquisa, foi proposto um modelo de interface próprio aos usuários cegos que utilizam a Web com auxílio de um leitor de tela. Com base no classificador desenvolvido, foi proposta uma abordagem para automaticamente transformar os links de navegação classificados pelo método, em um padrão de navegação otimizado aos leitores de tela. Como prova de conceito, foi realizada uma extração semiautomática de conteúdo das páginas Web, com intuito de transformar esse conteúdo para o novo modelo de interface proposto. Nesse contexto, foi desenvolvido um protótipo de mecanismo de apoio, denominado NavAux. Esse protótipo foi avaliado através de um percurso cognitivo. Para isso, foram definidas algumas tarefas e a exploração da interface foi realizada com apoio do leitor de tela JAWS. Os resultados apresentaram indícios de que a abordagem proposta pode ser considerada uma alternativa viável para minimizar os problemas de acessibilidade enfrentados pelos usuários cegos ao navegar na Web.

Palavras-chave: Acessibilidade, Deficiência Visual, Usabilidade. 



\section{ABSTRACT}

GERALDO, R. J.. Um auxílio à navegação acessível na web para usuários cegos. 2016. 144 f. Tese (Doutorado em Ciências - Ciências de Computação e Matemática Computacional) Instituto de Ciências Matemáticas e de Computação (ICMC/USP), São Carlos - SP.

Web Accessibility aims to enable that any individual may understand and interact with a Web page content, regardless of disabilities or other factors. Although there is a large number of research studies in this area, it can be noted individuals with some specific types of disabilities find it more difficulty browsing the Web, such as those who are blind. In order to minimize the problems faced by blind users when browsing the Web, the study reported in this thesis proposed an approach which consists in automatically extracting the navigation knowledge implicit in the visual presentation of a Web page and changing this navigation design to an optimized way to those users.

For this purpose, the research started with a review of the papers related to the main problems faced by blind users when interacting to the Web, as well as the specific sets of accessibility and usability guidelines to minimize these problems, based on a systematic mapping study conducted on the topic.

After identifying the problems and guidelines, the next step involved the development of a classifier based on the Naïve Bayes methods, considering three features commonly found in the design patterns of navigation menus, in order to automatically classify the links contained on each page into different classes relating to the navigation structures. After developed, the method was tested and assessed in governmental websites through an statistical analysis, showing a good success rate in its classifications.

Based on the difficulties encountered during the first step of the research, the study proposed an interface model tailored to blind users who use the Web with the help of a screen reader. Based on the developed classifier, the study proposed an approach to automatically transform the browsing links classified by the method into an optimized navigation standard to screen readers. As a proof of concept, the following step involved a semi-automatic extraction of Web pages content, in order to transform this content to a new proposed interface model. In this context, was developed a prototype of the mechanism, named NavAux. This prototype was evaluated through a cognitive walkthrough. To this, were defined some tasks and the interface operation was performed with support of the JAWS screen reader. The results presented signs that the proposed approach can be considered a viable alternative to minimize the accessibility problems faced by blind users when browsing the Web.

Key-words: Web Accessibility, Visually Impaired, Usability. 



\section{LISTA DE ILUSTRAÇÕES}

Figura 1 - ARIA e a relação entre o Agente de Usuário, API de Acessibilidade e Tecnologia Assistiva. . . . . . . . . . . . . . . . . 46

Figura 2 - Quantidade de resultados encontrados e selecionados em cada base (entre 2008 e 2013). . . . . . . . . . . . . . . . . . 55

Figura 3 - Quantidade de resultados encontrados e selecionados por ano (entre $2008 \mathrm{e}$ 2013). . . . . . . . . . . . . . . . 56

Figura 4 - Quantidade de resultados encontrados e selecionados em cada base (entre 2013 e 2016). . . . . . . . . . . . . . . . . . 57

Figura 5 - Quantidade de resultados encontrados e selecionados por ano (entre $2013 \mathrm{e}$

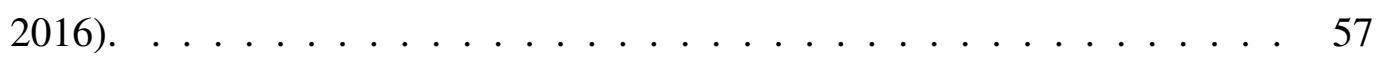

Figura 6 - Quantidade de artigos agrupados em categorias de problema. . . . . . . . . 68

Figura 7 - Padrão de projeto para menu horizontal em páginas Web. . . . . . . . . 73

Figura 8 - Três padrões de projeto para menu vertical em páginas Web. (A) apresenta apenas um nível, (B) apresenta um nível mas expande um segundo nível quando selecionado e (C) apresenta dois níveis agrupados por um título não-clicável de um nível. . . . . . . . . . . . . . . . . . . . . . . 74

Figura 9 - Padrão de projeto para menu L-invertido em páginas Web. . . . . . . . . . . 74

Figura 10 - Exemplos de links considerados como Menu Superior durante o treinamento no Portal do Governo do Estado de São Paulo. . . . . . . . . . . . . . . . . 81

Figura 11 - Exemplos de links considerados Menu Lateral Esquerdo durante o treinamento na página Cidadão.SP. . . . . . . . . . . . . . . . 81

Figura 12 - Exemplos de links considerados Menu Lateral Direito durante o treinamento no Portal do Governo do Estado de São Paulo. . . . . . . . . . . . . . . . . 82

Figura 13 - Exemplos de links considerados Rodapé durante o treinamento no Portal Brasil. 82

Figura 14 - Exemplos de links considerados pertencentes à classe Conteúdo durante o treinamento na página do Incra. . . . . . . . . . . . . . . . 83

Figura 15 - Pop-up para treinamento das amostras referentes às características de posicionamento de um link. . . . . . . . . . . . . . . . . . . . . . . . . . . 84

Figura 16 - Interface do OpenWebSpider. . . . . . . . . . . . . . . . 85

Figura 17 - Ajustes para cada distribuição resultantes do teste qui-quadrado para as amostras referentes ao posicionamento do link em relação a margem esquerda da página. . . . . . . . . . . . . . . 86 
Figura 18 - Ajustes para cada distribuição resultantes do teste qui-quadrado para as amostras referentes ao posicionamento do link em relação ao topo da página. 86

Figura 19 - Ajustes para cada distribuição resultantes do teste qui-quadrado para as amostras referentes a taxa de repetição do link no domínio. . . . . . . . . . 87

Figura 20 - Menus contidos no Rodapé do site Fundacentro. . . . . . . . . . . . . . . . 90

Figura 21 - Links considerados menus laterais no portal do Inmetro . . . . . . . . . . 9 91

Figura 22 - Exemplos simplificados de estruturas comuns encontradas em páginas Web. 95

Figura 23 - Proposta para a estrutura da página Web voltada aos usuários cegos. . . . . 99

Figura 24 - Exemplo de agrupamento para os links do Portal Brasil. . . . . . . . . . . . 105

Figura 25 - Exemplo de novo modelo de navegação construído com base na abordagem proposta. . . . . . . . . . . . . . . . 106 
Código-fonte 1 - Trecho de código HTML utilizado para representar ao cabeçalho da página Web. . . . . . . . . . . . . . . . . . . . . 94

Código-fonte 2 - Trecho de código HTML utilizado para representar a navegação em uma página Web. . . . . . . . . . . . . . . . . . . . 95

Código-fonte 3 - Trecho de código HTML utilizado para representar o conteúdo principal em uma página Web. . . . . . . . . . . . . . . . . . . 96

Código-fonte 4 - Trecho de código HTML utilizado para representar o rodapé em uma página Web. . . . . . . . . . . . . . . . . . . 96

Código-fonte 5 - Trecho de código HTML utilizado para representar conteúdos complementares em uma página Web. . . . . . . . . . . . . . . . . . . 96

Código-fonte 6 - Trecho de código HTML utilizado para representar a região de pesquisa em uma página Web. . . . . . . . . . . . . . . . . . . . . . . 97

Código-fonte 7 - Exemplos de redundância na marcação ARIA e HTML5. . . . . . . . . 97 Código-fonte 8 - Estrutura HTML5 básica do NavAux, com os respectivos atributos

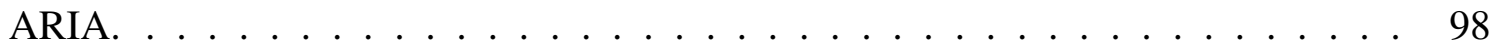





\section{LISTA DE TABELAS}

Tabela 1 - Categorias de problemas apresentados pelos usuários. . . . . . . . . . 51

Tabela 2 - Médias e variâncias das amostras de treinamento para as diferentes características e classes. . . . . . . . . . . . . . . . . . . . . . . . . 85

Tabela 3 - Resultados experimentais do classificador proposto. . . . . . . . . . . . 88

Tabela 4 - Links extraídos do Portal Brasil e classificados pelo método desenvolvido. . 104 

$1 \quad$ INTRODUÇÃO $\ldots \ldots \ldots \ldots \ldots \ldots$

$1.1 \quad$ Acessibilidade na Web e Usuários Cegos . . . . . . . . . . . . . 24

$1.2 \quad$ A Tese . . . . . . . . . . . . . . . . . . . . . . . . . . 27

1.3 Trabalhos Relacionados . . . . . . . . . . . . . . . . . 28

$1.4 \quad$ Metodologia de Pesquisa $\ldots \ldots \ldots \ldots$

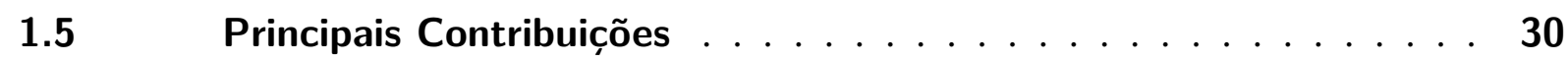

$1.6 \quad$ Estrutura da Tese $\ldots \ldots \ldots \ldots \ldots$

$2 \quad$ ACESSIBILIDADE NA WEB $\ldots \ldots \ldots \ldots \ldots \ldots$

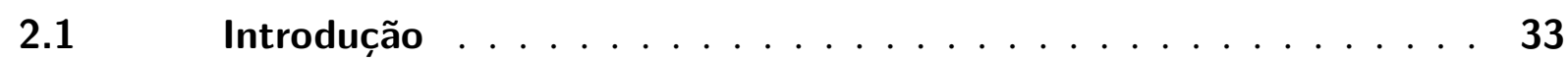

$2.1 .1 \quad$ Tecnologia Assistiva $\ldots \ldots \ldots \ldots \ldots$

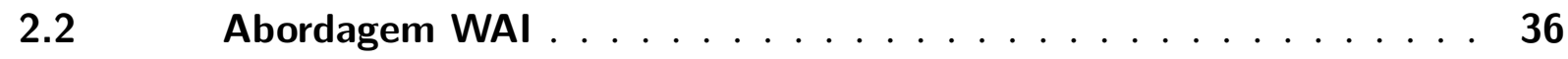

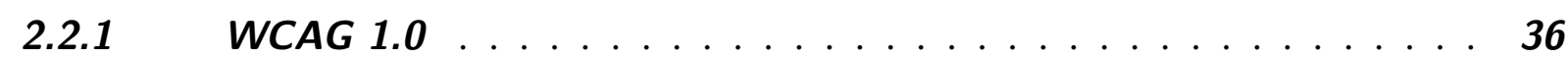

$2.2 .2 \quad$ WCAG $2.0 \ldots \ldots \ldots \ldots \ldots \ldots$

$2.2 .3 \quad$ ARIA . . . . . . . . . . . . . . . . . . . . . . . . . 44

$2.2 .4 \quad$ ARIA e Navegação via Teclado . . . . . . . . . . . . . . . 46

$2.2 .5 \quad$ ARIA 1.1 . . . . . . . . . . . . . . . . . . . . . 47

$2.3 \quad$ Pessoas com Deficiência Visual na Web . . . . . . . . . . . . . 48

$2.3 .1 \quad$ Leitores de Tela . . . . . . . . . . . . . . . . . . . . . . . 48

$2.3 .2 \quad$ Problemas Enfrentados pelos Usuários Cegos na Web . . . . . . 50

$2.4 \quad$ Considerações Finais $\ldots \ldots \ldots \ldots \ldots \ldots$

3 ACESSIBILIDADE E USABILIDADE PARA USUÁRIOS CEGOS. . 53

$3.1 \quad$ Planejamento do Mapeamento Sistemático . . . . . . . . . 54

$3.2 \quad$ Execução do Mapeamento Sistemático . . . . . . . . . . . 55

$3.2 .1 \quad$ Atualização do Mapeamento Sistemático . . . . . . . . . . . . 56

3.3 Dificuldades encontradas por usuários cegos ao navegar na Web . . 57

$3.3 .1 \quad$ Problemas técnicos $\ldots \ldots \ldots \ldots \ldots \ldots \ldots$

$3.3 .2 \quad$ Problemas semânticos ou cognitivos . . . . . . . . . . . . 59

$3.3 .3 \quad$ Problemas na navegação . . . . . . . . . . . . . . . . 62

$3.4 \quad$ Diretrizes de Acessibilidade e usabilidade . . . . . . . . . . . 63

$3.4 .1 \quad$ Diretrizes técnicas . . . . . . . . . . . . . . . . . . . . . . . . 64

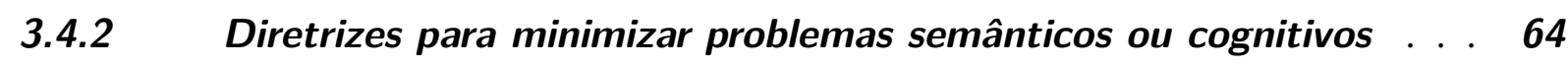


3.4.3 Diretrizes para minimizar problemas de navegação . . . . . . . . 66

3.5 Discussão dos Resultados . . . . . . . . . . . . . . . . . 67

3.5.1 Primeira versão do mapeamento sistemático . . . . . . . . . . . . 67

3.5.2 Atualização do mapeamento sistemático . . . . . . . . . . . . . 69

$3.6 \quad$ Considerações Finais $\ldots \ldots \ldots \ldots \ldots$

4 CLASSIFICAC̣ÃO AUTOMÁTICA DE LINKS DE NAVEGAÇÃO

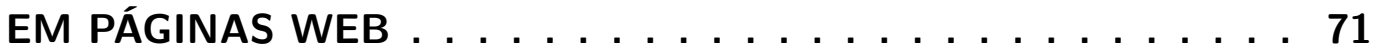

$4.1 \quad$ Menus de Navegação $\ldots \ldots \ldots \ldots$

4.1 .1 Menu Horizontal . . . . . . . . . . . . . . . . . . . . . . . . . 73

$4.1 .2 \quad$ Menu Vertical . . . . . . . . . . . . . . . . . . . . . . 73

4.1 .3 Menu L-Invertido . . . . . . . . . . . . . . . . . . . . . . . . 74

$4.2 \quad$ Metodologia Proposta $\ldots \ldots \ldots \ldots$. . . . . . . . . . . 75

$4.2 .1 \quad$ Nä̈ve Bayes . . . . . . . . . . . . . . . . . . . . 76

$4.2 .2 \quad$ Estimador por Método dos Momentos . . . . . . . . . . . . 78

$4.2 .3 \quad$ Teste Qui-Quadrado . . . . . . . . . . . . . . . . . . . 79

4.3 Desenvolvimento do Classificador . . . . . . . . . . . . . . . . . 79

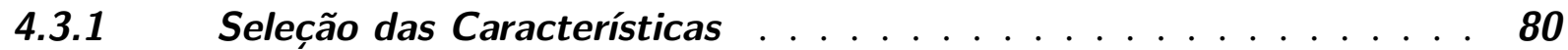

4.3.2 Definição das Classes . . . . . . . . . . . . . . . . . . . . . . 80

$4.3 .3 \quad$ Amostras de Treinamento . . . . . . . . . . . . . . . . . . 82

$4.3 .4 \quad$ Teste de Hipótese . . . . . . . . . . . . . . . . . . . . . . . . . 84

$4.3 .5 \quad$ Construção do Classificador . . . . . . . . . . . . . . . . . 86

$4.4 \quad$ Avaliação e Resultados Obtidos . . . . . . . . . . . . . . . . . 87

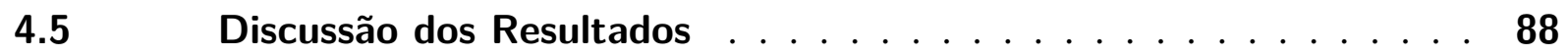

$4.6 \quad$ Considerações Finais $\ldots \ldots \ldots \ldots \ldots$

5 INTERFACE E NAVEGAÇÃO WEB OTIMIZADAS PARA USUÁ-

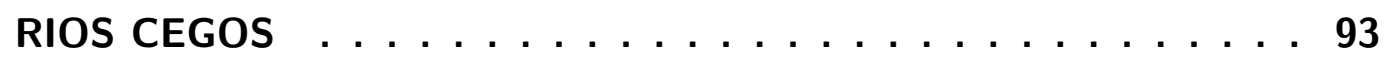

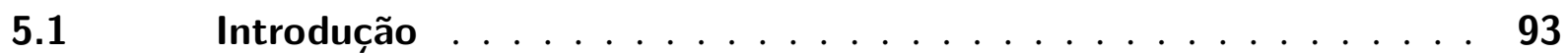

$5.2 \quad$ Estrutura de uma página Web $\ldots \ldots \ldots$. . . . . . . . . . 94

$5.3 \quad$ NavAux . . . . . . . . . . . . . . . . . . . . . . . . 97

5.3 .1 Estrutura Geral . . . . . . . . . . . . . . . . . . . 98

5.3.2 Cabeçalho - Atalhos/Busca . . . . . . . . . . . . . 100

5.3.3 Conteúdo Principal e Complementar . . . . . . . . . . . . . . . . . 100

$5.3 .4 \quad$ Navegação . . . . . . . . . . . . . . . . . . . . . 101

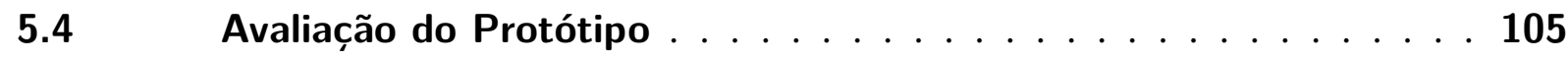

$5.4 .1 \quad$ Preparação . . . . . . . . . . . . . . . . . . 106

$5.4 .2 \quad$ Análise e Coleta de Dados . . . . . . . . . . . . . . . . . . . . 107

5.4 .3 Relato dos Resultados . . . . . . . . . . . . . . . . . 109

$5.5 \quad$ Considerações Finais $\ldots \ldots \ldots \ldots \ldots \ldots$ 


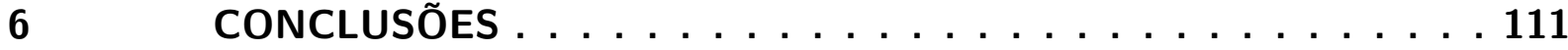

$6.1 \quad$ Limitações dos Estudos Realizados . . . . . . . . . . . . . . . . . 113

6.2 Trabalhos Futuros . . . . . . . . . . . . . . . . . . . . . . 114

REFERÊNCIAS . . . . . . . . . . . . . . . . . . . 117

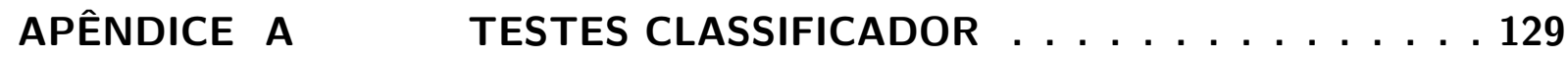

A.1 Resultados da Avaliação do Classificador . . . . . . . . . . . . 129

A.1.1 previdencia.gov.br . . . . . . . . . . . . . . . . 129

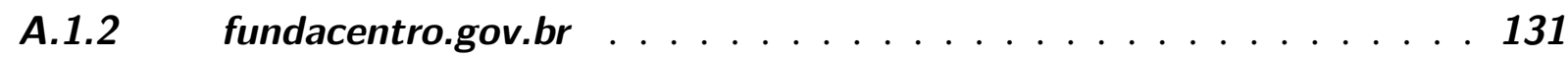

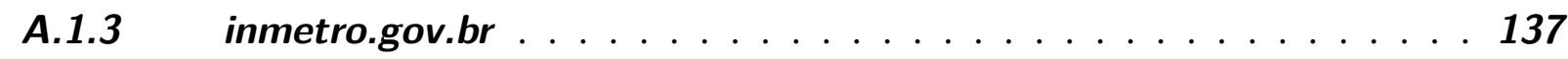

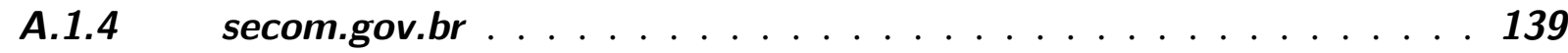

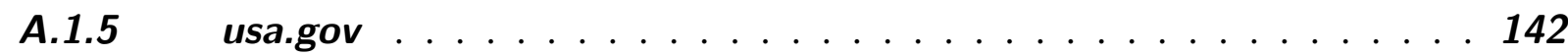



Pouco mais do que vinte anos após a sua criação, a Web permite aos seus usuários o acesso a uma grande variedade de informações e serviços, evidenciando uma evolução incontestável para a atual era da Sociedade da Informação. Porém, nem todas as pessoas podem usufruir dessa ampla gama de conteúdos disponibilizados pela rede, devido à existência de um grande número de páginas Web não acessíveis, impossibilitando, por exemplo, que pessoas com deficiência possam efetivamente utilizá-las. Para piorar a situação, estudos mostram que a Web está se tornando menos acessível às pessoas com algum tipo de deficiência ao passar do tempo KANE et al., 2007; GALLAGHER; PETRIE, 2013; HANSON; RICHARDS, 2013).

Acessibilidade incorpora a ideia de que todas as pessoas têm o direito de serem incluídas na sociedade, independente de deficiências, localização geográfica, barreiras de linguagem, ou outros fatores. Com isso, define-se acessibilidade na Web como a possibilidade de qualquer usuário, utilizando qualquer agente de software ou hardware que recupera e serializa conteúdo Web, entender e interagir com esse conteúdo (THATCHER; WADDELL, 2003). Acessibilidade também é utilizada para definir o acesso de pessoas que, por exemplo, tenham dificuldades em ler ou interpretar textos, ou que possuam conexão lenta com a Internet, ou que possuam um navegador Web que apresente apenas textos, ou não possuam teclado ou mouse, ou ainda, que estejam utilizando a Web de um local com alto nível de ruído sonoro, ou qualquer outro fator que possa limitar o seu acesso à rede (THATCHER; WADDELL, 2003).

Diversas estratégias são propostas para minimizar os problemas de acessibilidade atualmente encontrados. Dentre as principais abordagens estão o desenvolvimento de soluções e recursos de Tecnologia Assistiva (TA) (PORTA; RAVELLI, 2009) (KIRSCH et al., 2004) (BIGHAM; LADNER, 2007) (KUBER, 2006) e os métodos e ferramentas para avaliação automática de acessibilidade (BENAVÍDEZ et al. 2006) (PETRIE et al., 2007), que são desenvolvidos com base em diretrizes de acessibilidade para o desenvolvimento de páginas Web, como por exemplo, o Web Content Accessibility Guidelines (WCAG) (CHISHOLM; VANDERHEIDEN; 
JACOBS, 2001) (CALDWELL et al., 2008). Além de conscientizar os desenvolvedores sobre a importância da acessibilidade na Web, os conjuntos de diretrizes definem como devem ser desenvolvidas páginas Web acessíveis, influenciando diretamente no desenvolvimento dos novos padrões para tecnologias Web.

Apesar de uma quantidade cada vez maior de trabalhos nessa área (GALLAGHER; PETRIE, 2013), estudos ainda mostram que a acessibilidade das páginas e aplicações Web está aquém de um nível aceitável (LOPES; GOMES; CARRIÇO, 2010; KANE et al., 2007). As razões por trás dos níveis de acessibilidade pouco satisfatórios no conteúdo Web têm sido amplamente discutidas. Estudos realizados com grupos de usuários com diferentes deficiências apontam que muitos dos problemas vivenciados por eles não são uma violação de qualquer diretriz, e não seriam detectados sem testes com usuários (COMMISSION et al., 2004; POWER et al. 2012).

A legislação em muitos países tem reforçado a exigência de cumprimento de diretrizes de acessibilidade no desenvolvimento de páginas Web para todos os cidadãos, em especial os usuários com deficiência, como por exemplo, a Section $50 \$^{1}$ nos Estados Unidos e o e-MAG ${ }^{2}$ no Brasil. Porém, quando desenvolvedores utilizam essas diretrizes voltadas para uma enorme diversidade de usuários, observa-se que não são claras as reais dificuldades enfrentadas pelos usuários ao tentar usufruir de seus direitos como cidadãos na sociedade que atualmente conta, frequentemente, com as TICs (Tecnologias de Informação e Comunicação) se disseminando nos diversos setores de serviços.

Assim, são notados indícios de que a conformidade com o conjunto de diretrizes de acessibilidade é uma condição necessária, mas não suficiente para garantir que as páginas Web sejam acessíveis e utilizáveis por todas as pessoas com deficiência. Com base nesses indícios, uma outra abordagem na literatura busca minimizar problemas de acessibilidade na Web para domínios específicos de deficiências (WATANABE et al., 2010; FREIRE et al. 2010; SANTOS et al., 2011; WATANABE et al., 2009). Dentre os diferentes grupos de deficiências, um dos grupos de usuários que merece atenção especial é o grupo dos usuários cegos.

\subsection{Acessibilidade na Web e Usuários Cegos}

Comparado ao dos usuários com visão, o comportamento de navegação dos usuários cegos é completamente distinto. As estratégias para acessar as informações de uma página Web, por meio de uma Tecnologia Assistiva, um leitor de tela ou um terminal de braile, são muito diferentes das utilizadas na navegação visual e não podem ser comparadas (SAVIDIS; STEPHANIDIS, 1998). Em geral, para viabilizar a interação com os sistemas computacionais pelos cegos, diversas iniciativas são encontradas na literatura. Destacam-se iniciativas relacionadas

1 http://www.section508.gov/

2 http://www.governoeletronico.gov.br/acoes-e-projetos/e-MAG 
com recursos e soluções de Tecnologia Assistiva (TA) e as diretrizes que regulamentam as boas práticas de desenvolvimento dos componentes de software.

Segundo o Comitê de Ajudas Técnicas - CAT, do Ministério da Justiça, Tecnologia Assistiva é uma área do conhecimento, de característica interdisciplinar, que engloba produtos, recursos, metodologias, estratégias, práticas e serviços que objetivam promover a funcionalidade, relacionada à atividade e participação de pessoas com deficiência, incapacidades ou mobilidade reduzida, visando sua autonomia, independência, qualidade de vida e inclusão social.

Para pessoas com deficiência visual total (cegos), a utilização de Tecnologia Assistiva na forma do recurso de software "leitor de tela" é essencial. O leitor de tela é um software que realiza a leitura dos componentes apresentados na tela do computador, emitindo-os por voz, dedicado especialmente a indivíduos com deficiência visual. Dentre os leitores de tela disponíveis, pode-se destacar os softwares JAWS $\mathrm{3}^{3}$ e NVDA ${ }^{4}$ (NonVisual Desktop Access).

Observa-se que recursos visuais, como figuras, gráficos e representações diagramáticas diversas, devem conter uma descrição textual que possa ser processada (lida) pelos leitores de tela. Em especial, vale notar que não basta somente a adição de textos como alternativas às figuras, mas é fundamental que os textos alternativos sejam compreensíveis, ou seja, possuam semântica que transmita a real mensagem daquele elemento gráfico, quando ouvidos por usuários cegos.

Além de Tecnologia Assistiva, outra importante linha de ação para auxiliar a interação dos cegos com as páginas Web se concentra numa perspectiva mais prescritiva. Desse modo, são propostos princípios e diretrizes sobre como devem ser desenvolvidas as páginas Web acessíveis.

Diretrizes 5 para a criação de interfaces são bastante utilizadas no contexto de Interação Humano-Computador (IHC). Elas consistem em um conjunto de orientações para a solução de problemas conhecidos. Já os princípios são afirmações, bastante amplas, fundamentadas em pesquisas sobre como as pessoas aprendem e trabalham. Desta forma, entende-se que um princípio é apenas um objetivo geral, sem dizer como alcançá-lo. As diretrizes representam objetivos mais específicos refinados por especialistas em IHC a partir da pesquisa dos princípios para diferentes contextos. Um princípio pode originar muitas diretrizes, e diretrizes podem ser diferentes para combinações específicas de usuários, ambientes e tecnologia.

O W3C (World Wide Web Consortium), através da WAI (Web Accessibility Initiative), trabalha em diversos padrões e diretrizes que têm por objetivo melhorar a acessibilidade de sites, no entanto, por focar seus esforços em conformidade com suas diretrizes, o W3C promove uma visão mais técnica e mensurável da acessibilidade. Portanto, a WAI definiu um modelo de

\footnotetext{
http://www.freedomscientific.com/ http://www.nvaccess.org/

Apesar da tradução oficial do W3C indicar a tradução de guidelines como "recomendações", optou-se por utilizar a tradução "diretrizes", para não gerar confusão com o termo recomendação (recommendation), utilizado para designar a recomendação de tecnologias pelo W3C.
} 
conformidade com três conjuntos de diretrizes agregadas nos seguintes documentos: WCAG (Web Content Accessibility Guidelines), ATAG (Authoring Tool Accessibility Guidelines) e UAAG (User Agent Accessibility Guidelines).

Para cada diretriz descrita nesses documentos, são descritos checkpoints ou critérios de sucesso que definem etapas ou partes de um projeto que devem ser verificados, pois podem representar barreiras (ou dificuldades) a usuários com algum tipo de limitação (indivíduos cegos, surdos, com problemas cognitivos, entre outros).

O documento WCAG 1.0 foi lançado em 1999, sendo composto por um conjunto de 14 diretrizes que prometiam solucionar problemas de acessibilidade encontrados nos conteúdos Web. Em 2008 a WAI lançou uma nova versão do WCAG. Nessa segunda versão, o documento WCAG 2.0 (CALDWELL et al., 2008) tinha como objetivo resolver muitos dos problemas encontrados na primeira versão.

Entretanto, apesar de diversas mudanças, Alonso et al. (2010) e Power et al. (2012) apresentam indícios de que alguns problemas em relação à utilização do WCAG 1.0 por desenvolvedores e avaliadores ainda persistem no WCAG 2.0. Uma das grandes preocupações em relação às novas diretrizes é que durante os três anos após a criação do WCAG 2.0, novamente não houve melhora significativa na acessibilidade na Web (LOPES; GOMES; CARRIÇO, 2010). Além disso, ainda faltam evidências empíricas demonstrando que a conformidade com o WCAG 2.0 resulta em páginas mais acessíveis para usuários com deficiência. Esse fato contrasta com diretrizes de usabilidade na Web (LEAVITT; SHNEIDERMAN, 2006) e diretrizes de acessibilidade que foram definidas e validadas para grupos específicos de usuários (LEPORINI; PATERNÒ, 2008; LEUTHOLD; BARGAS-AVILA; OPWIS, 2008). Os usuários com deficiência visual podem ser citados como um desses grupos específicos.

Talvez essas diretrizes sejam suficientes para pessoas com deficiência visual parcial ou outros tipos de deficiência, porém para as pessoas cegas isso não é o bastante. Petrie, Hamilton e King (2004) mostram que dentre todos os grupos de usuários com algum tipo de deficiência, os usuários cegos apresentam a maior dificuldade para navegar na Web, visto que apenas $53 \%$ deles tiveram sucesso na realização das tarefas propostas. No mesmo estudo, foram encontrados 585 problemas dos quais apenas 55\% eram referenciados pelos pontos de verificação do WCAG 1.0.

Power et al. (2012) argumentam que a atualização do conjunto de diretrizes WCAG 2.0 não apresentou o efeito esperado. Os resultados mostraram que o fato de uma página Web estar em conformidade com o nível A do WCAG 2.0 não significa que os usuários encontrarão menos problemas nela. Dos problemas relatados pelos os usuários cegos, apenas 49,6\% eram cobertos pela nova versão do WCAG. A pesquisa ainda mostra que esses usuários relataram problemas quando eles encontravam um conteúdo que não era esperado ou quando eles não conseguiam encontrar o conteúdo em uma página Web, problemas esses que não são abordados pelo WCAG 2.0 . 
Em um estudo mais recente, Vigo e Harper (2013) analisaram como os usuários com deficiência visual (dentre eles, cegos) lidam com situações problemáticas encontradas durante a interação com a Web. Mesmo não sendo o objetivo principal do estudo, eles relatam um dado ainda mais alarmante: dos problemas encontrados pelos usuários com deficiência visual, apenas $19 \%$ eram cobertos pelo WCAG 2.0 .

Um dos motivos por trás disso pode estar relacionado ao fato de que as interfaces gráficas das páginas Web são projetadas para interação visual (GOBLE; HARPER; STEVENS, 2000). Diferentemente dos usuários com visão, os leitores de tela não conseguem interpretar o conhecimento estrutural e de navegação apresentado de forma implícita à apresentação visual da página (YESILADA et al., 2004). Assim, os usuários cegos que utilizam leitores de tela possuem uma percepção do conteúdo que diverge do que é apresentado na tela (CIPOLLA-FICARRA, 2010).

\subsection{A Tese}

Dado que: (i) todas as pessoas, independente das suas deficiências, devem ser capazes de navegar e interagir na Web; (ii) em contraste com os usuários com visão, os usuários cegos não têm acesso às sugestões visuais que auxiliam a distinguir as diferentes seções estruturais da página Web; (iii) estudos mostram que o conceito de design universal em acessibilidade tem se mostrado ineficiente para o caso das pessoas cegas e que páginas Web desenvolvidas de acordo com diretrizes de acessibilidade, como o WCAG 2.0, não garantem uma experiência satisfatória por parte dos usuários cegos; a seguinte questão de tese foi elaborada para guiar o andamento das pesquisas científicas apresentadas neste trabalho:

É possível extrair automaticamente as informações sobre a estrutura de navegação que estão implícitas na apresentação visual de uma página Web e alterar o design dessa navegação de uma maneira otimizada aos usuários cegos, de modo a minimizar os problemas enfrentados por esses usuários ao interagir com a Web?

A questão de tese envolve ainda a exploração das seguintes questões de pesquisa mais específicas:

i Quais as principais dificuldades dos usuários cegos ao navegar na Web, e quais são as recomendações para minimizar esses problemas encontrados na literatura?

ii É possível identificar automaticamente as informações referentes à estrutura de navegação que estão disponíveis apenas de maneira implícita na apresentação visual de uma página Web?

iii Uma página Web que apresente um modelo de navegação desenvolvido especificamente para os usuários cegos com base em suas principais necessidades, pode minimizar os 
problemas enfrentados por estes usuários ao navegar na Web?

\subsection{Trabalhos Relacionados}

Diversos trabalhos vêm sendo realizados, em diferentes linhas de pesquisa, com o objetivo de auxiliar pessoas cegas a navegar na Web. Alguns destes trabalhos procuram identificar o impacto das diretrizes de acessibilidade propostas pelo $\mathrm{W} 3 \mathrm{C}$ no desenvolvimento de sites acessíveis, assim como a eficácia dessas diretrizes frente aos problemas encontrados pelos usuários cegos (PETRIE; HAMILTON; KING, 2004) (POWER et al., 2012).

Outras pesquisas têm como objetivo identificar o comportamento dos usuários cegos ao navegar na Web. Vigo e Harper (2013) analisaramm como os usuários cegos se comportam frente a diversas situações problemáticas encontradas ao navegar na Web, com o objetivo de possibilitar uma melhoria nos métodos existentes de avaliação e modelagem Web. Voykinska et al. (2016) exploram as motivações, desafios, interações e experiências das pessoas cegas ao interagir com conteúdos visuais em redes sociais.

Diversos trabalhos abordam questões específicas para a acessibilidade na Web, como por exemplo, a acessibilidade de vídeos online com base em anotações de vídeo e enriquecimento de áudio composto por síntese de voz e ícones sonoros (earcons) (ENCELLE et al., 2011) e a exploração de dados georreferenciados por meio de coordenadas de mapas, sons não textuais e saída de voz (ZHAO et al., 2008).

Por fim, algumas pesquisas adotam o conceito de que as interfaces projetadas para usuários com visão podem não se adequar de maneira satisfatória aos usuários cegos, mesmo que em conformidade com as diretrizes de acessibilidade. Assim, são encontrados trabalhos na literatura com o enfoque do design elaborado especificamente para as pessoas cegas.

Leuthold, Bargas-Avila e Opwis (2008) desenvolveram uma interface do usuário textual (Enhanced Text user Interface - ETI) como uma alternativa às interfaces gráficas (GUI). Para avaliar essa nova interface, foi realizado um experimento com 39 usuários cegos, o qual apresentou um aumento de velocidade na tarefa de busca de conteúdo. Porém, a ETI não apresentou melhora na tarefa de navegação, possivelmente devido a problemas relacionados à falta de classificação do conteúdo.

Em uma outra abordagem, denominada ABBA (FAYZRAKHMANOV et al., 2010), a página Web é transformada em um modelo semântico formal multi-axial, em que os eixos oferecem meios para serializar o documento de acordo com diferentes visões semânticas. Com isso, uma pessoa cega pode navegar pelo conteúdo e ir diretamente aos eixos desejados, sendo direcionada para as partes relevantes da página. Porém, ainda em desenvolvimento, o ABBA possui um conjunto limitado de eixos desenvolvidos, e alguns desses eixos são definidos apenas manualmente. 
O trabalho desenvolvido por Guercio et al. (2011) apresenta o sistema WAVES (Web Accessible for Visually-impaired Extraction System), uma ferramenta projetada para cegos e deficientes visuais que tem como objetivo oferecer uma rápida recuperação de informações em uma página Web. Para isso, o sistema utiliza sinais visuais para filtrar o conteúdo e produzir um trecho de informação que auxilia o usuário a decidir se vale a pena ler a página. Os dados da página Web são apresentados ao leitor em um formato conciso e classificados por peso, o que reduz o tempo de acesso do leitor de tela a uma informação específica. Entretanto, o trabalho ainda encontra-se em fase de desenvolvimento e apenas um protótipo da ferramenta foi desenvolvido.

O conceito de uma solução técnica para filtrar informações redundantes e irrelevantes durante a navegação de pessoas cegas na Web é proposta por Giraud, Thérouanne e Steiner (2015). Esta solução é baseada em um algoritmo que analisa o conteúdo HTML das páginas Web, compara os elementos da página com os elementos das páginas visitadas anteriormente e com os elementos de um banco de dados compartilhado, com objetivo de filtrar informações que não são necessárias aos usuários do leitor de tela.

AL-MOUH et al. (2016) apresentaram um serviço de proxy que adapta as páginas Web e as apresenta de uma forma usável aos usuários com deficiência visual. O proxy VIPaware apresenta um serviço que recupera as principais informações a partir de qualquer página da Web, analisa o HTML da página solicitada e cria um DOM (Document Object Model), que é tratado para eliminar elementos inacessíveis.

\subsection{Metodologia de Pesquisa}

Para a realização das diferentes etapas de pesquisa propostas nesta tese, optou-se por utilizar o procedimento científico de pesquisa-ação. A pesquisa-ação pode ser definida como um tipo de investigação-ação, que é um termo genérico para qualquer processo que siga um ciclo no qual se aprimora a prática pela oscilação sistemática entre agir no campo da prática e investigar a respeito dela (TRIPP, 2005). As 4 fases do ciclo básico da pesquisa-ação são:

- PLANEJAR uma melhora na prática

- AGIR para implantar a melhora planejada

- Monitorar e DESCREVER os efeitos da ação

- AVALIAR os resultados da ação.

Assim, as pesquisas realizadas nesta tese envolveram 3 ciclos que seguem as fases apresentadas. No primeiro ciclo, foi identificado o problema caracterizado pela falta de um conjunto de diretrizes voltado especificamente aos usuários cegos, assim como um referencial 
contendo todos os problemas conhecidos enfrentados por esses usuários ao navegar pela Web. Assim, planejou-se realizar um mapeamento sistemático da literatura, que foi elaborado, discutido e avaliado no Capítulo 3.

No segundo ciclo, iniciou-se com a investigação sobre a possibilidade de classificar links de uma página Web com objetivo de identificar os links de navegação. Assim, planejou-se uma proposta de classificador Bayesiano que foi desenvolvido, testado e avaliado com casos reais e supervisionados (Capítulo 4).

O Capítulo 5 apresenta o terceiro ciclo da pesquisa-ação, que envolve a hipótese de que um design de navegação próprio para usuários cegos pode melhorar a satisfação desses usuários ao interagir com a Web. Assim, foi realizado o planejamento de um projeto de navegação com base nas dificuldades encontradas no primeiro ciclo de pesquisa. Feito isso, foi realizada a implementação de um protótipo e a avaliação do mesmo por meio de um percurso cognitivo, com apoio de um leitor de tela.

\subsection{Principais Contribuições}

Dentre as contribuições apresentadas nesta tese, pode-se citar principalmente:

- Apresentar um mapeamento sistemático da literatura referente às principais dificuldades enfrentadas pelos usuários cegos ao navegar na Web e às diferentes estratégias existentes com intuito de minimizar esses problemas.

- Elaborar um método para automaticamente classificar os links de uma página Web, com objetivo de identificar os links de navegação.

- Apresentar um design de navegação Web otimizado para usuários cegos, com intuito de minimizar as dificuldades previamente identificadas na literatura.

\subsection{Estrutura da Tese}

Este projeto está organizado da seguinte forma: no Capítulo 2 é apresentado um referencial teórico sobre os principais conceitos relacionados à área de Acessibilidade na Web e sobre o uso da Web pelos usuários cegos.

O Capítulo 3 apresenta um mapeamento sistemático da literatura elaborado com o objetivo de identificar as principais dificuldades encontrados pelos usuários cegos ao navegar na Web, assim como as sugestões encontradas para minimizar esses problemas. No Capítulo 4 é apresentado um classificador Bayesiano desenvolvido com o objetivo de classificar individualmente os links de uma página Web com base nas características visuais desses elementos, como o posicionamento e a repetição. 
Um projeto de navegação elaborado especificamente para usuários cegos, com base nas principais dificuldades encontradas pelos mesmos é apresentado no Capítulo 5, assim como o detalhamento do protótipo desenvolvido e da avaliação com o usuário. O Capítulo 6 apresenta as considerações finais, limitações da pesquisa e trabalhos futuros. 



\subsection{Introdução}

Desde a criação da Web, existe a preocupação em permitir que o conteúdo disponibilizado pela rede seja acessível por todos os seus possíveis usuários. O próprio criador da Web e atualmente diretor do W3C (World Wide Web Consortium), Tim Berners-Lee, destacou que:

"O poder da web está em sua universalidade. Ser acessada por todos, independente da deficiência, é um aspecto essencial."

A Web é um recurso cada vez mais importante em muitos aspectos da vida: educação, emprego, governo, comércio, saúde, recreação e muito mais. Dada a necessidade de viabilizar às pessoas o direito de usufruir aos conteúdos e serviços disponibilizados na Web, independente das deficiências ou barreiras tecnológicas existentes, o W3C lançou em 1997 a WAI (Web Accessibility Initiative), como um esforço para melhorar a acessibilidade na Web (W3C, 2016e).

Segundo a WAI, acessibilidade na Web significa possibilitar que pessoas com deficiência possam utilizar a Web. Mais especificamente, a acessibilidade na Web significa que pessoas com deficiência podem perceber, entender, navegar, interagir e contribuir com a Web. A acessibilidade na Web também beneficia outras pessoas, incluindo pessoas idosas com capacidades em mudança devido ao envelhecimento. Ainda, acessibilidade na Web abrange todas as deficiências que afetam o acesso à Web, incluindo as deficiências visuais, auditivas, físicas, de fala, cognitivas e neurológicas (W3C, 2005).

O W3C, através da WAI, trabalha em diversos padrões e diretrizes (guidelines) que têm por objetivo melhorar a acessibilidade de páginas Web. Por focar seus esforços em diretrizes e suas conformidades, o W3C promove uma visão mais técnica e mensurável da acessibilidade. Para isso, a WAI definiu um modelo de conformidade com três conjuntos de diretrizes agregadas nos seguintes documentos (W3C, 2015d): 
- WCAG (Web Content Accessibility Guidelines): explicam como tornar o conteúdo web acessível a indivíduos com deficiências e disponível a todos os usuários, qualquer que sejam os agentes de usuário que estejam sendo utilizados (navegadores desktop, navegadores por voz, celulares, entre outros) e restrições de operações (ambientes barulhentos, com pouca iluminação, entre outros). Duas versões foram elaboradas pela WAI até o momento: WCAG 1.0 (W3C, 1999) e WCAG 2.0 (W3C, 2008). As Seções 2.2.1 e 2.2.2 contemplam informações mais detalhadas sobre as versões 1.0 e 2.0 do WCAG, respectivamente.

- ATAG (Authoring Tool Accessibility Guidelines): auxiliam desenvolvedores na implementação de ferramentas de autoria de conteúdo Web que seja acessível e na criação de ferramentas de autoria acessíveis. Atualmente, as duas versões dessas diretrizes são: ATAG $1.0(\overline{\mathrm{W} 3 \mathrm{C}}, 2000)$ e ATAG 2.0 (W3C, 2015a).

- UAAG (User Agent Accessibility Guidelines): destinado ao desenvolvimento de agentes de usuário (user agents) que reduzam as barreiras de acessibilidade na Web para pessoas com deficiências (visual, auditiva, física, cognitiva e neurológica). Os agentes de usuário são os navegadores Web, media players, tecnologias de apoio e outros tipos de software que renderizam conteúdo Web. Assim como nos outros conjuntos de diretrizes, duas versões foram atualmente disponibilizadas pela WAI: UAAG 1.0 (W3C, 2002) e UAAG $2.0(\overline{\mathrm{W} 3 \mathrm{C}}, \mathbf{2 0 1 5 \mathrm { c }})$

Para cada diretriz descrita nesses documentos, são apresentados checkpoints que definem etapas ou partes de um projeto que podem apresentar barreiras (ou dificuldades) a usuários com algum tipo de limitação (indivíduos cegos, surdos, com problemas cognitivos, entre outros).

Além desses conjuntos de diretrizes, a WAI elaborou um documento descrevendo diretrizes técnicas para tornar mais acessível o conteúdo Web dinâmico, como por exemplo, as aplicações Web desenvolvidas com uso de Ajax, DHTML e outras tecnologias. Para isso, foi proposto o ARIA (Accessible Rich Internet Applications) (W3C, 2014a), definindo como deve ser implementada uma aplicação Web de modo a se comunicar corretamente com as tecnologias assistivas (W3C, 2016d). Uma discussão mais detalhada do ARIA é apresentada na Seção 2.2.3.

A seguir, a Seção 2.1.1 apresenta uma introdução sobre Tecnologia Assistiva.

\subsubsection{Tecnologia Assistiva}

A Sociedade de Esclerose Múltipla Norte-Americand ${ }^{1}$ define Tecnologia Assistiva como um termo utilizado para descrever todos os produtos, ferramentas e dispositivos, dos mais simples até os mais complexos, que podem facilitar ou possibilitar a realização de uma determinada função. Esta definição não apresenta o termo "deficiência", sendo isso o que a torna interessante, 
visto que itens comuns no cotidiano das pessoas, como óculos e controles remotos, também podem ser considerados exemplos de tecnologia assistiva (CONNOR, 2012).

No âmbito da Web, pode-se dizer que uma tecnologia assistiva é qualquer tipo de hardware ou software que (W3C, 2016b):

- depende de serviços fornecidos por um agente de usuário para recuperar e processar o conteúdo Web,

- trabalha com um agente de usuário ou com o próprio conteúdo Web através do uso de APIs, e,

- fornece serviços além dos oferecidos pelo agente de usuário para facilitar a interação de pessoas com deficiência com o conteúdo Web.

Algumas soluções de acessibilidade encontram-se incorporadas ao sistema operacional ou ao navegador Web, como a capacidade de ampliar visualmente o conteúdo ou de alterar as propriedades de estilo. Além disso, tecnologias assistivas específicas podem ser adotadas por pessoas com deficiências para permitir a interação do usuário, ou torná-la mais satisfatória.

O tipo de tecnologia assistiva utilizada varia de acordo com o tipo de deficiência, fornecendo diferentes maneira de acessar o conteúdo. Alguns exemplos de tecnologias assistivas que se destacam no contexto Web, incluem (W3C, 2016b):

- Ampliadores de Tela: é um software que interage com saída gráfica do computador para apresentar um conteúdo da tela ampliado. Frequentemente utilizado por pessoas com baixa visão, esses sistemas aumentam o tamanho de tudo o que é apresentado na tela, incluindo texto e imagens em páginas Web.

- Leitores de Tela: utilizados para transmitir as informações através de voz sintetizada ou um display Braille;

- Software de Reconhecimento de Voz: permite utilizar a voz para ditar textos e controlar o computador.

- Navegador Textual: um navegador Web que renderiza apenas o texto de páginas Web e ignora o conteúdo gráfico.

Dada a importância dos leitores de tela no contexto dessa tese, uma discussão mais detalhada sobre as características desses sistemas é apresentada na Seção 2.3.1. 


\subsection{Abordagem WAI}

Nessa seção, são apresentadas 3 abordagens do W3C-WAI elaboradas com o objetivo de melhorar a acessibilidade nas páginas e aplicações Web. A Seção 2.2.1 apresenta a versão inicial do conjunto de diretrizes para desenvolvimento de páginas Web acessíveis, o WCAG 1.0. A Seção 2.2.2 apresenta a evolução desse conjunto de diretrizes, denominado WCAG 2.0. Por fim, a Seção 2.2.3 apresenta o ARIA, uma abordagem do WAI para a implementação de aplicações Web mais acessíveis.

\subsubsection{WCAG 1.0}

Em 1999 a WAI definiu a primeira versão das Diretrizes de Acessibilidade ao Conteúdo Web (WCAG 1.0 - Web Content Accessibility Guidelines) (W3C, 1999). O WCAG 1.0 é composto por um conjunto de 14 diretrizes elaboradas para minimizar os problemas de acessibilidade encontrados nos conteúdos Web. Estas diretrizes são divididas em duas categorias:

1. Garantir a transformação harmoniosa das páginas;

2. Criar conteúdos de fácil navegação e compreensão.

A primeira categoria, Garantir a transformação harmoniosa das páginas, é voltada às diretrizes de 1 a 11. Para satisfazer essas diretrizes, deve-se obedecer aos principais conceitos:

- Separar a estrutura do aplicativo de sua apresentação;

- Fornecer texto (incluindo texto equivalente). O texto pode ser renderizado nas formas em que está disponível para quase todos os dispositivos e acessível a quase todos os usuários;

- Criar documentos que sejam interpretados mesmo que o usuário não possa ver e/ou ouvir;

- Criar documentos que não dependam de um tipo de hardware.

Já a segunda categoria, Criando conteúdos de fácil navegação e compreensão, define que o desenvolvedor deve fazer uso de linguagem simples e clara, além de disponibilizar mecanismos para auxiliar a navegação dentro de um conteúdo ou entre as páginas que compõem o conteúdo.

A seguir, segue um resumo das 14 diretrizes propostas pelo WCAG 1.0:

1. Fornecer alternativas para conteúdo sonoro e visual: deve-se disponibilizar conteúdo equivalente ao conteúdo sonoro ou visual. Assim, deve-se fornecer um equivalente textual a cada elemento não textual. 
2. Não recorrer apenas a cor: deve-se assegurar que todas as informações veiculadas por meio de cores estejam também disponíveis sem cor, por exemplo, a partir de informações do contexto ou de marcação apropriada, visto que existem pessoas que são incapazes de diferenciar algumas cores.

3. Utilizar corretamente marcações e folhas de estilo: deve-se utilizar corretamente as marcações através dos elementos estruturais adequados. Controlar a apresentação com folhas de estilo em vez de utilizar a apresentação com elementos e atributos.

4. Indicar claramente qual o idioma utilizado: deve-se utilizar marcações que facilitem a pronúncia ou interpretação de textos abreviados ou estrangeiros.

5. Criar tabelas passíveis de transformação harmoniosa: deve-se assegurar que as tabelas utilizem as marcações necessárias para serem transformadas por navegadores acessíveis e os outros navegadores.

6. Assegurar que as páginas dotadas de novas tecnologias sejam transformadas harmoniosamente: deve-se assegurar que as páginas são acessíveis mesmo quando novas tecnologias não são suportadas ou são desligadas.

7. Assegurar o controle do usuário sobre as alterações temporais do conteúdo: devese possibilitar a interrupção momentânea ou definitiva do movimento, intermitência, transcurso ou atualização automática de objetos e páginas.

8. Assegurar a acessibilidade direta em interfaces integradas pelo usuário: deve-se assegurar que a interface com o usuário siga os princípios de design para a acessibilidade: acesso independente de dispositivos, operacionalidade pelo teclado, possibilidade de emissão automática de voz.

9. Projetar páginas considerando a independência de dispositivos: deve-se utilizar características que permitam a ativação dos elementos da página através de uma variedade de dispositivos de entrada.

10. Utilizar soluções provisórias ou de transição: deve-se utilizar soluções de acessibilidade transitórias para que as tecnologias assistivas e os navegadores mais antigos possam funcionar corretamente.

11. Utilizar tecnologias e recomendações do W3C: deve-se utilizar as tecnologias $\mathrm{W} 3 \mathrm{C}$ (de acordo com a especificação) e seguir as orientações de acessibilidade. Quando não for possível a utilização de uma tecnologia W3C, ou o uso das mesmas resulte em um material que não possa ser transformado de forma graciosa, deve-se fornecer uma versão alternativa do conteúdo que seja acessível.

12. Fornecer informações de contexto e orientações: deve-se fornecer contexto e orientações para ajudar os usuários a entenderem as páginas ou elementos complexos. 
13. Fornecer mecanismos de navegação claros: deve-se fornecer mecanismos de navegação claros e coerentes - orientações, barras de navegação, um mapa do site, etc - para aumentar a probabilidade de que uma pessoa irá encontrar o que está procurando em um site.

14. Assegurar a clareza e a simplicidade dos documentos: deve-se assegurar que os documentos sejam claros e simples para que eles possam ser mais facilmente entendidos.

Cada uma destas diretrizes é dividida em pontos de verificação, que são classificados em três níveis de prioridade. O primeiro nível, Prioridade 1, determina os pontos em que o desenvolvedor Web tem a necessidade de satisfazer, evitando que os usuários com deficiências fiquem impossibilitados de compreender as informações contidas no site. A Prioridade 2 indica os pontos que devem ser satisfeitos pelo desenvolvedor para evitar que o usuário tenha dificuldades para acessar todas as informações contidas na página, evitando barreiras significativas ao conteúdo. Por fim, a Prioridade 3, apresenta os pontos em que o desenvolvedor Web pode satisfazer para melhorar o acesso ao conteúdo.

Além disso, o WCAG 1.0 define os níveis de conformidade, que representam uma classificação que varia de acordo com a satisfação das diretrizes propostas. São definidos três níveis de conformidade: .

- Nível de conformidade A: Todos os pontos de verificação de Prioridade 1 são satisfeitos;

- Nível de conformidade AA: Todos os pontos de verificação de Prioridade 1 e de Prioridade 2 são satisfeitos;

- Nível de conformidade AAA: Todos os pontos de verificação de Prioridade 1, 2 e 3 são satisfeitos.

\subsubsection{WCAG 2.0}

Por praticamente uma década, a primeira versão do WCAG foi utilizada como um padrão de fato para a acessibilidade na Web. Apesar disso, o impacto dessas diretrizes no aumento da acessibilidade na Web não foi muito significativo nesse período, com estudos mostrando que nem sempre atingir um bom nível de acessibilidade segundo o WCAG 1.0, garante que um site ou aplicação Web possua uma boa usabilidade (PETRIE; KHEIR, 2007).

Sendo assim, a maior preocupação sobre o WCAG 1.0 era a falta de evidências comprovando que uma página com nível de conformidade AAA era realmente mais acessível às pessoas com deficiência do que as páginas com nível A de conformidade. A partir dessa preocupação, foram realizados estudos para analisar a eficiência do WCAG. A Disability Rights Commission (DRC) conduziu uma investigação envolvendo mais de 100 páginas Web que foram avaliadas por especialistas e um grande número de pessoas com diferentes tipos de deficiência (COMMISSION et al. 2004). O estudo mostrou que $45 \%$ dos problemas encontrados pelos usuários com 
deficiência não eram cobertos pelo WCAG 1.0. Com base nesses resultados, observou-se que essa desconfiança no WCAG era um importante problema a ser abordado.

Assim, em 2008, a Web Accessibility Initiative (WAI) lançou uma nova versão do WCAG, com o objetivo de resolver muitos dos problemas encontrados na primeira versão. O WCAG 2.0 está organizado de uma maneira hierárquica em 4 camadas, sendo elas: Princípios, Diretrizes, Critérios de Sucesso e Técnicas (W3C, 2008).

- Princípios: Esta camada apresenta quatro princípios que fornecem a base para a acessibilidade na Web. Um site deve ser Perceptível, Operável, Compreensível e Robusto.

- Diretrizes: Após a camada Princípios, são apresentadas 12 diretrizes que fornecem aos autores os objetivos básicos que devem ser trabalhados com o intuito de tornar o conteúdo mais acessível aos usuários com diferentes deficiências. Essas diretrizes não são testáveis, mas fornecem a estrutura e os objetivos gerais para auxiliar os autores a entenderem os critérios de sucesso e implementar as técnicas.

- Critérios de Sucesso: Cada uma das diretrizes presentes na camada anterior possuem um ou mais critérios de sucesso testáveis, permitindo assim que o WCAG 2.0 possa ser utilizado nos casos em que testes de requisitos e de conformidade sejam necessários. Existem 3 níveis de conformidade, análogos aos apresentados no WCAG 1.0: A (mais baixo), AA e AAA (o mais alto).

- Técnicas: Para cada diretriz e critério de sucesso, é apresentada uma grande variedade de técnicas informativas. Essas técnicas estão divididas em duas categorias: as do tipo suficiente e as do tipo sugerida. As técnicas do tipo suficiente são aquelas que cumprem os critérios de sucesso. A segunda categoria, sugerida, vai além dos requisitos dos critérios de sucesso e apresenta sugestões de como melhorar a acessibilidade das páginas Web. As técnicas são organizadas nas seguintes seções: Técnicas gerais, HTML e XHTML, CSS, Scripts do lado cliente, Scripts do lado servidor, SMIL, texto puro, ARIA, Flash, Silverlight, PDF e falhas comuns.

Essas 4 camadas são utilizadas em conjunto para fornecer um guia de como tornar o conteúdo Web mais acessível.

Uma inovação do WCAG 2.0 em relação à primeira versão está justamente nessa organização das diretrizes em princípios. Como visto, o conjunto de diretrizes foi classificado em quatro princípios de acessibilidade na Web, que determinam que um conteúdo deva ser: Perceptível, Operável, Compreensível e Robusto (W3C, 2008). 
Princípio 1: Perceptível - As informações e os componentes da interface do usuário devem ser apresentados de uma maneira que possa ser percebida pelo usuário.

Um site pode ser visitado por pessoas com diferentes tipos de preferências e necessidades, assim como por ferramentas automáticas (motores de busca, tradutores automáticos, entre outros). As informações dos componentes de interface devem se adequar a todos esses casos, além de dar alternativas aos usuários que não podem utilizar um de seus sentidos. Esse primeiro princípio, apresenta 4 diretrizes de acessibilidade, sendo elas:

Diretriz 1.1: Alternativas em Texto - Fornecer alternativas textuais para qualquer conteúdo não textual, para que possa ser transformado em outras formas de acordo com as necessidades dos usuários, tais como impressão com tamanho de fontes maiores, braille, fala, símbolos ou linguagem mais simples.

O texto em uma página Web pode ser processado de forma visual, oral, tátil ou mesmo por qualquer combinação das mesmas. Assim, a informação textual pode ser apresentada e manipulada da maneira que melhor atenda às necessidades do usuário. Por exemplo, um usuário cego pode compreender uma imagem ao utilizar um leitor de tela que lê em voz alta o texto alternativo contido no código desta imagem. Uma pessoa surda pode entender um arquivo de áudio, se o mesmo apresentar uma alternativa textual.

Diretriz 1.2: Mídias com base em tempo - Fornecer alternativas para mídias baseadas em tempo.

Essa diretriz está relacionada aos conteúdos de áudio e vídeo contidos nas páginas Web, assim como outros componentes interativos em que o tempo é uma parte importante da experiência sensorial. $\mathrm{O}$ uso de legendas, audiodescrição e linguagem de sinais, são exemplos de alternativas para esses conteúdos.

Diretriz 1.3: Adaptável - Criar conteúdo que pode ser apresentado de diferentes maneiras (por exemplo, um layout simplificado) sem perder informação ou estrutura.

Um site pode possuir um público com diferentes preferências ou necessidades. Assim, deve-se garantir que todas as informações na página Web estejam disponíveis de uma forma que possam ser percebidas de diferentes maneiras (visual, oral, tátil, etc) por todos os usuários. Além do próprio conteúdo apresentado na página, existem outras informações incorporadas ao layout que devem ser especificadas no código, como por exemplo, informações referentes à estrutura e organização da página.

Diretriz 1.4: Discernível - Facilitar a audição e a visualização de conteúdo aos usuários, incluindo a separação entre o primeiro plano e o plano de fundo.

Essa diretriz apresenta aspectos que devem ser levados em consideração para garantir que o conteúdo visual ou auditivo seja facilmente percebido por pessoas com diferentes defici- 
ências. Apresenta critérios sobre o uso de contraste, não apenas das cores apresentadas no conteúdo visual, como também das "vozes"contidas nos conteúdos de áudio.

Princípio 2: Operável - Os componentes de interface de usuário e a navegação devem ser operáveis.

Os usuários podem utilizar diferentes tecnologias e dispositivos para acessar páginas Web. Estando ciente desse fato, os designers devem desenvolver componentes de interface e elementos de navegação que sejam operáveis em todos os casos. São apresentadas 4 diretrizes para auxiliar os desenvolvedores a cumprir esse objetivo:

Diretriz 2.1: Acessível por Teclado - Fazer com que toda funcionalidade fique disponível a partir de um teclado.

Tornar uma funcionalidade da página disponível via teclado, não impede o uso de outros dispositivos de entrada, como mouse ou voz. Porém, caso uma funcionalidade da página seja acessível apenas através do mouse ou de entrada por voz, algumas tecnologias assistivas não serão capazes de interagir com esses elementos. Assim, é fundamental que toda funcionalidade também deva ser acessível a partir de um teclado.

Diretriz 2.2: Tempo Suficiente - Fornecer aos usuários tempo suficiente para ler e utilizar o conteúdo.

As pessoas precisam de tempos diferentes para completar a mesma tarefa. Com base nisso, essa diretriz tem como objetivo eliminar limites de tempos, ou providenciar tempo suficiente para que qualquer pessoa possa acessar o conteúdo ou completar as tarefas solicitadas em uma página Web.

Diretriz 2.3: Convulsões - Não criar conteúdo de uma forma conhecida por causar convulsões.

Essa diretriz é voltada às pessoas que sofrem de convulsões devido à fotossensibilidade. Assim, define-se que uma página não deve incluir nenhum conteúdo que pisque. Caso, por algum motivo, seja necessário utilizar esse tipo de conteúdo, deve-se garantir que o conteúdo não pisque em uma taxa maior do que três vezes por segundo.

Diretriz 2.4: Navegável - Fornecer maneiras de ajudar os usuários a navegar, localizar conteúdos e determinar onde se encontram.

Encontrar um conteúdo ou manter o controle sobre a sua localização atual são tarefas difíceis para algumas pessoas com deficiência, como os usuários que utilizam um leitor de tela. Essa diretriz busca minimizar essas dificuldades. 
Princípio 3: Compreensível - A informação e a operação da interface de usuário devem ser compreensíveis.

A interface de um site e o conteúdo encontrando no mesmo devem ser amigáveis e compreensíveis. Todo usuário deve ser capaz de compreender o conteúdo e não se sentir perdido ao navegar pelo site. O WCAG 2.0 apresenta 3 diretrizes sob esse princípio.

\section{Diretriz 3.1: Legível - Tornar o conteúdo do texto legível e compreensível.}

Textos e conteúdos complexos podem ser realmente difíceis de ler, tanto para os usuários quanto para as tecnologias assistivas. Essa diretriz apresenta aos editores as linhas gerais de como o texto deve ser preparado para que todos possam compreendê-lo.

Diretriz 3.2: Previsível - Fazer com que as páginas web apareçam e funcionem de modo previsível.

Ações não previstas, como atualização automática da página ou links abrindo novas janelas, podem confundir os usuários com ou sem deficiência. Essa diretriz define como ser consistente e coerente com o layout da página Web, permitindo que todos acessem o conteúdo de uma maneira fácil.

Diretriz 3.3: Assistência de Entrada - Ajudar os usuários a evitar e corrigir erros.

Todos os usuários estão sujeitos a erros. A página Web deve ser capaz de prevenir erros, e, caso eles ocorram, deve-se auxiliar o usuário a se recuperar do erro.

Princípio 4: Robusto - O conteúdo deve ser robusto o suficiente para poder ser interpretado de forma confiável por uma ampla variedade de agentes de usuário, incluindo tecnologias assistivas.

Os agentes de usuário são qualquer software que recupera e apresenta conteúdo Web, como navegadores, media players, plug-ins e outros, incluindo tecnologias assistivas (leitores de tela, lente de aumento, etc). Então, ao projetar um site, é necessário ter em mente essa infinidade de softwares. Desta forma, deve-se sempre estar ciente da evolução das tecnologias para que seja possível adaptar a página Web às suas novas capacidades.

Diretriz 4.1: Compatível - Maximizar a compatibilidade entre os atuais e futuros agentes de usuário, incluindo tecnologias assistivas.

Esta é uma diretriz voltada aos desenvolvedores. Além do código do site ser tão limpo quanto possível, o mesmo deve respeitar os padrões Web, garantindo que os navegadores sejam capazes de renderizar a página corretamente. 


\section{Conformidade no WCAG 2.0}

Como apresentado, as diretrizes são separadas em diferentes critérios de sucesso. Esses critérios de sucesso são classificados em 3 níveis (A, AA e AAA), similares às prioridades presentes no WCAG 1.0. No WCAG 2.0, o menor nível (A) garante o acesso ao conteúdo de uma página Web, enquanto que o maior nível (AAA), garante uma maior usabilidade.

Assim, para garantir que uma página esteja em conformidade com o WCAG 2.0, todos os requisitos de conformidade devem ser satisfeitos, de acordo com os níveis a seguir:

- Nível A: Para garantir o menor nível de conformidade, a página deve satisfazer todos os critérios de sucesso do Nível A.

- Nível AA: Para garantir o nível médio de conformidade, a página deve satisfazer todos os critérios de sucesso dos Níveis A e AA.

- Nível AAA: Para garantir o maior nível de conformidade, a página deve satisfazer todos os critérios de sucesso do Níveis A, AA e AAA.

Vale ressaltar que o conceito sobre conformidade está relacionado à página Web completa, ou seja, não apenas aos códigos HTML e CSS, mas também aos elementos inseridos nesses códigos, como vídeos, elementos em Flash, jogos, sons, etc. Entretanto, caso seja fornecida uma alternativa a um conteúdo não acessível, o mesmo também é considerado parte da página Web e permite que a conformidade seja alcançada.

Outros aspectos ainda devem ser considerados ao buscar a conformidade da página Web. Caso a página seja uma parte presente em um processo (como por exemplo, o pagamento de um produto durante uma compra), todas as páginas envolvidas nesse mesmo processo devem ser auditadas. Assim, não é possível garantir um nível de conformidade específico se qualquer página do processo não possuir aquele mesmo nível de conformidade. Por fim, os conteúdos ou tecnologias não acessíveis não devem bloquear o restante da página, como por exemplo, os elementos em Flash que retém o foco, não permitindo assim retomar o controle do restante da página.

Apesar de todas as mudanças, estudos mostram que muitos problemas do WCAG 1.0 ainda persistem no WCAG 2.0 (PETRIE et al., 2011; BRAJNIK; YESILADA; HARPER, 2010, ALONSO et al. 2010). Uma das grandes preocupações em relação às novas diretrizes é que durante os três anos após a criação do WCAG 2.0, novamente não houve melhora significativa na acessibilidade na Web (LOPES; GOMES; CARRIÇO, 2010). Além disso, ainda faltam evidências empíricas demonstrando que a conformidade com o WCAG 2.0 resulta em páginas mais acessíveis para usuários com deficiência. Esse fato contrasta com diretrizes de usabilidade na Web (SERVICES; ADMINISTRATION, 2006) e diretrizes de acessibilidade que foram definidas 
e validadas para grupos específicos de usuários (LEPORINI; PATERNÒ, 2008)(LEUTHOLD; BARGAS-AVILA; OPWIS, 2008).

\subsubsection{ARIA}

As páginas Web baseadas em conteúdos estáticos vêm sendo rapidamente substituídas e o uso de conteúdo dinâmico nas páginas Web vem aumentando de forma significativa ao longo dos anos. Esses conteúdos dinâmicos são geralmente desenvolvidos com o apoio de tecnologias como Ajax e JavaScript, que apresentam novos desafios de acessibilidade e podem impor dificuldades adicionais aos usuários que utilizam algum tipo de tecnologia assistiva ou dependem da navegação pelo teclado ( $\mathrm{W} 3 \mathrm{C}, 2016 \mathrm{~d})$.

Apenas 2 tipos de elementos nativos do HTML 4 podem ser acessados pelo teclado: os elementos $<h r e f>$ e os controles de fomulário $(<$ form $>$ ). Já no HTML 5, muitos dos novos elementos e controles podem ser acessados pelo teclado, como por exemplo: os elementos $\langle$ audio $\rangle$, $<$ datalist $>,<$ date $>,<$ month $>$, <number $>$, < range $>$, <summary $>$, entre outros (CONNOR, 2012).

Porém, o simples fato de um elemento possuir acesso via teclado não garante que o mesmo seja totalmente acessível. Para se garantir a acessibilidade desses componentes, os mesmos devem expor algumas informações através de uma API de acessibilidade para as tecnologias assistivas. Isto porém não ocorre para diversos controles presentes no HTML 5. Além disso, mesmo que o usuário tenha acesso aos controles através do teclado, isso não necessariamente implica que ele compreenda o significado desses controles ou qual o seu propósito.

Pensando em minimizar esses problemas apresentados, a WAI propôs a especificação WAI-ARIA (Accessible Rich Internet Applications Suite), que define uma maneira de tornar o conteúdo e as aplicações Web mais acessíveis às pessoas com deficiência. Essa especificação é voltada especialmente aos conteúdos dinâmicos e controles de interface de usuário avançadas, desenvolvidas através do uso de Ajax, HTML, JavaScript e tecnologias relacionadas. Em 20 de Março de 2014 a especificação ARIA foi publicada como uma Recomendação W3C.

ARIA permite estender a semântica nativa dos elementos HTML através de um conjunto específico de atributos que definem papéis (Roles), propriedades (Properties) e estados (States) destes elementos, usados para melhorar a acessibilidade.

- Atributos Role: São utilizados para descrever widgets que não estão disponíveis na especificação do HTML 4, tais como, sliders, barras de menus, tabs, e caixas de diálogo. Além disso, permitem descrever a estrutura da página Web, como cabeçalhos, seções e tabelas.

- Atributos Property: Descrevem as propriedades e características das widgets, como por 
exemplo, se elas podem ser arrastadas, possuem um elemento obrigatório ou possuem um рорир associado.

- Atributos State: Utilizados para descrever o estado de interação de um elemento, tornando possível à tecnologias assistivas reconhecer se esse elemento está ocupado, desabilitado, selecionado ou escondido.

Existem muitos papéis, propriedades e estados para se considerar ao implementar a especificação ARIA, que apresenta uma ontologia formal com uma taxonomia que define como esses atributos se relacionam uns com os outros.

Os atributos ARIA são projetados para serem interpretados automaticamente pelo navegador e traduzidos às APIs de acessibilidade nativas do sistema operacional. Quando a especificação ARIA é implementada, as tecnologias assistivas são capazes de reconhecer e interagir com controles JavaScript da mesma forma com que interagem com as versões desktop desses controles. Isso promove uma experiência do usuário mais consistente do que nas gerações anteriores das aplicações Web, visto que os usuários podem aplicar todo o seu conhecimento sobre como funcionam as aplicações desktop ao utilizar as aplicações Web.

A Figura 1 ilustra a relação entre os agentes do usuário, APIs de acessibilidade e tecnologias assistivas. Ela descreve o "contrato" fornecido pelo agente de usuário às tecnologias assistivas, que inclui informações típicas utilizadas pelas APIs de acessibilidade. O DOM (Document Object Model), geralmente HTML, atua como o modelo e visão, da arquitetura MVC (model-view-controller) (KRASNER; POPE et al., 1988), enquanto que o JavaScript funciona como o controlador, através da manipulação das folhas de estilo e conteúdos. O agente do usuário transmite informações relevantes para a API de acessibilidade do sistema operacional, que pode ser usado por qualquer Tecnologia Assistiva, como leitores de tela (W3C, 2016c).

Atualmente, a especificação ARIA é suportada pelas versões mais novas de todos os navegadores mais importantes, como Firefox, Safari, Opera, Chrome e Internet Explorer. Muitas tecnologias assistivas, como os leitores de tela NVDA e ORCA, também dão suporte à especificação ARIA. Cada vez mais, as bibliotecas de widgets JavaScript, como jQuery UI ${ }^{2}$, YU! Google Closure ${ }^{4}$, e Dojo Dijit 5 , estão se adequando para fornecer seus componentes com a devida marcação ARIA.

Ao ser implementada corretamente, a especificação ARIA pode tornar as aplicações Web mais acessíveis. Dentre alguns benefícios específicos da sua integração às aplicações Web, destacam-se:

- Melhor organização do conteúdo, facilitando a navegação pela página Web.

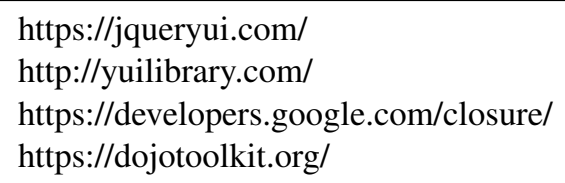




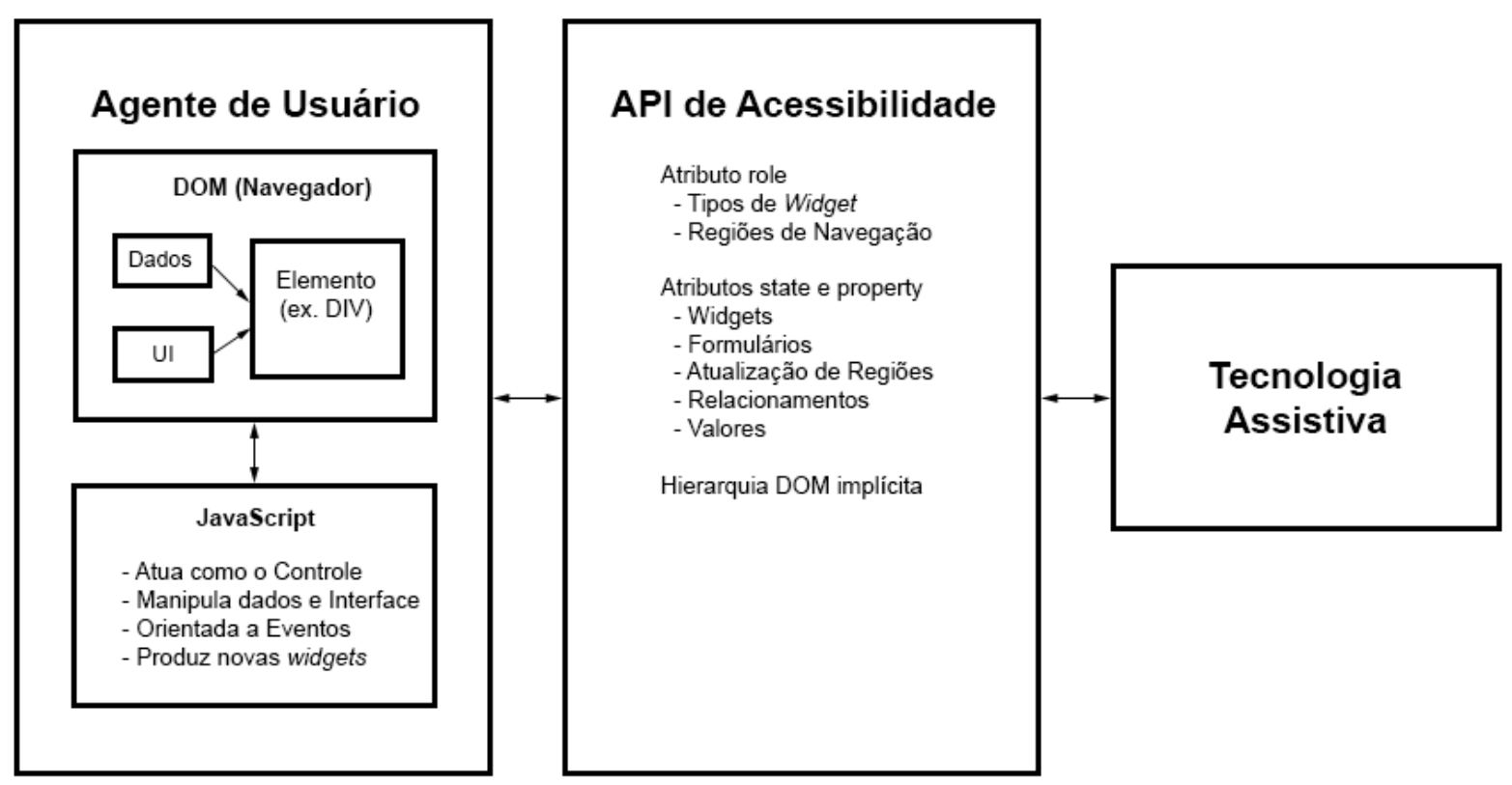

Figura 1 - ARIA e a relação entre o Agente de Usuário, API de Acessibilidade e Tecnologia Assistiva.

Figura adaptada de (W3C, 2016c)

- Clareza sobre as relações entre conteúdos anteriormente desconectados.

- Notificações e entrega dos conteúdos atualizados de maneira assíncrona.

- Uma representação mais completa e semanticamente mais consistente dos controles de usuário mais complexos.

Alguns desses benefícios são facilmente habilitados, enquanto outros podem ser mais desafiadores. Apesar da especificação ARIA não ser nova, apenas recentemente ela foi incorporada ao HTML 5. Tanto ARIA quanto o HTML possuem níveis variados de suporte entre os diferentes navegadores e tecnologias assistivas. Assim, ARIA é melhor implementada através do uso de uma abordagem de otimização progressiva (CONNOR, 2012).

Para isso, primeiramente deve-se fornecer uma experiência do usuário accessível baseada apenas em HTML, e progressivamente otimizar essa experiência através do uso de ARIA, CSS e JavaScript.

Essa abordagem progressiva em camadas garante que todos os conteúdos e funcionalidades básicas da aplicação Web estejam igualmente acessíveis a todos, permitindo simultaneamente fornecer uma experiência otimizada para os usuários de tecnologias assistivas.

\subsubsection{ARIA e Navegação via Teclado}

Durante o desenvolvimento de widgets personalizadas, os desenvolvedores muitas vezes esquecem de implementar o suporte via teclado. Como visto, é de extrema importância que todas 
as funcionalidades de uma aplicação Web tenham acesso via teclado, sem a necessidade de um mouse. Na prática, isso normalmente envolve seguir as convenções suportadas pelas versões desktop dessas widgets, através do uso das teclas Tab, Enter, Barra de Espaço e Setas.

Tradicionalmente, a navegação pelo teclado na Web tem sido limitada à tecla Tab. Os usuários pressionam o Tab para mover o foco entre os links, botões ou formulários presentes na página Web, de uma maneira linear, sendo que a combinação das teclas Shift-Tab permite a navegação inversa.

Em uma página Web complexa, esse tipo de navegação unidimensional pode forçar o usuário que depende apenas do teclado a apertar a tecla Tab diversas vezes antes de encontrar o conteúdo desejado. Assim, seguir a especificação ARIA e implementar aplicações Web que imitam as convenções encontradas nas versões desktop dessas aplicações, tem o potencial de significativamente aumentar a velocidade com que esses usuários navegam pela página.

Os itens a seguir mostram como a navegação pelo teclado deve funcionar nas aplicações Web implementadas de acordo com a especificação ARIA:

- A tecla Tab deve fornecer o foco para a widget como um todo. Por exemplo, a navegação por Tab até uma barra de menu deve colocar o foco no primeiro elemento deste menu.

- As Setas devem permitir a seleção ou navegação dentro do widget. Por exemplo, as Setas esquerda e direita devem mover o foco para, respectivamente, o item de menu anterior e seguinte.

- Quando o widget não está dentro de um formulário, tanto a tecla Enter quanto a Barra de Espaço devem selecionar ou ativar o controle.

- Dentro de um formulário, a tecla Barra de Espaço deve selecionar ou ativar o controle, enquanto a tecla Enter é responsável por submeter o formulário.

- Em caso de dúvida, deve-se imitar o comportamento padrão da versão desktop do controle sendo implementado.

\subsubsection{ARIA 1.1}

A versão 1.1 do ARIA atualmente encontra-se como um projeto de trabalho (W3C Working Draft), e está sendo elaborada com o objetivo de adicionar um pequeno número de recursos para completar o modelo de acessibilidade HTML + ARIA (W3C, 2016a). Nesta versão, será fornecido um conjunto de especificações com orientações para implementação nos agentes de usuários, que descrevem como mapear a semântica do ARIA e de outras linguagens Web nas APIs de acessibilidade. 


\subsection{Pessoas com Deficiência Visual na Web}

Os deficientes visuais, em geral, utilizam leitores de tela ou ampliadores de tela para navegar pela Web, o que em muitos casos, pode ser um grande desafio para esses usuários. Um usuário com visão pode rapidamente analisar uma página Web para obter uma visão geral da estrutura da página e encontrar o conteúdo relevante de forma eficaz. No entanto, para pessoas com deficiência visual que se apoiam em algum tipo de tecnologia assistiva para interagir com a Web, isso geralmente é um grande desafio e pode ser um processo demorado e frustrante. (BABU; SINGH, 2009) (LAZAR et al., 2007)

Existem também outras ferramentas que podem ser utilizadas além dos usuais leitores de tela e ampliadores (CIPOLLA-FICARRA, 2010).

- Sistema texto-voz: Converte o texto escrito para voz, através de algum sintetizador de voz;

- Feedback Auditivo: representa o uso de sons em resposta às interações do usuário, como os sons que acompanham os cliques, abertura e fechamento de janelas, a exclusão de um arquivo, entre outros;

- Interface Tátil: uma interface que utiliza o toque para a entrada e saída, como um leitor de braille.

\subsubsection{Leitores de Tela}

Os leitores de tela são ferramentas que permitem às pessoas cegas ou com deficiência visual utilizar um computador. Um leitor de tela interpreta o conteúdo visual apresentado na tela e descreve essa informação para o usuário através de uma voz sintetizada. O conteúdo é lido para o utilizador de uma maneira linear, de modo que um utilizador interage apenas com um elemento de cada vez (ASAKAWA; LEPORINI, 2009).

Diversos leitores de tela foram desenvolvidos nos últimos anos, dente eles: JAWS 6 , NVDA 7 ZoomText $t^{8}$, Windows Bridge 9 , Windows-Eyes ${ }^{10}$ e Hal ${ }^{11}$

A seguir, é apresentada uma descrição mais detalhada sobre os leitores de tela JAWS e NVDA, visto que são amplamente utilizados atualmente ${ }^{12}$.

\footnotetext{
http://www.freedomscientific.com/

http://www.nvaccess.org/

http://www.zoomtext.com/products/zoomtext-magnifierreader/

http://www.synthavoice.on.ca/

10 http://www.gwmicro.com/

$11 \mathrm{http}: / / \mathrm{www}$. dolphincomputeraccess.com/

12 http://webaim.org/projects/screenreadersurvey6/
} 
JAWS

A ferramenta JAWS (Job Access With Speech), desenvolvida para sistemas Windows pela Freedom Scientific, é um dos leitores de tela mais comumente utilizados atualmente. Ao interagir com conteúdos Web, o leitor de tela JAWS utiliza o denominado "cursor virtual". Assim, o leitor não interage diretamente com a página Web, mas sim com uma versão virtual que é carregada no sistema ao atualizar essa página.

Ao navegar na Web com apoio do JAWS, alguns atalhos permitem percorrer os elementos da página Web pressionando uma única tecla: $\mathrm{H}$ para os cabeçalhos (headings), $\mathrm{T}$ para as tabelas, F para os controles de formulários, entre outros. Essa é uma ótima maneira de facilitar a tarefa dos usuários de encontrar o conteúdo desejado em uma página Web. Porém, esses atalhos são completamente dependentes da estrutura semântica da página. Caso a página não possua cabeçalhos, ou possua uma marcação HTML mal formada, esses atalhos simplesmente não irão funcionar.

As teclas mais comuns do JAWS para interagir com texto (em relação ao foco atual), são:

- NUM PAD 5: lê o carácter;

- INSERT+NUM PAD 5: lê a palavra;

- INSERT+NUM PAD 5 (duplo clique): soletra a palavra;

- INSERT+SETA ESQUERDA: lê a palavra anterior;

- INSERT+SETA DIREITA: lê a próxima palavra;

- INSERT+SETA PARA CIMA: lê a linha;

- INSERT+HOME: lê até o cursor;

- INSERT+PAGE UP: lê a partir do cursor;

- INSERT+PAGE DOWN: lê a última linha da janela;

- INSERT+END: lê a primeira linha da janela;

- CTRL: interrompe a fala.

NVDA

O NVDA (NonVisual Desktop Access) também é um dos leitores de tela mais populares atualmente, principalmente devido à ferramenta ser gratuita e open source, ter boa integração com o ARIA e possibilitar o feedback via fala sintética e braille. O NVDA permite que pessoas cegas ou deficientes visuais possam interagir com o sistema operacional Windows e muitas outras aplicações de terceiros. 
Dentre os principais destaques do NVDA, pode-se citar:

- Suporte à aplicações populares, como navegadores Web, clientes de e-mail, suítes de escritório, entre outras;

- Sintetizador de voz embutido que suporta mais de 20 idiomas;

- Descrição da formatação do texto quando disponível, como nome da fonte, tamanho, estilo do texto e erros de digitação;

- Pode ser utilizado diretamente de um pen drive, sem a necessidade de instalação;

- Traduzido em muitos idiomas;

- Suporta versões atuais do Windows, tanto 32 bits quanto 64 bits;

- Pode ser executado nas telas de login do Windows, assim como em outras telas de segurança;

- Suporte para interfaces de acessibilidade comuns, como por exemplo, Microsoft Active Accessibility, Java Access Bridge, IAccessible2 e UI Automation

O NVDA possui o seu próprio sintetizador de voz, denominado eSpeak, mas também pode ser integrado a outros sintetizadores existentes, como o SAPI (Microsoft Speech API).

\subsubsection{Problemas Enfrentados pelos Usuários Cegos na Web}

Em geral, a acessibilidade na Web é avaliada com base nos critérios de sucesso do WCAG, apresentado nas Seções 2.2.1 e 2.2.2. Porém, de acordo com algumas pesquisas, mesmo que uma página Web esteja em conformidade com o WCAG, isso não necessariamente garante a acessibilidade destas páginas a todas as pessoas com diferentes tipos de deficiências (RØMEN; SVANÆS, 2008; HARRISON; PETRIE, 2006). Os usuários com deficiência interagem com a Web de diferentes maneiras (W3C, 2012), sendo necessário analisar as características particulares destes usuários, a fim de compreender quais barreiras de acesso têm mais impacto em cada caso. Por exemplo, estudos sugerem que pessoas cegas têm mais dificuldade em navegar na Web do que pessoas com outros tipos de deficiências. Power et al. (2012) apresentam que apenas 49,6\% dos problemas encontrados pelos usuários cegos ao interagir com a Web eram cobertos pelo WCAG, como visto na Tabela 1 , que apresenta os problemas relatados pelos usuários separados por categorias, e o número e porcentagem desses problemas que são atualmente cobertos pelo WCAG.

Um dos principais problemas para os usuários cegos que navegam na Web por meio de um leitor de tela é compreender a estrutura da interface das páginas Web, visto que elas são projetadas para a interação visual (GOBLE; HARPER; STEVENS, 2000). Em contraste com os 


\begin{tabular}{|c|c|c|}
\hline Categoria & $\begin{array}{c}\text { Total de } \\
\text { problemas dos } \\
\text { usuários }\end{array}$ & $\begin{array}{c}\%(\mathrm{Nro}) \\
\text { cobertos pelo } \\
\text { WCAG } 2.0\end{array}$ \\
\hline $\begin{array}{l}\text { O conteúdo encontrado na página não era o esperado pelos usuá- } \\
\text { rios }\end{array}$ & 99 & 0 \\
\hline $\begin{array}{l}\text { Conteúdo não encontrado nas páginas em que era esperado pelos } \\
\text { usuários }\end{array}$ & 88 & 0 \\
\hline Páginas muito lentas para carregar & 27 & 0 \\
\hline Não há alternativa ao formato de documento (ex. PDF) & 17 & 0 \\
\hline $\begin{array}{l}\text { Arquitetura de informação muito complexa (ex. muitos passos } \\
\text { para encontrar páginas) }\end{array}$ & 15 & 0 \\
\hline Links quebrados & 10 & 0 \\
\hline Funcionalidade não funciona (como esperado) & 50 & $26.0(13)$ \\
\hline Funcionalidade esperada não está presente & 29 & $34.5(10)$ \\
\hline $\begin{array}{l}\text { Organização de conteúdo é inconsistente com as convenções/- } \\
\text { senso comum da web }\end{array}$ & 39 & $35.9(14)$ \\
\hline Conteúdo irrelevante antes de conteúdo tarefa & 86 & $45.3(39)$ \\
\hline Os usuários não podem dar sentido ao conteúdo & 65 & $67.6(44)$ \\
\hline $\begin{array}{l}\text { Feedback inexistente ou insuficiente para informar que as ações } \\
\text { tiveram um efeito }\end{array}$ & 72 & $68.1(49)$ \\
\hline
\end{tabular}

Tabela 1 - Categorias de problemas apresentados pelos usuários.

Tabela adaptada de (POWER et al. 2012)

usuários com visão, os leitores de tela não são capazes de interpretar o conhecimento sobre a estrutura e navegação implícita na apresentação visual das páginas (YESILADA et al., 2004). Assim, para o usuário cego, a percepção do conteúdo da página pode divergir muito do que é realmente apresentado na tela. Estas diferenças de percepção podem causar uma considerável frustração.

Sendo assim, pode-se perceber que o uso das diretrizes de acessibilidade não é suficiente para garantir que o conteúdo esteja acessível pelos usuários cegos. Porém, outro aspecto que deve ser considerado é o de que tornar um conteúdo acessível não necessariamente o torna usável. Isso ocorre pois as interfaces gráficas são desenvolvidas por pessoas que enxergam, para pessoas que enxergam. Como exemplo, pode ser citado o problema em relação aos leitores de tela, que transcrevem informações visuais e gráficas em informações auditivas, porém, sem levar em conta o contexto. Com isso, entender as informações pode ser extremamente difícil, e o tempo de navegação Web para usuários cegos se torna muito maior do que para usuários que enxergam.

\subsection{Considerações Finais}

Esse capítulo apresentou uma introdução sobre os conceitos básicos relacionados ao tema de acessibilidade Web, assim como algumas abordagens utilizadas para minimizar esses problemas.

Algumas abordagens elaboradas pelo W3C através da WAI receberam uma atenção especial, visto que são abordagens consolidadas na literatura e que estão diretamente relacionadas 
ao tema proposto nessa tese. Em particular, foi apresentado o primeiro esforço da WAI em relação à elaboração de diretrizes para guiar o desenvolvimento de conteúdos Web acessíveis (WCAG 1.0), assim como a sua evolução (WCAG 2.0). Além desses conjuntos de diretrizes, foi apresentado o ARIA, que tem como objetivo permitir o desenvolvimento de aplicações Web mais acessíveis, principalmente em relação à integração com as tecnologias assistivas.

Dado o contexto dessa tese, foi apresentado o caso específico dos deficientes visuais e usuários cegos, expondo as formas com que esses usuários interagem com o conteúdo Web, assim como uma breve descrição sobre os leitores de tela, dada a importância dessa tecnologia assistiva na interação desses usuários com a Web. Por fim, uma breve discussão sobre alguns problemas atualmente encontrados pelos usuários cegos durante a interação com a Web mostra que ainda é necessário realizar pesquisas que ofereçam alternativas de como minimizar esses problemas, buscando maior satisfação desses usuários ao navegar na Web. 


\section{3}

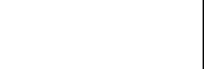

\section{ACESSIBILIDADE E USABILIDADE PARA USUÁRIOS CEGOS}

Conforme apresentado no Capítulo 2, os conjuntos de diretrizes de acessibilidade, como o WCAG e a especificação WAI-ARIA, apresentam especialmente diretrizes técnicas para auxiliar os desenvolvedores a projetarem interfaces que forneçam conteúdo acessível ao maior número e diversificado tipo de usuários, incluindo os que possuem diferentes tipos de deficiência. Mesmo que esses conjuntos de diretrizes sejam suficientes para deficientes visuais ou outros tipos de deficientes, para as pessoas cegas, que possuem o mais alto grau de deficiência visual, essas técnicas ainda não são suficientes (PETRIE; HAMILTON; KING, 2004) (POWER et al., 2012) (VIGO; HARPER, 2013).

Sendo assim, mesmo que os conjuntos de diretrizes de acessibilidade sejam um importante ponto de partida para o desenvolvimento de páginas Web acessíveis, ainda há uma necessidade de compreender melhor as dificuldades encontradas pelos usuários cegos. Neste contexto, foi realizado um mapeamento sistemático com objetivo de identificar na literatura quais as principais dificuldades enfrentadas pelas pessoas cegas ao interagir com a Web, além das possíveis diretrizes de acessibilidade e usabilidade, sugeridas nos trabalhos científicos, que visam minimizar estas dificuldades.

A escolha pela realização de um mapeamento sistemático como procedimento científico neste trabalho foi devido ao fato do tema ser muito abrangente, visto que nesses casos, o mapeamento é mais indicado do que a revisão sistemática. O mapeamento é projetado para prover uma visão mais ampla de um tópico de pesquisa, de modo a identificar se há evidência de pesquisa nesse tópico e prover uma indicação da quantidade de evidências (KITCHENHAM; CHARTERS, 2007).

Assim, o planejamento do mapeamento sistemático realizado é descrito na Seção 3.1 enquanto que a Seção 3.2 apresenta os dados sobre sua execução. Os resultados obtidos sobre os principais problemas encontrados pelos usuários cegos, assim como as diretrizes sugeridas para 
contornar esses problemas são apresentados, respectivamente, nas Seções 3.3 e 3.4 . Por fim, uma discussão sobre os resultados observados é apresentada na Seção 3.5 .

\subsection{Planejamento do Mapeamento Sistemático}

Com base nos objetivos propostos, de identificar na literatura quais as principais dificuldades enfrentadas pelas pessoas cegas no uso de conteúdos Web e quais as propostas de diretrizes de acessibilidade e usabilidade para minimizar tais dificuldades, foram definidas as seguintes questões primária e secundária para guiar o mapeamento sistemático.

- Questão Primária:

Quais as principais dificuldades encontradas pelos usuários cegos ao navegar na Web com auxílio de algum tipo de tecnologia assistiva?

- Questão Secundária:

Quais os princípios de acessibilidade e usabilidade na área Web têm sido utilizados para minimizar as dificuldades encontradas pelos usuários cegos que usam tecnologia assistiva?

Vale observar que a consideração sobre o uso de tecnologia assistiva em ambas as questões foi para assegurar que as buscas por trabalhos na literatura fossem realmente direcionados para o público de pessoas cegas, uma vez que para elas é estritamente necessário o uso de alguma tecnologia assistiva para acesso e uso de conteúdos Web.

Para obter as respostas para as questões primária e secundária formuladas, foi realizado um levantamento de artigos e outros trabalhos através da busca em três bases de dados eletrônicas: ACM Digital Library, IEEE Xplore e ScienceDirect. A string de busca foi definida da seguinte forma:

(Web AND (Accessibility OR Usability) AND (Guidelines OR Principles) AND

(Blind OR Visually Impaired)) AND (Assistive Technology)

Uma versão em Português desta string de busca foi utilizada, porém não retornou nenhum resultado.

Após a consulta nas bases eletrônicas, os trabalhos obtidos foram selecionados seguindose critérios pré-definidos. Para a exclusão dos artigos encontrados, foram definidos os seguintes critérios:

1. O trabalho não apresenta dificuldades enfrentadas pelos cegos ou diretrizes para minimizar estas dificuldades. 
2. O conteúdo apresentado não é voltado para usuários cegos.

3. O conteúdo apresentado não é voltado para a área Web.

4. A referência se encontra incompleta ou inconsistente.

Alguns artigos que foram incluídos no mapeamento sistemático mesmo não sendo um resultado da busca. Para isso, foi definido o seguinte critério:

1. Trabalho relacionado que aparece com frequência nas referências dos artigos selecionados durante a execução do mapeamento sistemático.

Durante a elaboração deste planejamento, em 2013, decidiu-se pesquisar apenas pelos trabalhos realizados nos últimos anos, ou seja, a partir de 2008. Essa decisão foi tomada considerando-se que a área Web apresenta uma evolução muito rápida. Porém, alguns trabalhos anteriores a 2008 foram manualmente incluídos, visto que são constantemente citados pelos estudos selecionados durante a execução do mapeamento sistemático.

\subsection{Execução do Mapeamento Sistemático}

Após estabelecer o protocolo descrito na Seção 3.1. o mapeamento sistemático foi realizado. A execução da string de busca foi efetuada no dia 08 de janeiro de 2013 e retornou 128 resultados: 68 na ACM Digital Library, 4 na IEEE Xplore e 56 na ScienceDirect.

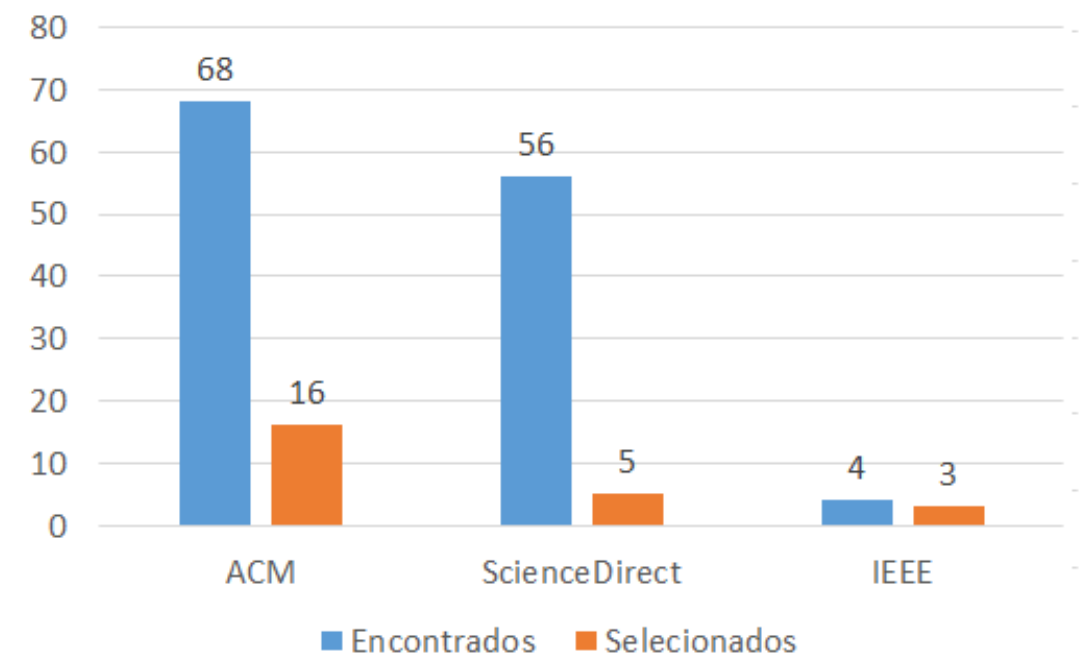

Figura 2 - Quantidade de resultados encontrados e selecionados em cada base (entre 2008 e 2013).

Dentre os 128 trabalhos encontrados, 24 foram selecionados: 16 trabalhos da ACM, 5 do ScienceDirect e 3 do IEEE, como demonstrado na Figura 2. A quantidade de artigos encontrados e selecionados agrupados por ano de publicação é apresentada na Figura 3. 


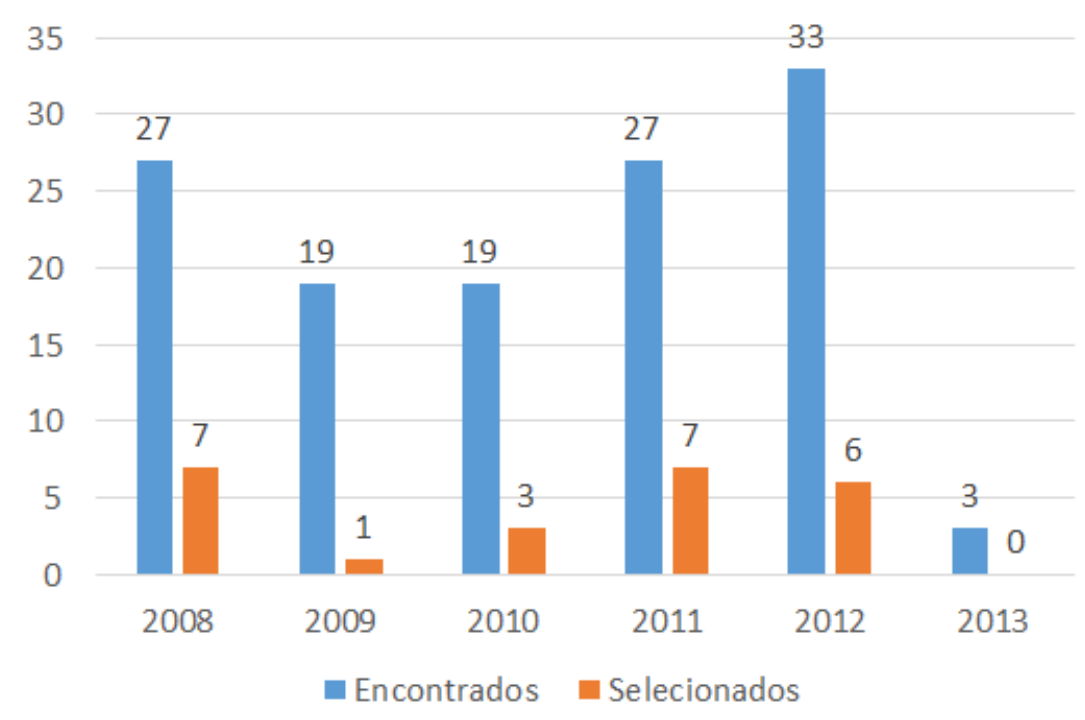

Figura 3 - Quantidade de resultados encontrados e selecionados por ano (entre 2008 e 2013).

Ainda, dado o critério de inclusão previamente definido, outros 5 artigos foram manualmente inseridos no estudo.

Após selecionar os artigos, foi realizada a etapa de extração de dados. Nessa fase, todas os dados a respeito das dificuldades encontradas pelos cegos e as diretrizes sugeridas para minimizar estas dificuldades foram coletados.

Por fim, os dados coletados foram analisados e organizados. As Seções 3.3 e 3.4 apresentam, respectivamente, os principais resultados sobre as dificuldades encontradas pelos cegos ao navegar na Web e as diretrizes recomendadas para minimizar estas dificuldades.

\subsubsection{Atualização do Mapeamento Sistemático}

Em 2016, decidiu-se atualizar o mapeamento sistemático, considerando o período posterior ao ano de 2013. A atualização do mapeamento sistemático foi realizada com base no mesmo protocolo descrito na Seção 3.1. Sendo assim, a busca foi novamente realizada no dia 04 de janeiro de 2016 e retornou 96 resultados: 26 na ACM Digital Library, 1 na IEEE Xplore e 69 na ScienceDirect.

Dentre os 96 trabalhos encontrados durante essa atualização, apenas 12 foram selecionados: 7 trabalhos da ACM, 4 do ScienceDirect e 1 do IEEE, como demonstrado na Figura 4. A quantidade de artigos encontrados e selecionados agrupados por ano de publicação é apresentada na Figura 5 .

A etapa de extração de dados resultou em resultados semelhantes aos resultados obtidos na primeira versão deste mapeamento sistemático. Assim, tanto os dados obtidos sobre as dificuldades encontradas pelos cegos quanto as diretrizes sugeridas para contornar essas dificuldades são apresentados respectivamente nas Seções $3.3 \mathrm{e} 3.4$. junto aos dados previamente encontrados 
na primeira versão do mapeamento. Optou-se por unir esses dados para evitar a duplicação das informações resultantes da análise dos artigos. Porém, na Seção 3.5 é apresentada uma discussão sobre as tendências de pesquisa observadas em cada uma das versões realizadas desse mapeamento sistemático.

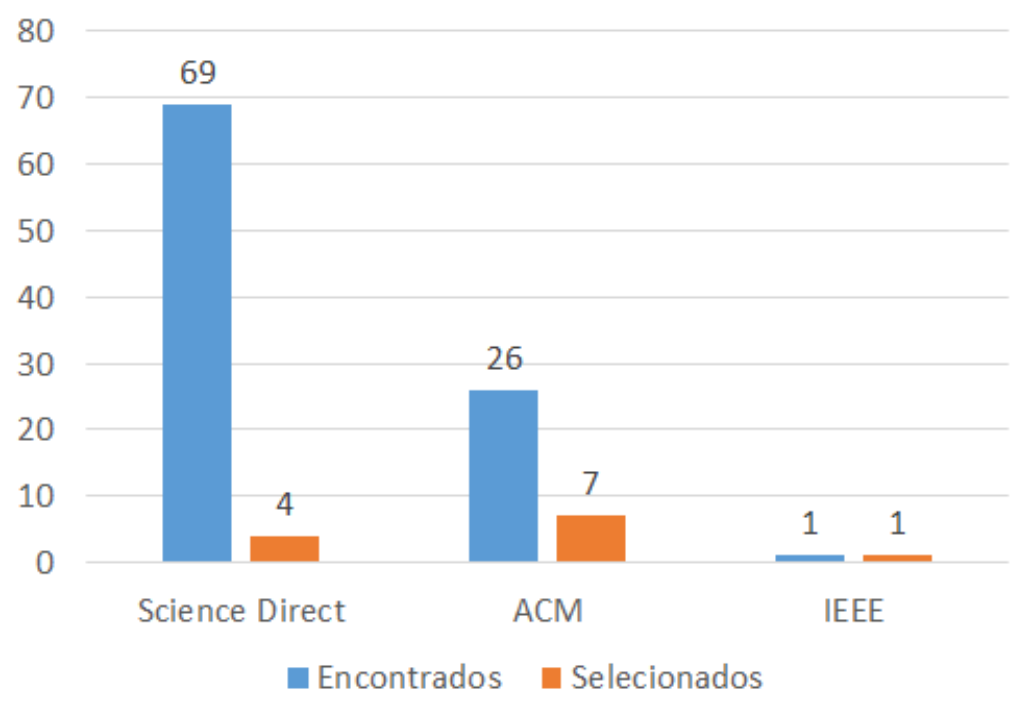

Figura 4 - Quantidade de resultados encontrados e selecionados em cada base (entre 2013 e 2016).

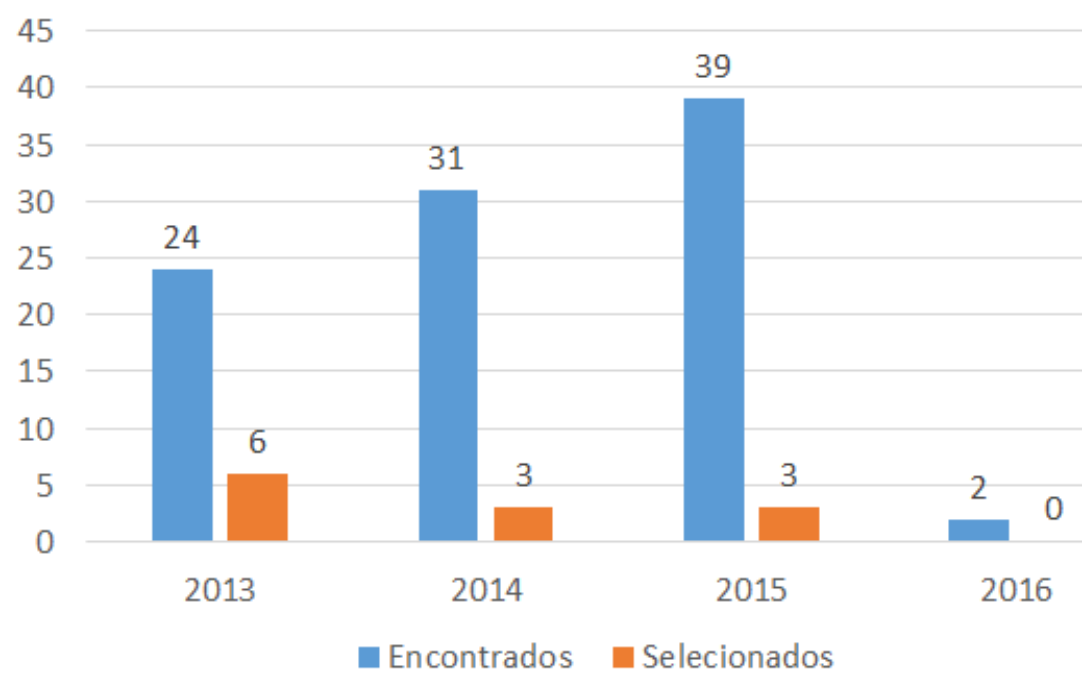

Figura 5 - Quantidade de resultados encontrados e selecionados por ano (entre 2013 e 2016).

\subsection{Dificuldades encontradas por usuários cegos ao nave- gar na Web}

Esta seção apresenta um levantamento dos principais resultados encontrados sobre os problemas enfrentados pelos usuários cegos que navegam na Web com auxílio de um leitor de 
tela. Com base na análise destes resultados, foi proposta uma organização dos problemas em três categorias: problemas técnicos, problemas semânticos e cognitivos e problemas na navegação.

\subsubsection{Problemas técnicos}

São considerados problemas técnicos os problemas decorrentes do mal uso dos recursos disponíveis para a criação da página Web e o seu conteúdo. A seguir estão listados os principais problemas técnicos encontrados:

1. Atualização automática da página: A página Web é automaticamente atualizada após um certo tempo decorrido (BRAJNIK, 2009). Como isso não é informado ao usuário cego, ele perde totalmente o controle e foco da interação atual. Além disso, como os usuários do leitor de tela levam mais tempo para percorrer uma página, a atualização automática pode forçar esses usuários a reiniciar a operação de busca do conteúdo desejado.

2. Formulários sem rótulos adequados: A página apresenta um formulário em que seus campos apresentam labels ausentes ou irrelevantes (BRAJNIK, 2009). Isso impossibilita que o usuário cego possa interagir com o formulário. Além disso, o uso de símbolos, como o asterisco, para representar obrigatoriedade do preenchimento de um campo do formulário apresenta uma dificuldade para os usuários cegos, visto que geralmente os leitores de tela ignoram esse tipo de símbolo durante a leitura do conteúdo (FERREIRA; NUNES; SILVEIRA, 2012).

3. Novas janelas: A página contém código que abre novas janelas do navegador quando o usuário utiliza links ou botões ou após a página ter carregado. Isso afeta o foco do usuário cego, dificultado a sua navegação (BRAJNIK, 2009).

4. Formulários com redirecionamento: A página contém um formulário que seu botão de submissão leva a uma nova atualização de página. Isso faz com que o navegador exiba uma nova página e posicione o foco do usuário no início desta página (BRAJNIK, 2009).

5. Componentes inacessíveis: A página apresenta componentes inacessíveis pelo leitor de tela, por exemplo, um objeto Flash ou um menu que não pode ser utilizado pelo teclado (BRAJNIK, 2009).

6. Eventos disparados apenas com uso do mouse: A página possui funções Javascript que são invocadas apenas com a utilização de mouse, como por exemplo, on mouse over e on mouse out (BRAJNIK, 2009).

7. Imagens sem descrição equivalente: A página apresenta imagens como fonte de informação, porém não existe uma descrição textual equivalente para descrever essas imagens (BRAJNIK, 2009). Ainda, mesmo que as imagens apresentem uma descrição, a mesma 
pode ser irrelevante e não descrever corretamente as informações apresentadas (PEREIRA et al., 2014)(MORASH et al., 2015).

8. Imagens funcionais sem texto alternativo: A página contém imagens utilizadas como botões ou links clicáveis, porém falta um texto equivalente para descrever essas funções (BRAJNIK, 2009).

9. Imagens funcionais incorporadas no plano de fundo: A página contém imagens funcionais incorporadas ao plano de fundo do site, impossibilitando que sejam associadas descrições textuais equivalentes a essas imagens (BRAJNIK, 2009).

10. Uso de frames: O projeto da página é baseado em frames. Isso faz com que ação tomada pelo usuário na página possa afetar outro frame que está fora do foco atual do usuário do leitor de tela (BRAJNIK, 2009).

11. Vídeos sem descrição: A página contém um elemento multimídia com um vídeo ou uma animação sem uma descrição textual equivalente para os diálogos e cenas (ENCELLE et al., 2011).

12. Páginas sem títulos: A página não possui a tag TITLE, ou o conteúdo dessa tag não provê informação útil (BRAJNIK, 2009). Isso faz com que o usuário cego não possa induzir corretamente o que será encontrado nessa página.

13. Tag de idioma não definida: A página não define o atributo LANG corretamente na tag HTML. Os leitores de tela podem utilizar essa informação para saber em qual idioma o conteúdo deverá ser lido (FERREIRA; NUNES; SILVEIRA, 2012).

14. Página sem uso de headings: A página não utiliza as tags $h 1, \mathrm{~h} 2, \ldots$, h6 para organizar o seu conteúdo (BRAJNIK, 2009). O uso dessas tags facilita a compreensão da página pelo usuário cego.

15. Janela sem controles do navegador: A página foi iniciada em uma nova janela do navegador, porém os controles usuais do navegador, como a barra de endereço e os botões voltar, avançar e atualizar não estão aparecendo (BRAJNIK, 2009).

16. Captcha: A página utiliza um serviço de Captcha que faz o usuário ler um conjunto distorcido de caracteres de uma imagem e digitar estes caracteres em um formulários (FUGLERUD et al., 2012) (PEREIRA; FERREIRA; ARCHAMBAULT, 2015). Alguns serviços de Captcha também fornecem áudio, mas problemas graves de usabilidade e acessibilidade também foram encontrados nesses serviços (BIGHAM; CAVENDER, 2009).

\subsubsection{Problemas semânticos ou cognitivos}

São considerados problemas semânticos ou cognitivos os problemas que dificultam a compreensão do conteúdo de uma página Web, e os problemas que sobrecarregam fatores 
cognitivos como a memória, percepção, raciocínio, etc., que dificultam na aquisição do conhecimento. Os principais problemas semânticos ou cognitivos encontrados durante a Mapeamento Sistemático estão listados a seguir:

1. Conteúdo alterado dinamicamente: A página apresenta um mecanismo que atualiza a página com nova informação ou realoca a informação existente sem o reconhecimento dos usuários (BAVANI; JAAFAR; YATIM, 2010). Essa adaptação dinâmica do conteúdo pode causa desorientação nos usuários cegos (CANDAN et al., 2009). Esse problema ocorre devido à falta de feedback para informar sobre as ações que modificaram a página (POWER et al., 2012).

2. Conteúdo irrelevante: A página apresenta um conteúdo irrelevante que não pode ser evitado e está posicionado antes do conteúdo desejado, como por exemplo, um menu superior de navegação (POWER et al., 2012). Isso frustra os usuários, que são forçados a percorrer esse conteúdo irrelevante a cada atualização de página (BAVANI; JAAFAR; YATIM, 2010), causando um grande número passos desnecessários para chegar ao conteúdo principal (PEREIRA et al., 2014). As pessoas cegas muitas vezes só aprendem por acaso que esse conteúdo, como as opções de navegação, são recorrentes em todas as páginas (LEUTHOLD; BARGAS-AVILA; OPWIS, 2008). Além disso, como os leitores de tela utilizam uma estratégia linear para processar cada página (de cima para baixo e da esquerda para direita), é muito difícil, tedioso e frustrante ser obrigado a sempre evitar as informações necessárias até encontrar o conteúdo ou link desejado.

3. Layout da página muito complexo: A página apresenta um layout complexo, dificultando que a pessoa cega tenha uma visão geral da página Web (BAVANI; JAAFAR; YATIM. 2010).

4. Layout baseado em tabelas: O layout da página é baseado em tabelas, misturando conteúdo e estrutura. Como as tabelas não podem ser linearizadas, o leitor de tela (que interpreta estas tabelas linha a linha) anuncia o conteúdo da página fora de ordem, consequentemente, a informação se torna confusa ou enganosa para o usuário cego (BUZZI et al., 2010) (CALVO; IGLESIAS; MORENO, 2014) (PEREIRA; FERREIRA; ARCHAMBAULT, 2015). As tabelas também não devem ser utilizadas para organizar componentes da página, como formulários por exemplo (BUZZI et al., 2010).

5. Dados em tabelas: A página apresenta uma tabela e o seu conteúdo está organizado em colunas. Uma vez que os leitores de tela interpretam o conteúdo da tabela por linhas, ele irá anunciar fora de ordem o conteúdo desta tabela (BUZZI et al., 2010). Além disso, a necessidade de memorização dos dados da tabela também gera uma barreira aos usuários cegos (FERREIRA; NUNES; SILVEIRA, 2012). 
6. Conteúdo inconsistente: A página apresenta conteúdo inconsistente, como por exemplo: links quebrados, conteúdo encontrado não era o esperado pelo usuário, o conteúdo não é encontrado onde era esperado, a funcionalidade não funciona como o esperado, funcionalidade esperada não está presente e a organização do conteúdo se encontra inconsistente com as convenções da Web ou o senso comum (POWER et al., 2012).

7. Páginas com carregamento lento (POWER et al., 2012): O problema ocorre pois o leitor de tela pode não fornecer o feedback informando que todo o conteúdo da página não terminou de ser carregado, causando desorientação ao usuário cego.

8. Falta de contexto: $O$ conteúdo da página Web apresenta falta de semântica (RUTHJANNECK, 2011) e as pessoas cegas não são capazes de dar sentido ao conteúdo (POWER et al., 2012) (LEPORINI; PATERNÒ, 2008). Os usuários do leitor de tela precisam construir uma representação mental da página Web e das estruturas de navegação para que eles possam buscar o conteúdo de forma eficiente. Sem um monitor persistente, as pessoas cegas ficam facilmente desorientadas (ZHAO et al., 2008).

9. Dados que necessitam de auxílio visual: A página contém dados que dependem de ajuda visual para o seu entendimento, como por exemplo, dados georreferenciados (ZHAO et al. 2008).

10. Alterações no layout da página: O layout de uma página Web existente é alterado, obrigando os usuários cegos a novamente aprender o nome de posição de todos os elementos importantes da página (FERREIRA; NUNES; SILVEIRA, 2012). Além disso, a falta de feedback na alteração do layout pode causar desorientação no usuário cego, que estava esperando por outro conteúdo ao voltar a página já previamente conhecida. O mesmo problema pode ocorrer quando o site apresenta estruturas de páginas e/ou funcionalidades inconsistentes entre as diferentes páginas (CALVO; IGLESIAS; MORENO, 2014).

11. Links sem separação: A página apresenta uma sequência de links que não são separados por nenhum caractere ou símbolo. Assim, o usuário cego pode enfrentar dificuldade para entender onde termina um link e começa outro (BRAJNIK, 2009).

12. Página com muitos links: A página Web apresenta muitos links, causando desorientação na pessoa cega que é obrigada a memorizá-los para eventualmente decidir qual dos links deve ser utilizado. O problema piora consideravelmente caso os links não estejam organizados em categorias significativas (BRAJNIK, 2009). Além disso, O uso do leitor de tela e do teclado para buscar por um link pode ser ineficiente em grandes documentos com muitos links ou hierarquias profundas (CANDAN et al., 2009).

13. Texto Espaçado: A página Web apresenta palavras ou termos que contêm espaços extras, como por exemplo o texto "S E J A - B E M - V I N D O", com o objetivo de conseguir um determinado efeito visual (BRAJNIK, 2009). 
14. Links indevidamente rotulados: A página apresenta links inadequadamente rotulados, como por exemplo, "clique aqui", "acesse aqui" ou "link" (BAVANI; JAAFAR; YATIM. 2010). Como o usuário cego navega pelo site através dos links, ele não é capaz de compreender o significado destes links mal rotulados sem acessar toda a informação contextual em torno dos mesmos.

15. Arte ASCII: A página Web contém texto que representa decorações em vez de palavras, como por exemplo, smileys (BRAJNIK, 2009).

16. Dependência de cor: A conteúdo da página Web contém material (texto, imagem, fundo, vídeos) em que a cor é usada como o único meio de transporte de informação, como por exemplo, o uso de diferentes cores para links previamente acessados (BRAJNIK, 2009).

17. Sobrecarga de informação: A página apresenta uma sobrecarga de informação, que prejudica a experiência de navegação dos usuários cegos (PUZIS et al., 2011) (por exemplo, muitos passos para encontrar o conteúdo (POWER et al., 2012). Durante a exploração de uma página, até mesmo um espaço em branco é lido, forçando os usuários cegos a utilizar recursos cognitivos para processar informação inútil (GIRAUD et al., 2011). Além disso, o usuário pode ficar confuso com grandes trechos de texto (LUNN; HARPER; BECHHOFER, 2011) e partes importantes do conteúdo na página se torna difícil ou até mesmo impossível de se descobrir e acessar (ISLAM et al., 2010). Isso confunde os usuários, e faz com que os mesmos possam encontrar um conteúdo não esperado assim como não encontrar o conteúdo esperado(AIZPURUA; ARRUE; VIGO, 2015).

\subsubsection{Problemas na navegação}

São considerados problemas na navegação todos os fatores que dificultam a interação do usuário com o conteúdo da página Web. Os principais problemas de navegação encontrados durante esse levantamento estão listados a seguir:

1. Menus muito complexos: A página apresenta menus muito complexos, com muitos links, o que dificulta a navegação através do uso de um leitor de tela. Isso ocorre pois o usuário cego apresenta dificuldade em encontrar links relevantes em meio a grandes quantidades de links oralizados, resultado em desorientação (BUZZI et al., 2009). Além disso, em geral não há nada explicitamente afirmando que um elemento da página é um menu. $\mathrm{O}$ conhecimento sobre qual elemento é um menu está implícita na sua representação visual (LUNN; HARPER; BECHHOFER, 2011). Usuários cegos não são capazes de adivinhar as relações entre os itens primários e secundários de navegação se elas forem expressas apenas visualmente (LEUTHOLD; BARGAS-AVILA; OPWIS, 2008).

2. Aplicações de Internet Rica: A página apresenta um componente RIA (Rich Internet Application) que foi implementado sem seguir as diretrizes de acessibilidade (FUGLERUD 
et al. 2012). RIAs estão repletas de elementos dinâmicos e interativos, tornando-se assim, difíceis de serem utilizadas com um leitor de tela (GIRAUD et al., 2011).

3. Retorno ao conteúdo previamente acessado: A página não apresenta uma maneira de auxiliar os usuários de leitor de tela a retomar o conteúdo previamente acessado. Esse problema ocorre quando estes usuários necessitam voltar para buscar por alguma informação específica ou retomar orientação. Como eles necessitam ouvir novamente e reconhecer pelo menos uma parte de cada página intermediária antes de atingir o conteúdo desejado, o retorno ao conteúdo previamente acessado com o uso de leitores de tela é um processo longo e ineficiente (GHAHARI et al., 2012).

4. Conteúdo inacessível pelo teclado: A página requer o uso de mouse para a sua navegação. Pessoas cegas não são capazes de utilizar uma página Web que apresenta a navegação pelo mouse como única alternativa, dado que eles não conseguem ver onde clicar (FUGLERUD et al. 2012).

5. Falta de feedback e ajuda (FERREIRA; NUNES; SILVEIRA, 2012): A página apresenta elementos interativos que não fornecem feedback adequado durante o seu uso. Além disso, a página não apresenta nenhum auxílio ao usuário em caso de questionamento sobre o sistema (manual de uso, mapa do site, estado atual da interação, etc). Por exemplo, caso não notificada, a expiração da sessão do usuário pode causar uma interrupção na navegação (PEREIRA; FERREIRA; ARCHAMBAULT, 2015).

6. Falta de recuperação de erro: A página apresenta elementos não válidos do atual contexto e não auxilia o usuário a se recuperar de um possível erro durante a interação (FERREIRA; NUNES; SILVEIRA, 2012), como por exemplo, a incapacidade de cancelar uma operação em andamento (PEREIRA; FERREIRA; ARCHAMBAULT, 2015).

7. Armadilhas para o teclado: A página contém elementos que travam o foco do usuário assim que ele os atinge com o teclado. Isso força o usuário a recarregar a página para retomar o controle do foco (BRAJNIK, 2009).

\subsection{Diretrizes de Acessibilidade e usabilidade}

Esta seção apresenta um levantamento das principais diretrizes de acessibilidade e usabilidade que visam minimizar alguns dos problemas apresentados na Seção 3.3 . Assim, elas foram também agrupadas nas três categorias: diretrizes para redução de problemas técnicos, diretrizes para reduzir problemas semânticos e cognitivos e, diretrizes para reduzir problemas na navegação. 


\subsubsection{Diretrizes técnicas}

1. Deve-se fornecer ajuda para cada entrada de formulário (FOLEY, 1996).

2. Declarar a tag language para especificar o idioma a ser utilizado pelo leitor de tela (FERREIRA; NUNES; SILVEIRA, 2012).

3. Sempre utilizar o atributo alt para descrever ícones e imagens (FERREIRA; NUNES; SILVEIRA, 2012).

4. Deve-se evitar que o conteúdo de um link seja aberto em uma nova janela ou em um рор-ир (FERREIRA; NUNES; SILVEIRA, 2012).

5. Nos formulários, os botões de ação devem aparecer após os campos (LEUTHOLD; BARGAS-AVILA; OPWIS, 2008).

6. Nenhuma informação deve ser apresentada apenas visualmente (LEUTHOLD; BARGASAVILA; OPWIS, 2008).

7. Notificações de áudio devem ser utilizadas com moderação para evitar aborrecimentos aos usuários (ENCELLE et al., 2011).

8. Anotação (áudio) em vídeo deve: ser breve e não dizer muito, para preservar o trabalho original; não sobrepor partes importantes da trilha sonora; ser o mais neutra possível (ENCELLE et al., 2011).

9. Recursos externos (como documentos no formato pdf, ppt e doc) contidos na página Web também devem ser acessíveis (CALVO; IGLESIAS; MORENO, 2014). É necessário prover alternativas acessíveis para apresentar estes tipos de documentos (CANDAN et al., 2009). Também devem ser oferecidas alternativas para tecnologias para arquivos multimídia desenvolvidos em Flash (PEREIRA; FERREIRA; ARCHAMBAULT, 2015).

10. Múltiplos sons não devem se sobrepor (ZHAO et al., 2008).

11. Função de edição de texto deve ser simples e seguir as seguintes diretrizes: (a) utilizar uma página separada para edição; (b) adicionar somente os campos utilizados pela edição nessa página; (c) prover formas alternativas rápidas para utilizar os comandos de formatação; (d) prover uma entrada textual alternativa; (e) prover uma forma mais simples para inserção de símbolos especiais; (f) controlar o foco da edição (BUZZI; LEPORINI, 2008).

\subsubsection{Diretrizes para minimizar problemas semânticos ou cognitivos}

1. A interface deve ser tão simples quanto possível (FERREIRA; NUNES; SILVEIRA, 2012). 
2. Um número máximo de links deve ser considerado em cada página (BUZZI; LEPORINI, 2008).

3. Deve-se agrupar links semelhantes em listas (BUZZI; LEPORINI, 2008).

4. Evitar o uso de banners de anúncios (FERREIRA; NUNES; SILVEIRA, 2012).

5. Itens que não são válidos no contexto atual devem ser escondidos ou desabilitados (FERREIRA; NUNES; SILVEIRA, 2012).

6. Seria preferível que o leitor de tela fizesse a releitura de cada título da coluna antes do valor real da célula, para minimizar a necessidade de memorização (FERREIRA; NUNES; SILVEIRA, 2012).

7. Quando o usuário segue um link, sua nova localização deve ser informada de alguma forma (FERREIRA; NUNES; SILVEIRA, 2012). Isso pode ser feito utilizando o mesmo nome para o rótulo do link e para a página de seu destino (FERREIRA; LEITE, 2003).

8. É essencial que o texto que descreve um link seja apresentado de um modo útil e informativo (LEPORINI; PATERNÒ, 2008). Os links devem ser auto-explicativos e não depender do contexto (BUZZI; LEPORINI, 2008) (FERREIRA; NUNES; SILVEIRA, 2012).

9. O nome da seção deve ser colocado no atributo título para indicar ao usuário cego qual seção ele está acessando no presente momento (FERREIRA; NUNES; SILVEIRA, 2012).

10. Evitar o uso de asterisco para indicar obrigatoriedade em formulários, visto que os leitores de tela geralmente desabilitam a leitura de pontuação (FERREIRA; NUNES; SILVEIRA. 2012).

11. A tag "language" deve ser definida

12. Notificar o usuário sempre que uma nova versão da página entrar em vigor (FERREIRA; NUNES; SILVEIRA, 2012).

13. Implementar mecanismos, como skip links, que auxiliem o usuário a evitar conteúdos não desejados (FERREIRA; NUNES; SILVEIRA, 2012).

14. Utilizar links internos para facilitar o acesso a seções importantes do conteúdo, como por exemplo, "ir ao conteúdo principal" ou "ir ao menu de navegação" (FERREIRA; NUNES; SILVEIRA, 2012) (GIRAUD et al., 2011) (MELO et al., 2013).

15. Todas as alterações dinâmicas ocorridas nas páginas devem ser automaticamente notificadas (BROWN; JAY; HARPER, 2012). O usuário deve perceber, pelo leitor de tela, quando uma parte da interface é recarregada e entender o contexto sobre o evento relacionado a essa mudança (BUZZI et al., 2010). 
16. Enriquecer vídeos com descrições auditivas dos elementos visuais mais importantes (ENCELLE et al., 2011).

17. Utilizar equivalentes textuais de dados gráficos para fornecer saída útil ao usuário de leitores de tela (ZHAO et al., 2008).

18. Agrupar e customizar regiões (por exemplo, navegação, conteúdo principal, busca, entre outras) para facilitar uma visão global do usuário (BUZZI et al., 2010).

19. Definir as tags de cabeçalho (heading) auxilia na divisão lógica da página Web e facilita que o usuário analise e encontre o conteúdo de interesse de forma mais rápida (BRUDVIK et al. 2008)Brudvik et al., 2008).

20. Fornecer um resumo do conteúdo encontrado na página (LUNN; HARPER; BECHHOFER, 2011).

21. As principais funcionalidades ou informações da página devem ser apresentadas primeiro (GIRAUD et al., 2011).

\subsubsection{Diretrizes para minimizar problemas de navegação}

1. Os menus devem possuir entre 5 e 9 itens (MILLER, 1956).

2. Todos os itens presentes em um menu e em seu sub-menu devem ser acessíveis pelo teclado (FERREIRA; NUNES; SILVEIRA, 2012).

3. Comunicar a estrutura de menus através de numeração (LEUTHOLD; BARGAS-AVILA; OPWIS, 2008).

4. Não utilizar menus de navegação no topo da página (LEUTHOLD; BARGAS-AVILA; OPWIS, 2008).

5. Campos de busca devem ser posicionados no início da página (LEUTHOLD; BARGASAVILA; OPWIS, 2008).

6. O usuário deve ter a possibilidade de a qualquer momento requisitar informações sobre onde ele está na interface, o seu estado, e o que ele pode fazer a partir desse ponto (BUZZI et al., 2010) (ZHAO et al., 2008).

7. No caso de menus com muitos itens, um índice sonoro (por exemplo, earcons ou spearcons) melhora a performance da navegação e a sua aceitação (JEON; WALKER, 2011).

8. A navegação deve ser simples, intuitiva e óbvia, devendo permanecer na mesma localização em todas as páginas (FRANCIS; AL-JUMEILY; LUND, 2013). 
9. Facilitar o retrocesso às páginas visitadas anteriormente. Estratégias de navegação para facilitar a volta ao conteúdo de interesse mostraram-se eficientes e efetivas: Retrocesso na navegação baseada em tópicos; Retrocesso na navegação baseada em listas (GHAHARI $e t$ al., 2012).

\subsection{Discussão dos Resultados}

Após organizar os resultados encontrados sobre as principais dificuldades dos usuários cegos ao interagir e navegar na Web e também de algumas diretrizes sugeridas para minimizar esses problemas, foi realizada uma análise sobre os artigos encontrados com o objetivo de identificar tendências de pesquisa nessa área.

Como o mapeamento sistemático foi realizado durante dois períodos distintos, sendo a primeira versão no início de 2013 (considerando artigos entre 2008 e início de 2013) e a segunda versão em 2016 (considerando artigos entre 2013 e início de 2016), optou-se por separar a discussão dos resultados de acordo com o período do mapeamento sistemático.

\subsubsection{Primeira versão do mapeamento sistemático}

Para analisar os artigos obtidos na primeira versão do mapeamento sistemático (artigos publicados entre 2008 e início de 2013), inicialmente foi realizada uma classificação destes artigos, seguida de uma distribuição de frequência para identificar a quantidade de trabalhos que aborda cada uma das três categorias de dificuldade apresentadas na Seção 3.3. Assim, levando em consideração que os artigos podem abordar mais de uma classificação de dificuldade, a quantidade de artigos que discutem sobre cada categoria de dificuldade é apresentada na Figura 6. O mesmo processo não foi repetido para as diretrizes de acessibilidade ou usabilidade apresentadas nos artigos, visto que os resultados seriam muito semelhantes, uma vez que cada trabalho em geral apresenta diretrizes sobre problemas previamente discutidos no artigo.

Os problemas semânticos e cognitivos são os mais abordados pelos artigos (23 artigos), enquanto que os problemas na navegação (10 artigos) e os problemas técnicos (11 artigos) não são tão recorrentes. Apesar disso, a razão por trás do menor número de trabalhos que abordam os problemas técnicos e de navegação tende a ser diferente para os dois casos.

Os artigos que discutem sobre os problemas técnicos fazem isso de uma forma introdutória e sem entrar em maiores detalhes. Além disso, as discussões técnicas costumam aparecer seguidas de referências aos conjuntos de diretrizes WCAG 2.0 (CALDWELL et al., 2008) e ARIA (CRAIG; SCHWERDTFEGER; SEEMAN, 2008), que são bem abrangentes no aspecto técnico.

O mesmo não ocorre com os artigos que abordam problemas de navegação. Grande parte desses artigos discute o problema como algo recente e que deve ser trabalhado para melhorar a 


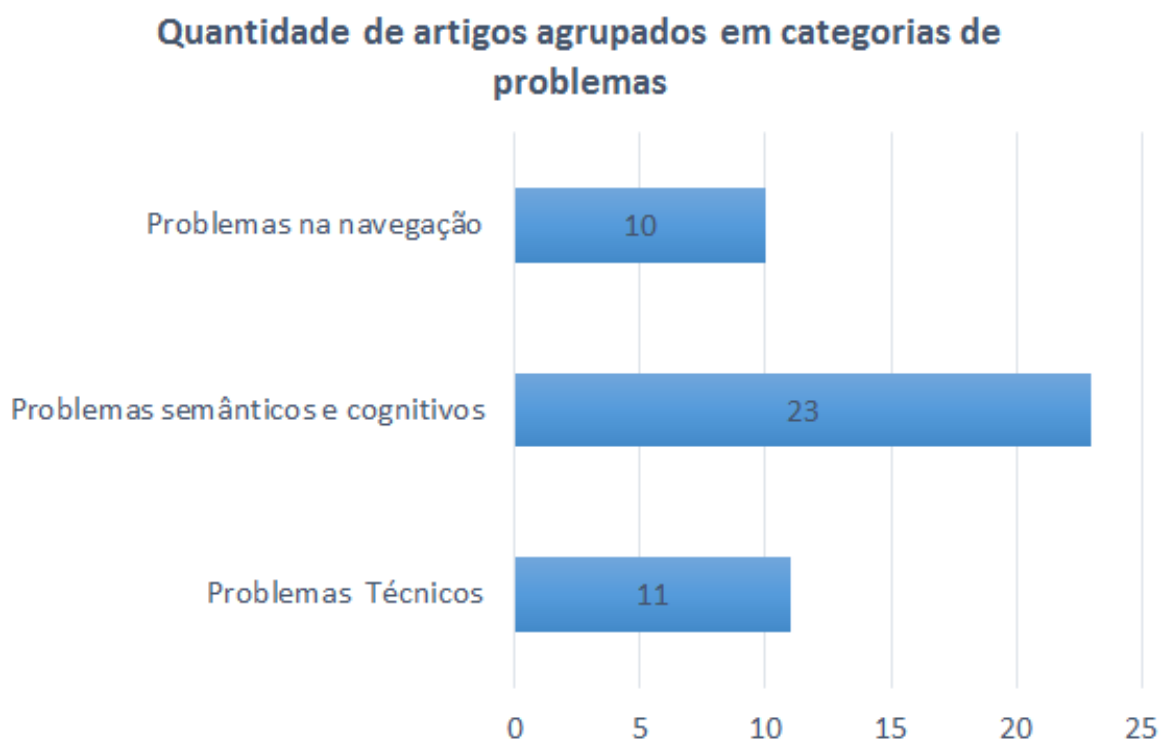

Figura 6 - Quantidade de artigos agrupados em categorias de problema.

acessibilidade e usabilidade dos usuários cegos enquanto navegam na Web, como por exemplo os trabalhos que sugerem melhorias na criação de menus (JEON; WALKER, 2011), (YALLA; WALKER, 2008), (HOCHHEISER; LAZAR, 2010) ou o trabalho que propõe métodos para facilitar o retrocesso ao conteúdo das páginas Web previamente acessadas (GHAHARI et al. 2012).

Vale ressaltar que na versão inicial do mapeamento sistemático, foram selecionados apenas os trabalhos realizados a partir de 2008. A segunda versão do WCAG foi lançada no ano de 2008, apresentando de forma abrangente os requisitos técnicos de acessibilidade com o objetivo de minimizar os problemas encontrados por todos os tipos de usuários. Como pesquisas começaram a indicar que os níveis de acessibilidade na Web não estavam melhorando, e mesmo as páginas em conformidade com o WCAG apresentavam problemas (POWER et al., 2012), outros aspectos começaram a ser investigados a partir desse ponto. Assim, percebe-se uma tendência em pesquisas envolvendo a semântica do conteúdo e o processo cognitivo, com o objetivo de entender melhor a maneira como os usuários cegos interagem com esse conteúdo. Com a análise desses aspectos, novas possibilidades de pesquisa surgiram, como é o caso da melhoria da navegação na Web para os usuários cegos que utilizam leitores de tela.

Outra tendência que é possível notar é a emergente preocupação com a usabilidade das páginas Web para os usuários cegos. O WCAG, por exemplo, apresenta diretrizes de acessibilidade, buscando garantir o acesso ao conteúdo. Porém, no caso dos usuários cegos, isso não é suficiente para garantir a acessibilidade. Estudos mostram que a navegação para cegos é cerca de 10 vezes mais lenta do que para usuários com visão (BORODIN et al., 2010). Isso faz com que as pessoas cegas fiquem frustradas e desistam de buscar pelo conteúdo desejado. Assim, pode-se dizer que no caso dos usuários cegos, a acessibilidade está fortemente relacionada às questões de usabilidade. 
Por fim, alguns artigos sugerem indícios de que adaptar uma página Web para que a mesma fique acessível para todos os tipos de usuários pode não ser a melhor solução no caso das pessoas cegas. Como pode-se perceber pela descrição das principais dificuldades enfrentadas pelos usuários cegos, diversas estratégias para interagir com a Web são completamente distintas das utilizadas pelas pessoas com visão. Assim, a versão inicial do mapeamento sistemático aponta uma tendência que sugere o desenvolvimento de modelos específicos de interface e navegação voltados para esses usuários.

\subsubsection{Atualização do mapeamento sistemático}

Ao analisar a atualização feita desse mapeamento sistemático (considerando os artigos publicados entre 2013 e início de 2016), o primeiro fato que causa estranheza é o baixo número de artigos incluídos perante o número de artigos encontrados (apenas 12,5\% destes artigos encontrados foram incluídos). Uma das possíveis razões por trás dessa baixa porcentagem de artigos selecionados encontra-se no primeiro critério para exclusão dos artigos encontrados: “o trabalho não apresenta dificuldades enfrentadas pelos cegos ou diretrizes para minimizar estas dificuldades". Diversos trabalhos encontrados nesse novo período apresentam uma discussão dos problemas enfrentados pelos cegos na interação Web com base em outras referências, como o WCAG 2.0 ou outros artigos previamente encontrados durante a primeira versão desse mapeamento. Sendo assim, como esses trabalhos apenas citavam problemas ou diretrizes já conhecidas da literatura, um número menor de trabalhos foram incluídos para a análise.

Apesar de não serem incluídos por não atenderem aos objetivos principais desse mapeamento, foi possível notar em diversos artigos alguns aspectos interessantes sobre as pesquisas realizadas no período posterior a primeira versão do mapeamento sistemático. Inicialmente nota-se que já é amplamente aceito o fato de que os conjuntos de diretrizes, como o WCAG, são insuficientes para garantir a acessibilidade de usuários cegos. Assim, a principal vertente de pesquisa que pôde-se observar durante a análise dos artigos encontrados foi a necessidade de entender melhor o comportamento e as necessidades dos usuários cegos durante a interação com a Web. Em Ferati et al. (2014) foram analisados dados recolhidos durante 3 workshops, com o objetivo de identificar fatores importantes para garantir acessibilidade para a comunidade de usuários cegos e com deficiência visual. Dentre os fatores encontrados, os autores destacam que um modelo único para entregar conteúdo acessível aos usuários com diferentes tipos de deficiências visuais não é uma solução satisfatória. Aizpurua, Arrue e Vigo (2015) analisaram a interação Web de 11 usuários cegos com o objetivo de compreender melhor os aspectos que influenciam a percepção sobre os problemas de acessibilidade na Web enfrentadas por esses usuários. Vigo e Harper (2013) analisaram como os usuários com deficiência visual lidam com os problemas encontrados durante a navegação Web. Entender as táticas que os usuários empregam perante os problemas encontrados permite aos desenvolvedores ficar cientes dos problemas que causam esse comportamento, além de possibilitar que esses comportamentos sejam integrados a 
algoritmos, permitindo reconhecer situações problemáticas em tempo real para fornecer ajuda automaticamente. Haanperä e Nieminen (2013) analisam a interação com um leitor de tela em 4 bibliotecas acadêmicas digitais, identificando problemas e fornecendo sugestões de como tornar essas interfaces mais usáveis para os usuários cegos.

Assim, pôde-se notar uma tendência na diminuição do número de pesquisas que buscam uma solução técnica para os problemas e um aumento das pesquisas centradas em descobrir as necessidades dos usuários cegos, assim como as pesquisas que visam o entendimento das características cognitivas desses usuários na interação com a Web.

\subsection{Considerações Finais}

Esse capítulo apresentou o planejamento e execução de um mapeamento sistemático realizado com objetivo de identificar e compreender melhor as dificuldades enfrentadas pelos usuários cegos ao navegar na Web, assim como as diretrizes de acessibilidade e usabilidade sugeridas na literatura para minimizar alguns destes problemas.

Os problemas encontrados foram agrupados e apresentados em 3 categorias: problemas técnicos, problemas semânticos e cognitivos e problemas na navegação. As mesmas categorias foram utilizadas para apresentar as diretrizes recomendadas.

Ainda, foi apresentada uma discussão referente aos trabalhos encontrados durante esse mapeamento sistemático, assim como algumas tendências de pesquisa na área.

A elaboração desse mapeamento possibilitou compreender melhor como os usuários cegos interagem com a Web e quais as maiores dificuldades encontradas. Como visto, os mecanismos de navegação encontrados nas páginas Web são um dos maiores desafios para esses usuários, visto que são projetados para uma interface visual. Sendo assim, no Capítulo 4, é apresentado um método para automaticamente classificar links de uma página Web referentes às estruturas de navegação. No Capítulo 5, é proposta uma abordagem para automaticamente transformar esses links extraídos em um modelo de navegação otimizado aos usuários cegos. 


\section{4}

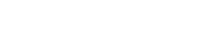

\section{CLASSIFICAÇÃO AUTOMÁTICA DE LINKS DE NAVEGAÇÃO EM PÁGINAS WEB}

Ao navegar pela $\mathrm{Web}$, as pessoas visualizam uma página por meio de um navegador, obtendo uma apresentação 2D que possui sugestões visuais para ajudar a distinguir diferentes partes da página. Geralmente, o desenvolvedor organiza o conteúdo da página web para facilitar a leitura do usuário. Assim, o conteúdo semanticamente relacionado é geralmente agrupado e toda a página é dividida em regiões de diferentes conteúdos usando separadores visuais explícitos ou implícitos, tais como linhas, áreas em branco, imagens, cores, etc (YANG; ZHANG, 2001).

Porém, usuários cegos não acessam as informações de uma página Web da mesma forma que os usuários com visão. O leitor de tela serializa o conteúdo de maneira sequencial, de acordo com a ordem apresentada no código da página Web. Isso faz com que os usuários cegos deixem de obter um conhecimento importante sobre a estrutura da página, inviabilizando uma interação mais objetiva.

Uma maneira de minimizar esse problema é incorporar ao código o conhecimento semântico sobre a estrutura da página Web. Existem algumas possibilidades para que isso seja feito, como por exemplo, o uso das seguintes especificações:

HTML 5: A quinta versão do HTML (HyperText Markup Language) apresenta novos elementos com significados semânticos, como por exemplo, os elementos <header>, $<$ footer $>$ e $<$ nav $>$, que são utilizados para representar, respectivamente, o cabeçalho da página, o rodapé e os menus de navegação. Esses novos elementos permitem ao desenvolvedor incorporar à sintaxe HTML um conhecimento semântico sobre a estrutura da página (W3C, 2014b).

Microdados: Essa abordagem propõe mesclar atributos próprios aos elementos do HTML, sendo uma estratégia simples e coerente de ser adota em diferentes tipos de código. 
Com o apoio de grandes empresas como Microsoft, Google e Yahoo, foi criado um site, denominado Schema.org $[1$, com um catálogo completo de formatos para representar entidades do mundo real utilizando microdados, como por exemplo, pessoas, eventos, receitas, livros, entre outros (W3C, 2013).

WAI-ARIA: Uma abordagem voltada particularmente aos elementos interativos presentes nas páginas Web, como menus de navegação e botões. Consiste de um padrão de desenvolvimento que permite fornecer informações extra aos leitores de tela através de atributos incluídos em qualquer elemento HTML. Por exemplo, o WAI-ARIA introduz o atributo role, que é utilizado para indicar a finalidade de um determinado elemento (W3C, 2014a).

Além dessas tecnologias que permitem adicionar ao código o conhecimento semântico sobre a estrutura da página, alguns trabalhos na literatura apresentam abordagens de como desenvolver menus mais acessíveis (ANTONELLI; FORTES, 2015) (YALLA; WALKER, 2008) (JEON; WALKER, 2011).

Para incorporar esses conceitos e especificações às páginas Web, os desenvolvedores devem possuir uma ampla gama de conhecimentos sobre essas diferentes abordagens. Porém, dada a complexidade dessas especificações, isso pode ser difícil para a maioria dos desenvolvedores (LEE; HENSCHEN, 2015). Em um estudo recente, Watanabe, Geraldo e Fortes (2015) realizaram uma avaliação em 32 sites que continham componentes Tab e 74 sites que continham componentes de Menu, a partir dos 150 sites mais acessados de acordo com a classificação do serviço Alexa $a^{2}$, com o objetivo de identificar o uso correto dos atributos da especificação WAI-ARIA. O estudo mostrou que, além de nenhum site estar completamente de acordo com a especificação WAI-ARIA, apenas 5 dentre os 74 sites em que foi analisado o Menu, e 1 dentre os 32 sites em que foi estudado o componente Tab, utilizavam parcialmente a especificação ARIA.

Assim, enquanto essas tecnologias não são amplamente adotadas e o seu uso esteja em conformidade com as suas especificações, é necessário pesquisar alternativas para que os usuários cegos possam interagir com a Web de uma maneira mais eficaz.

Como apresentado no Capítulo 3, algumas das principais dificuldades dos usuários cegos ao interagir com a Web estão relacionadas à navegação. Em particular, a falta de semântica no código referente aos menus, tanto para informar que um elemento da página é um menu (LUNN; HARPER; BECHHOFER, 2011) quanto para relacionar itens primários e secundários de navegação (LEUTHOLD; BARGAS-AVILA; OPWIS, 2008) é um dos principais fatores que dificultam a navegação dos usuários cegos por meio de um leitor de tela.

Assim, esse capítulo apresenta uma abordagem que tem como objetivo classificar automaticamente links de navegação em uma página Web, com base apenas nas características

1 http://www.schema.org/

2 http://www.alexa.com/topsites 
visuais destes links. O intuito desse classificador é possibilitar uma transformação automática desses links de navegação em modelo otimizado aos usuários cegos.

Este capítulo está organizado como segue. A Seção 4.1 apresenta uma definição sobre menus de navegação. A Seção 4.2 apresenta a metodologia proposta para o classificador, enquanto que o seu desenvolvimento é apresentado na Seção 4.3. A Seção 4.4 apresenta a avaliação do método proposto e a Seção 4.5 apresenta uma discussão sobre os resultados obtidos.

\subsection{Menus de Navegação}

Toda página Web deve fornecer aos seus usuários um mecanismo para auxiliá-los a navegar pelo site. Para esse propósito, em geral, são utilizados os menus de navegação, visto que auxiliam os usuários a conhecer a estrutura do site e os informa sobre onde estão e que ações podem tomar a partir desse ponto. Para isso, o design da página Web também deve ser consistente e os menus de navegação devem estar sempre visíveis e em uma posição fixa na página (WELIE, 2007a).

Existem diversas maneiras de se projetar menus de navegação em uma página Web. No entanto, as formas mais comuns são os menus horizontal, vertical e o menu L-invertido, que são apresentados, respectivamente, nas Seções 4.1.1, 4.1.2 e 4.1.3.

\subsubsection{Menu Horizontal}

Segundo Welie (2007a), esse tipo de menu consiste basicamente de uma barra horizontal posicionada no topo da página Web, com vários itens clicáveis, como apresentado na Figura 7. 0 seu posicionamento permanece inalterado durante a navegação do site e deve estar presente em todas as páginas. Quanto à sua estrutura de informação, uma das principais limitações deste tipo de menu encontra-se no número máximo de itens, que deve variar entre 6 ou 8 , de acordo com o tamanho médio das palavras, tamanho da fonte e largura da página Web. Uma de suas principais vantagens está no fato deste tipo de menu não consumir muito espaço vertical, possibilitando maximizar a largura do conteúdo da página Web.

\begin{tabular}{|l|l|l|l|}
\hline ITEM NIVEL 1 & ITEM NÍVEL 1 & ITEM NÍVEL 1 & ITEM NÍVEL 1 \\
\hline
\end{tabular}

Figura 7 - Padrão de projeto para menu horizontal em páginas Web.

Figura adaptada de (WELIE, 2007a)

\subsubsection{Menu Vertical}

Consiste basicamente de uma lista de links de navegação apresentados na vertical, como apresentado na Figura 8. Quando o menu vertical é utilizado, a página Web é dividida em pelo 
menos duas colunas. A grande vantagem desse tipo de menu está na possibilidade de se utilizar quantos itens desejar, visto que o mesmo se expande na vertical. Porém, utilizar muitos itens pode se tornar uma desvantagem, uma vez que os itens não seriam visíveis antes de rolar a página para baixo.

\begin{tabular}{|l|}
\hline$\underline{\text { ITEM NIVEL } 1}$ \\
$\underline{\text { ITEM NIVEL } 1}$ \\
$\underline{\text { ITEM NIVEL } 1}$ \\
$\underline{\text { ITEM NIVEL } 1}$ \\
$\underline{\text { ITEM NIVEL } 1}$ \\
$\underline{\text { ITEM NIVEL } 1}$ \\
$\underline{\text { ITEM NIVEL } 1}$
\end{tabular}

(A)

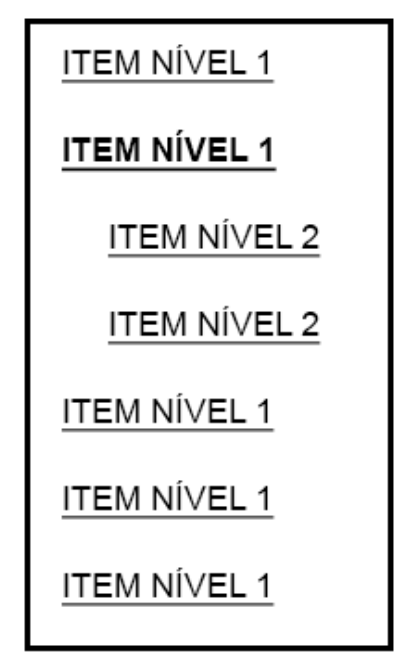

(B)

\section{NÍVEL 1 - RÓTULO \\ ITEM NIVEL 2 \\ ITEM NIVEL 2 \\ NÍVEL 1 - RÓTULO \\ ITEM NIVEL 2 \\ ITEM NÍVEL 2}

Figura 8 - Três padrões de projeto para menu vertical em páginas Web. (A) apresenta apenas um nível, (B) apresenta um nível mas expande um segundo nível quando selecionado e (C) apresenta dois níveis agrupados por um título não-clicável de um nível.

Figura adaptada de WELIE, 2007a

\subsubsection{Menu L-Invertido}

O menu no formato L-Invertido consiste basicamente de uma combinação dos menus horizontal e vertical, utilizado nos casos em que é necessário o uso de uma maior quantidade de links de navegação, ou mesmo, quando deseja-se estruturar os links em uma hierarquia com mais de um nível. A Figura 9 apresenta o padrão de projeto para esse tipo de menu.

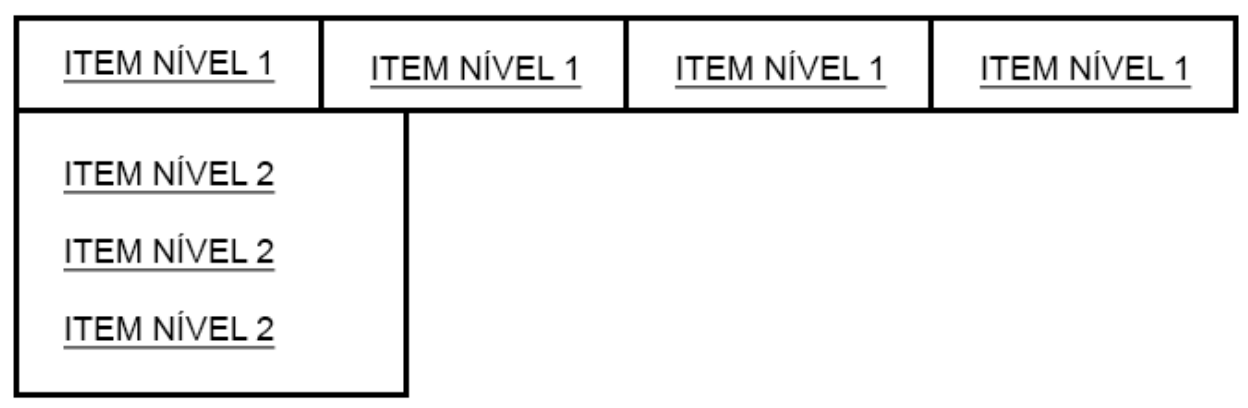

Figura 9 - Padrão de projeto para menu L-invertido em páginas Web.

Figura adaptada de (WELIE, 2007a) 


\subsection{Metodologia Proposta}

Existem diversas abordagens na literatura para a classificação de elementos em páginas Web e para a detecção de blocos de informação baseadas na análise do código HTML das páginas Web, que é geralmente representada pelo DOM (Document Object Model) (CHAKRABARTI; KUMAR; PUNERA, 2008) (GUPTA et al., 2003) (LIN; HO, 2002) (SONG; SUN; LIAO, 2015). Apesar de muito utilizada na literatura, esse tipo de abordagem não permite levar em consideração algumas informações contidas na apresentação visual das páginas Web, visto que o DOM fornece apenas uma aproximação da página resultante. Assim, informações como a posição dos elementos após a renderização não podem ser consideradas.

Por outro lado, as abordagens baseadas no processamento da página renderizada normalmente trabalham com uma representação visual da página obtida por meio de segmentação (ZHANG et al., 2013) (BURGET; RUDOLFOVA, 2009) (YI; LIU; LI, 2003).

Diferente das abordagens tradicionais que segmentam a página em blocos, propõe-se elaborar um método capaz de classificar individualmente os links encontrados em uma página Web. Isso é importante visto que o foco principal do trabalho é voltado à acessibilidade para usuários cegos, e portanto, além de classificar os links de uma página, espera-se obter um melhor entendimento das características desses links, possibilitando automaticamente adaptar esses links em um possível modelo de navegação otimizado para esses usuários.

Assim, com o intuito de classificar individualmente quais links em uma página podem ser considerados links de um menu de navegação, foi proposto um classificador com base no método Naïve Bayes, com base em três características visuais comumente encontradas nos padrões de projeto de menus de navegação apresentados na Seção 4.2: o posicionamento do link em relação à margem esquerda da página, o posicionamento do link em relação ao topo da página $\mathrm{e}$ a repetição do mesmo entre as páginas do site.

No entanto, ao limitar o classificador apenas a estas 3 características, torna-se inviável a tentativa de classificar de forma binária os links encontrados, apenas como sendo ou não um menu de navegação, dada a arbitrariedade no planejamento e desenvolvimento de páginas Web. Em particular, as características referentes ao posicionamento dos links na página não poderiam ser estudadas analiticamente, visto que esse posicionamento pode variar de acordo com as decisões de projeto tomadas pelo desenvolvedor do site. Por exemplo, um menu de navegação pode estar localizado na parte superior ou inferior do site, orientado horizontalmente. Por outro lado, menus de navegação verticais podem estar posicionados nas laterais (esquerda e direita) da página. Assim, se todos estes menus fossem submetidos à mesma classe de interesse, a análise estatística dos resultados do treinamento não retratariam a realidade destes menus.

Assim, com o objetivo de contornar esse problema, decidiu-se considerar 4 classes de interesse para classificação de um link pertencente a um menu, sendo estas denominadas: "menu de navegação superior", "menu de navegação lateral esquerdo", "menu de navegação lateral 
direito"e "menu de navegação no rodapé". Além destas 4 classes, foram considerado os casos em que o link não pertence a nenhum menu de navegação, sendo essa classe denominada "conteúdo", totalizando assim 5 possíveis classes de interesse para um link.

Após o planejamento inicial, foi realizado um treinamento para obter amostras que representam cada uma das 3 características referentes às 5 classes de interesse. Um teste de hipóteses não paramétrico foi utilizado, considerando-se os dados obtidos durante o treinamento, para determinar qual função densidade de probabilidade melhor representa cada característica. O método utilizado foi o Teste Qui-Quadrado, apresentado na Seção 4.2.3. Para isso, foram utilizadas diferentes densidades de probabilidade definidas na semi-reta não negativa (refletindo o fato de que os dados das características adotadas pelo classificador sempre apresentam valores não-negativos). Assim, os dados obtidos no treinamento foram comparados às densidades Gama, Exponencial, Qui-quadrado (sendo estas duas casos particulares da Gama), Rayleigh, Nakagami, Gaussiana-Inversa, Beta, Log-Normal e Weibull. Além dessas densidades, também foi utilizada a densidade Normal, visto que é uma densidade amplamente utilizada na literatura.

Após determinar qual função densidade de probabilidade melhor se adequa a cada característica, foram calculados os parâmetros destas funções pelo método dos momentos, novamente com base nos dados de treinamento.

Os dados de treinamentos utilizados para elaborar o classificador foram obtidos em sites governamentais. Esse domínio de sites foi selecionado uma vez que são fundamentalmente utilizados para fornecer informações e serviços aos cidadãos, sendo assim, são considerados uma forma muito importante de comunicação entre o governo e a população (BÉLANGER; CARTER, 2008). Dessa forma, devido à natureza dos conteúdos e à importância do acesso à informação por todos no país, é de extrema importância manter estes sites como foco de estudo, com o objetivo constante de garantir a acessibilidade e usabilidade nestes sites. Sendo assim, para avaliar o desempenho do classificador desenvolvido, foram novamente utilizados sites governamentais.

As Seções 4.2.1, 4.2.2 e 4.2.3 apresentam o referencial teórico sobre, respectivamente, o classificador Naïve Bayes, o estimador por Métodos dos Momentos e o Teste Qui-Quadrado. A Seção 4.3.2 apresenta com maiores detalhes as classes de interesse consideradas. As Seções 4.3.3, 4.3.4 e 4.3.5 apresentam, respectivamente, como os dados de treinamento foram obtidos, como as distribuições para cada classe foram escolhidas e o desenvolvimento do classificador. Por fim, a Seção 4.4 apresenta o método de avaliação proposto e os resultados obtidos.

\subsubsection{Naiive Bayes}

O método Naïve Bayes é uma técnica simples e bastante utilizada para a construção de classificadores baseados na Regra de Bayes. O classificador Naïve Bayes é geralmente aplicado em situações em que se tem um conjunto de características representando cada casoteste (treinamento), e cada um desses treinamentos estão associados a uma classe. Assim, este 
classificador é utilizado para obter a classe de um treinamento ainda não visto com base em outros exemplos de treinamento. O classificador Naïve Bayes é particularmente adequado para dados de alta dimensionalidade (ZHANG, 2004). Este classificador é capaz de manipular um número arbitrário de variáveis contínuas ou categóricas, assumindo os valores dessas variáveis independentes. Considere uma variável classe $C_{j}(j=1, \ldots, J)$ e um conjunto de variáveis aleatórias $\mathbf{x}=\left(x_{1}, \ldots, x_{n}\right)$ representando os valores de $n$ características ou atributos (variáveis independentes), a regra de Bayes estabelece a seguinte relação

$$
p\left(C_{j} \mid x_{1}, \ldots, x_{n}\right)=\frac{p\left(x_{1}, \ldots, x_{n} \mid C_{j}\right) p\left(C_{j}\right)}{p\left(x_{1}, \ldots, x_{n}\right)},
$$

em que $p\left(C_{j} \mid x_{1}, \ldots, x_{n}\right)$ é a probabilidade a posteriori da classe associada, isto é, a probabilidade da classe $C_{j}$ dado a característica $\mathbf{x}$, e $p\left(C_{j}\right)$ representa a probabilidade a priori de $C_{j}$, ou seja, a probabilidade de obtenção da classe $C_{j}$ sem levar em consideração os dados de treinamento.

Com base na suposição de independência condicional do classificador Naïve Bayes, podemos decompor a verossimilhança como um produto de termos, ou seja,

$$
p\left(\mathbf{x} \mid C_{j}\right)=\prod_{k=1}^{n} p\left(x_{k} \mid C_{j}\right),
$$

em que $p\left(x_{k} \mid C_{j}\right)$ é a distribuição da $k$-ésima característica condicionada a $j$-ésima classe $C_{j}$. Em outras palavras, a Equação (4.2) mostra que a probabilidade de observar $\mathbf{x}=\left(x_{1}, \ldots, x_{n}\right)$ é, simplesmente, o produto das probabilidades de cada característica individual.

Assim, para todo $k$, a Equação 4.1 pode ser reescrita como

$$
p\left(C_{j} \mid x_{1}, \ldots, x_{n}\right)=\frac{p\left(C_{j}\right) \prod_{k=1}^{n} p\left(x_{k} \mid C_{j}\right)}{p\left(x_{1}, \ldots, x_{n}\right)} .
$$

Visto que $p\left(x_{1}, \ldots, x_{n}\right)$ é constante e depende somente de $\mathbf{x}=\left(x_{1}, \ldots, x_{n}\right)$, a probabilidade a posteriori pode então ser expressa como

$$
p\left(C_{j} \mid x_{1}, \ldots, x_{n}\right) \propto p\left(C_{j}\right) \prod_{k=1}^{n} p\left(x_{k} \mid C_{j}\right) .
$$

Então, o classificador Naïve Bayes pode ser obtido aplicando-se a regra de Bayes discutida acima para calcular a probabilidade de cada classe dado os valores das características no exemplo de treinamento, e escolhendo-se a que resulta em maior probabilidade. Ou seja, para um novo conjunto de variáveis $\mathbf{x}$, a classe a qual estas variáveis pertencem será aquela com maior valor para $p\left(C_{j} \mid \mathbf{x}\right)$. Com isso, a função de decisão do classificador Naïve Bayes pode ser expressa por

$$
\hat{y}=\arg \max _{j \in\{1, \ldots, J\}} p\left(C_{j}\right) \prod_{k=1}^{n} p\left(x_{k} \mid C_{j}\right) .
$$


Para estimar $p\left(C_{j} \mid \mathbf{x}\right)$ o classificador Naïve Bayes utiliza o critério do Máximo a Posteriori (MAP) (SARIDIS, 1983). Os diferentes classificadores Naïve Bayes diferem principalmente pelas suposições acerca da distribuição de $p\left(x_{k} \mid C_{j}\right)$. Embora a suposição básica de independência entre todas as características nem sempre seja precisa, o método Naïve Bayes simplifica a tarefa de classificação, uma vez que permite que as densidades condicionais $p\left(x_{k} \mid C_{j}\right)$ sejam calculadas separadamente para cada variável. Dessa forma, o classificador Naïve Bayes ameniza o problema da dimensionalidade.

\subsubsection{Estimador por Método dos Momentos}

O método dos momentos é um dos métodos mais antigos para encontrar estimadores pontuais. Esse método é bastante simples de se utilizar e quase sempre é possível encontrar algum tipo de estimativa. Neste trabalho, o método dos momentos é utilizado para estimar os parâmetros das distribuições de probabilidade que representam cada uma das três características adotadas.

O funcionamento do estimador é apresentado como segue. Sejam $X_{1}, \ldots, X_{n}$ amostras de uma população com função densidade de probabilidade dada por $f\left(x \mid \theta_{1}, \ldots, \theta_{k}\right)$. Os estimadores do método dos momentos para $\left(\theta_{1}, \ldots, \theta_{k}\right)$ são encontrados igualando primeiramente os $k$ momentos amostrais aos correspondentes $k$ momentos populacionais, e em seguida resolvendo o sistema resultante das equações simultâneas. Mais precisamente, são obtidos da solução das $k$ equações (CASELLA; BERGER, 2002)

$$
E\left(X^{r}\right)=\frac{1}{n} \sum_{i=1}^{n} X_{i}^{r} \quad \text { para } r=1, \ldots, k
$$

sendo $E\left(X^{r}\right)$ o $r$-ésimo momento não central populacional e $1 / n \sum_{i=1}^{n} X_{i}^{r}$ o $r$-ésimo momento não central amostral.

Neste trabalho são adotadas distribuições com até dois parâmetros e, dessa maneira, o sistema de equações para obter as estimativas pelo método dos momentos se reduz às equações (4.7) e (4.8)

$$
\begin{gathered}
E(X)=\frac{1}{n} \sum_{i=1}^{n} X_{i} \\
E\left(X^{2}\right)=\frac{1}{n} \sum_{i=1}^{n} X_{i}^{2}
\end{gathered}
$$

Aplicando a fórmula da variância na equação 4.8 obtém-se a equação 4.9

$$
E\left(X^{2}\right)=\operatorname{Var}(X)+[E(X)]^{2}=\frac{1}{n} \sum_{i=1}^{n} X_{i}^{2}
$$

Assim, após algumas manipulações algébricas é possível chegar na equação 4.10)

$$
\operatorname{Var}(X)=\frac{1}{n} \sum_{i=1}^{n}\left(X_{i}-\bar{X}\right)^{2}
$$


em que $\bar{X}$ é a média amostral.

Assim, para encontrar as estimativas dos parâmetros pelo método dos momentos basta igualar a média populacional à média amostral como sugere a equação (4.7), bem como igualar a variância populacional à variância amostral como na equação 4.10.

\subsubsection{Teste Qui-Quadrado}

O teste qui-quadrado (SNEDEGOR; COCHRAN, 1989) é um teste de hipóteses não paramétrico utilizado para comparar dados observados com os dados que se espera obter de acordo com uma hipótese específica. Ou seja, esse teste compara a diferença entre uma amostra real e outra de uma distribuição hipotética ou estabelecida. O teste qui-quadrado também pode ser usado para testar as diferenças entre dois ou mais grupos.

Para o teste qui-quadrado, os dados são divididos em $k$ categorias e o número real de observações em cada categoria é comparado ao número esperado de observações. Sendo assim, a estatística do teste é calculada em função dessa diferença e pode ser definida pela equação 4.11)

$$
\chi^{2}=\sum_{i=1}^{k} \frac{\left(O_{i}-E_{i}\right)^{2}}{E_{i}}
$$

em que $O_{i}$ e $E_{i}$ são, respectivamente, a frequência observada e a frequência esperada para a categoria $i$.

\subsection{Desenvolvimento do Classificador}

Com base na metologia apresentada na Seção 4.2, a construção do classificador proposto foi essencialmente dividido em 5 etapas:

1. Seleção das características para classificação dos links

2. Definição das classes de interesse

3. Obtenção de um conjunto completo de amostras de treinamento

4. Testes de Hipótese para definição da melhor função densidade de probabilidade para cada uma das características

5. Estimação dos parâmetros das funções densidade pelo método dos momentos e construção do classificador

As Seções 4.3.1 - 4.3.5 apresentam em detalhes cada uma destas etapas realizadas. O método de avaliação para o classificador proposto, assim como os resultados obtidos, são apresentados na Seção 4.4 . 


\subsubsection{Seleção das Características}

Como apresentado da Seção 4.2, optou-se por utilizar apenas características visuais para o classificador proposto. Assim, foram mensurados 3 fatores: a posição do link referente à margem esquerda do site, a posição do link referente ao topo do site e a repetição de um link entre as diversas páginas do domínio.

Visto que diferentes sites podem possuir diferentes larguras, alturas e número de páginas, optou-se por mensurar todas essas características utilizando as suas proporções. Assim, a posição do link referente a margem esquerda e ao topo, foram divididas respectivamente, pela largura e altura total da página. O número de repetições de um link no mesmo domínio, foi dividido pela quantidade total de páginas analisadas nesse mesmo domínio.

\subsubsection{Definição das Classes}

Dada a utilização do posicionamento dos links para a classificação dos menus, seria incoerente não considerar a localização desses menus ao se definir as classes. Assim, considerouse que um link pode pertencer a uma das cinco classes: Menu de Navegação Superior, Lateral Esquerdo, Lateral Direito, Rodapé ou não ser um Menu, que foi denominado link de Conteúdo.

Links do tipo âncora ou JavaScript foram ignorados, sendo assim, não foram associados a nenhuma classe durante o treinamento.

A página pode não apresentar um menu de navegação específico, ou pode apresentar mais de um menu da mesma classe. Por exemplo, a Figura 10 apresenta o caso do portal do governo de São Paulo, que apresenta 2 Menus de Navegação Superior.

\section{Menu de Navegação Superior}

Foram considerados Menu de Navegação Superior os links pertencentes a um menu horizontal localizado no topo da página Web. A Figura 10 apresenta a página inicial do portal do governo de São Paulo, e o tracejado vermelho indica a presença dos menus superiores. O tracejado azul, representa links que não foram considerados pertencentes à classe Menu de Navegação Superior, visto que são apenas atalhos para funções JavaScript na página, e não redirecionam para outras páginas do site.

\section{Menu de Navegação Lateral Esquerdo}

O Menu de Navegação Lateral Esquerdo caracteriza-se por um menu vertical posicionado na lateral esquerda da página. A Figura 11 apresenta um exemplo de menu de navegação classificado como Lateral Esquerdo. 


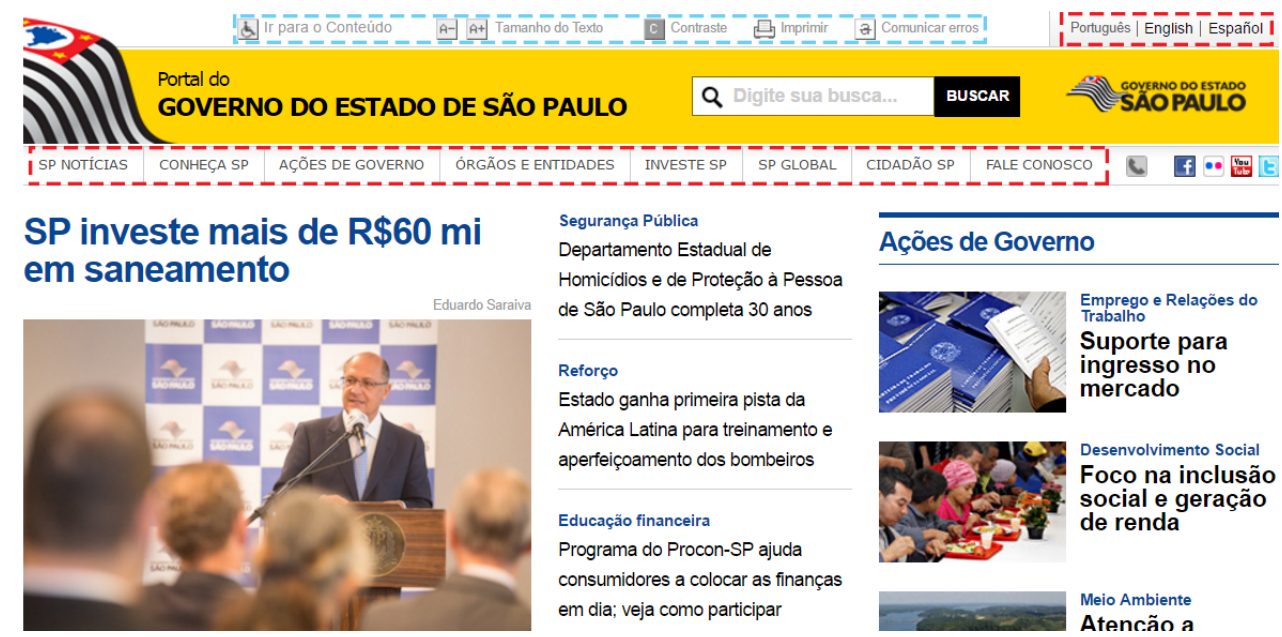

Figura 10 - Exemplos de links considerados como Menu Superior durante o treinamento no Portal do Governo do Estado de São Paulo.

Menu de Navegação Lateral Direito

O Menu de Navegação Lateral Direito é similar ao Lateral Esquerdo, porém localizado à direita da página. A Figura 12 apresenta um exemplo de Menu Lateral Direito.

Menu de Navegação no Rodapé

Os links pertencentes à classe Menu de Navegação no Rodapé são aqueles que se encontram no menu horizontal ou vertical localizado na parte inferior da página. A Figura 13 apresenta um exemplo de 4 menus verticais classificados como Rodapé.

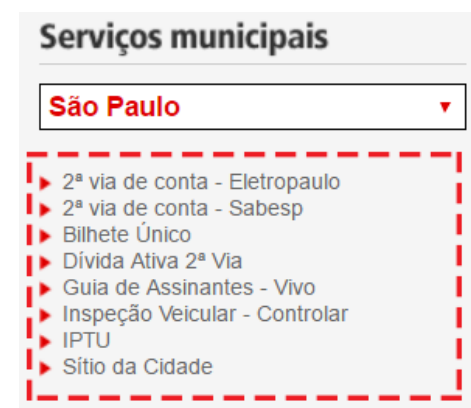

Serviços federais

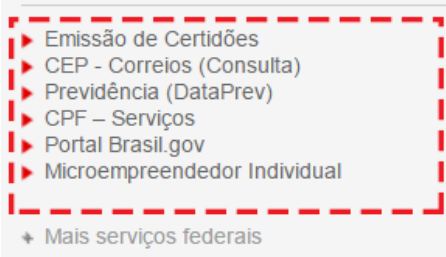

Emissão de Certidões

CEP - Correios (Consulta)

I. Microempreendedor Individual

+ Mais serviços federai

\section{Últimas noticias}

$14 \mathrm{mar}$ | SP Notícias $\mathrm{Z}$

Departamento

Estadual de

Homicídios e de

Proteção à Pessoa

de São Paulo completa 30 anos

SP Noticias $[7$

$\mathrm{SP}$ investe mais de $\mathrm{R} \$ 60 \mathrm{mi}$ em saneamento $[T$

SP Noticias $[T$

Turismo recebe investimento superior

a R\$ 76 milhões $[7$

SP Noticias $[7$

Mais de mil novos agentes reforçam segurança em SP $[$ ?
10 mar $\mid$ SP Noticias [

Estado ganha primeira pista da América Latina para treinamento e aperfeiçoamento dos bombeiros $[?$

14 mar $\mid$ SP Noticias ए

Programa do Procon-

SP ajuda

consumidores a

colocar as finanças

em dia; veja como

participar $\mathrm{E}$

14 mar | SP Noticias ए

SP tem delegacia

para investigar maus-

tratnc cu ie fi unciona

Figura 11 - Exemplos de links considerados Menu Lateral Esquerdo durante o treinamento na página Cidadão.SP. 


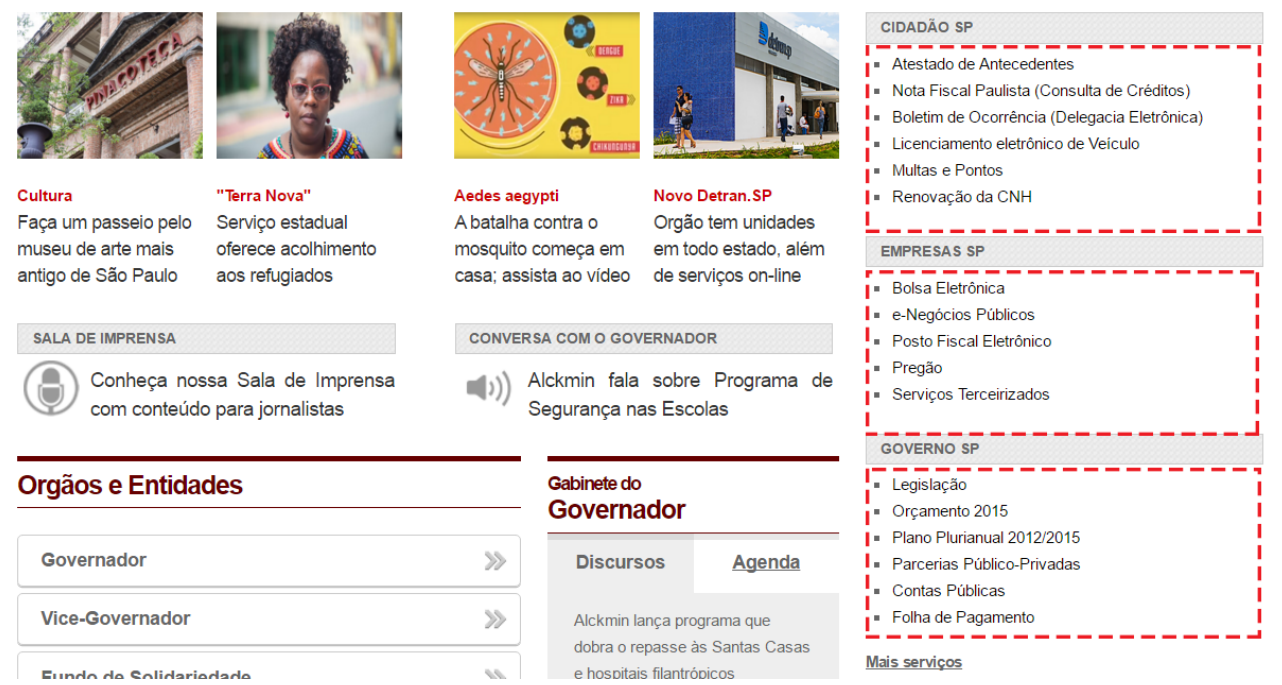

Figura 12 - Exemplos de links considerados Menu Lateral Direito durante o treinamento no Portal do Governo do Estado de São Paulo.

\section{Conteúdo}

Os links classificados como Conteúdo são aqueles que não pertencem a nenhuma das classes de Menu de Navegação definidas entre as Seções 4.3.2 e 4.3.2. Em geral, esses links encontram-se na parte central da página, relacionado ao conteúdo da mesma. A Figura 14 apresenta exemplos de links classificados como Conteúdo.

\subsubsection{Amostras de Treinamento}

Como o classificador proposto é baseado no método Naïve Bayes, inicialmente foi necessário realizar um treinamento supervisionado para se obter um conjunto de amostras de características classificadas de acordo com as classes definidas na Seção 4.3.2.

Visto que o Naïve Bayes é um método que assume a independência entre as características,

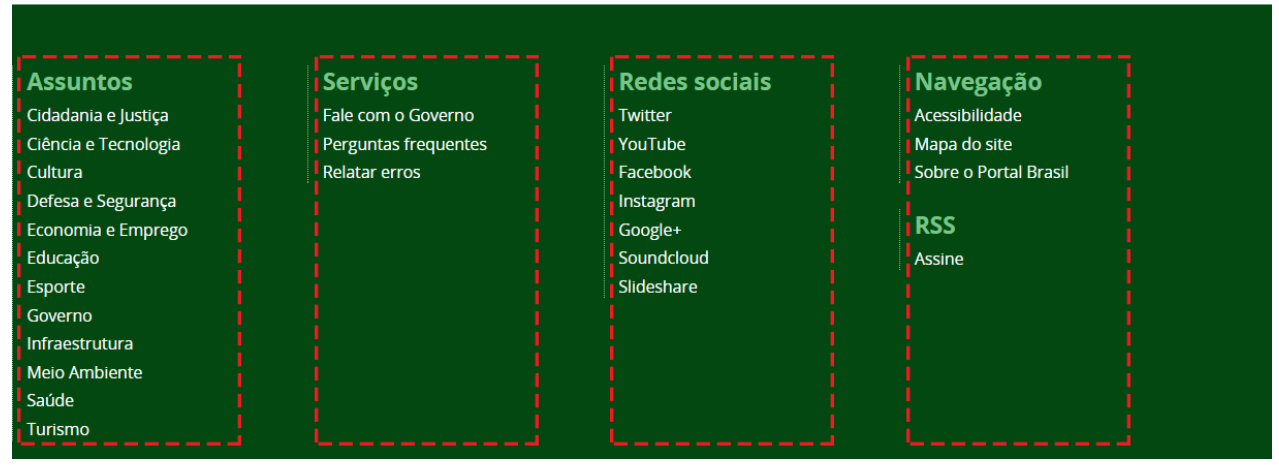

Figura 13 - Exemplos de links considerados Rodapé durante o treinamento no Portal Brasil. 


\begin{tabular}{|l|}
\hline Obtenção de Terras \\
\hline $\begin{array}{l}\text { OOdenamento Estrutura } \\
\text { Fundiária }\end{array}$ \\
\hline Quilombolas \\
\hline Cadastro Rural \\
\hline Georreferenciamento \\
\hline Certificação de imóveis \\
\hline Aquisição de Terras por \\
Estrangeiros \\
\hline Módulo fiscal \\
\hline INSTITUCıONAL \\
\hline O Incra \\
\hline Quem é quem \\
\hline Incra nos Estados \\
\hline Sala de Imprensa \\
\hline Legislação \\
\hline Procuradoria Federal \\
Especializada
\end{tabular}

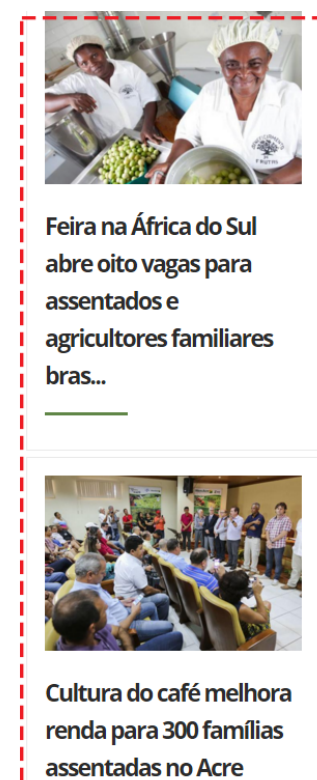

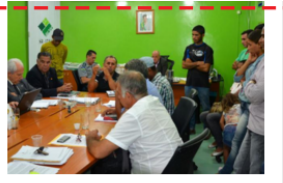

Comissão de Combate à

Violência no Campo recebe relatório em Rondônia e adota medidas...

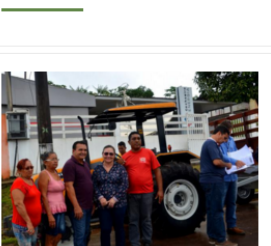

Parceria assegura benefícios em infraestrutura a

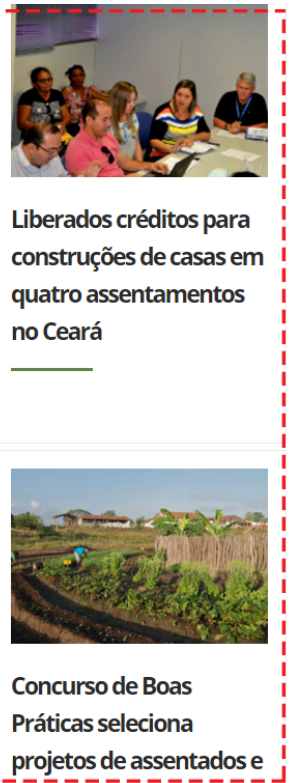

projetos de assentadose

Figura 14 - Exemplos de links considerados pertencentes à classe Conteúdo durante o treinamento na página do Incra.

o treinamento não requer a classificação das três características em conjunto. Assim, o conjunto de amostras classificadas foi obtido considerando-se duas principais etapas, a classificação dos links de acordo com sua posição (distância da margem esquerda e topo) e a obtenção dos valores referentes à repetição de um link entre as diversas páginas do domínio.

Como discutido na Seção 4.2, optou-se por utilizar sites governamentais para realizar o treinamento. Assim, foram selecionados 10 sites governamentais, tomando-se o cuidado para selecionar sites com diferentes layouts. Como os menus de navegação devem ser posicionados na mesma posição entre as diferentes páginas do domínio, optou-se por realizar o treinamento apenas na página inicial desses sites, com o objetivo de evitar redundância nas amostras de treinamento.

\section{Posição dos Links}

Para se obter as amostras de treinamento referentes ao posicionamento dos links, foi desenvolvido um sistema na linguagem PHP. Esse sistema foi responsável por extrair e armazenar localmente o conteúdo original da página a ser treinada. Após obter esse conteúdo, o sistema introduzia um código JavaScript no conteúdo original. Assim, ao passar o mouse sobre um determinado link, esse script possibilitava a renderização de um pop-up com as opções de treinamento, como apresentado na Figura 15.

Dessa forma, ao selecionar um link, o treinamento era realizado diretamente nos botões do pop-up, que enviava as informações para uma base SQL por meio de Ajax. 


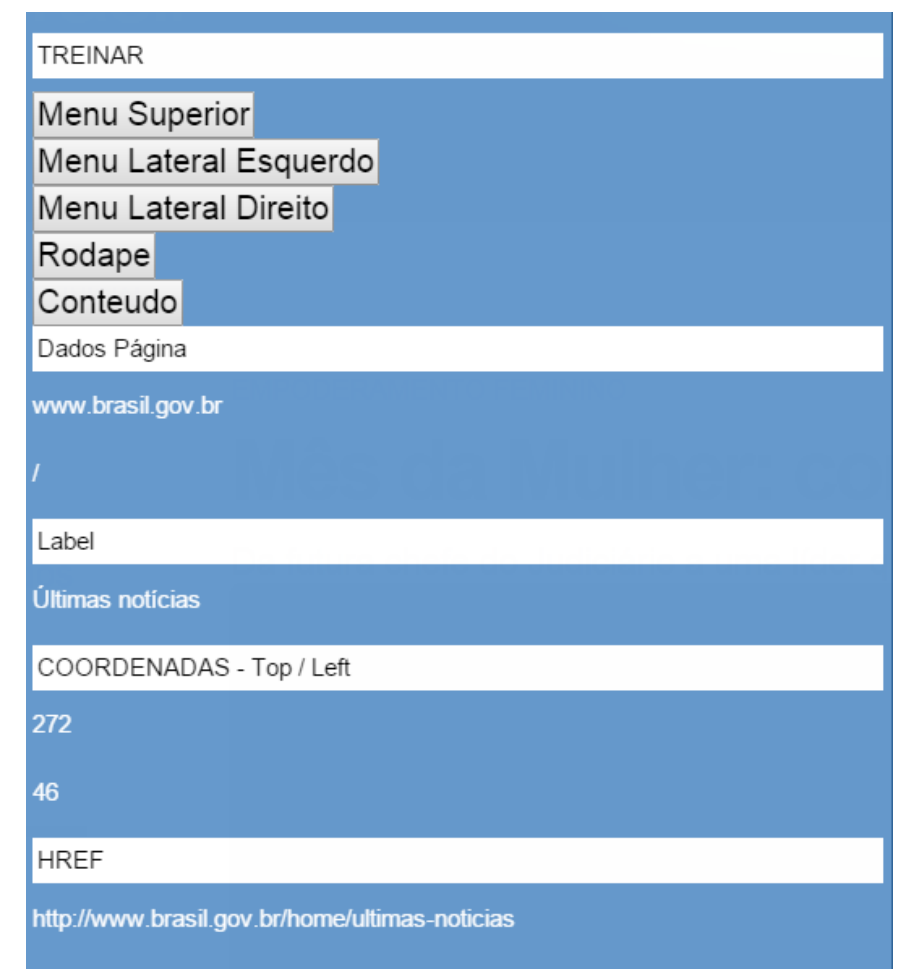

Figura 15 - Pop-up para treinamento das amostras referentes às características de posicionamento de um link.

\section{Repetição dos Links}

Para a obtenção das amostras de treinamento referentes à repetição dos links, foi necessário o uso de um Web Crawler. Com esse propósito, foi utilizado o OpenWebSpider ${ }^{3}$, que possibilita percorrer um domínio específico e armazenar em uma base de dados o mapeamento obtido. A Figura 16 apresenta a interface do sistema OpenWebSpider.

Como mencionado na Seção 4.2, durante esse treinamento não foram considerados links do tipo âncora, assim como links que apontam para endereços externos ao domínio sendo analisado. Além disso, como os domínios possuem uma quantidade diferente de páginas, e em alguns casos, podem possuir centenas de milhares de páginas, optou-se por limitar a atuação do Web Crawler a 500 páginas. Uma vez que foi utilizada a taxa entre o número de repetições do link e a quantidade de páginas, considerou-se 500 páginas como um número suficiente para o treinamento.

A Tabela 2 apresenta as médias e variâncias de cada característica por cada classe, com base nos dados obtidos das amostras de treinamento.

\subsubsection{Teste de Hipótese}

Após obter as amostras de treinamento, foram testadas diferentes distribuições de probabilidade para cada uma das 3 características adotadas, incluindo as distribuições Normal, 


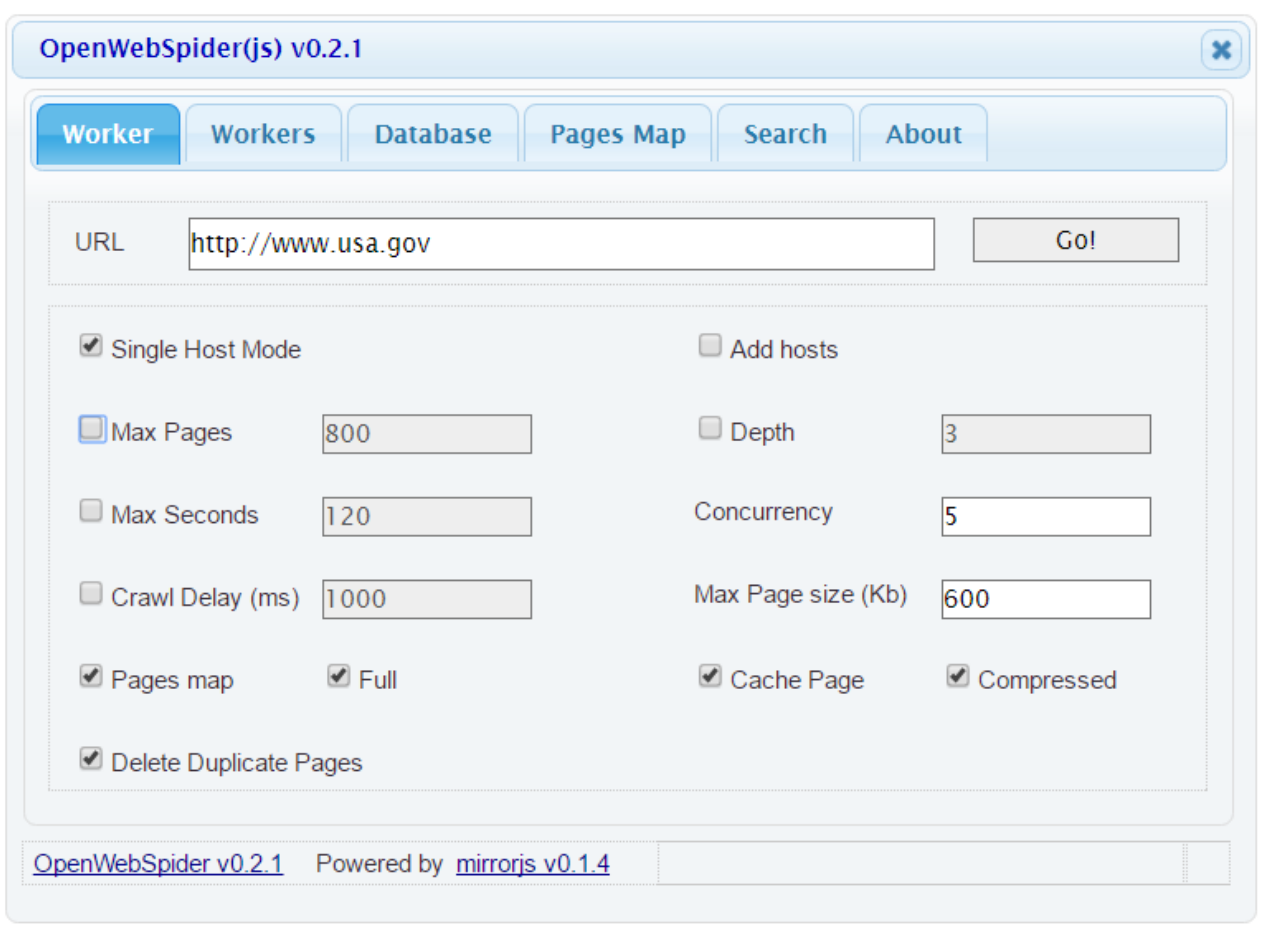

Figura 16 - Interface do OpenWebSpider.

Tabela 2 - Médias e variâncias das amostras de treinamento para as diferentes características e classes.

\begin{tabular}{cccccccc}
\hline & \multicolumn{2}{c}{ Repetição } & \multicolumn{2}{c}{ Distância Topo } & \multicolumn{2}{c}{ Distância Esquerda } \\
\hline & Média & Variância & Média & Variância & Média & Vâriancia \\
Menu Superior & 0,916346942 & 0,025900173 & 0,05258996 & 0,003570285 & 0,517960781 & 0,089800336 \\
Menu Lateral Esquerdo & 0,926808238 & 0,033994382 & 0,439681742 & 0,080298128 & 0,120984776 & 0,01770224 \\
Menu Lateral Direito & 0,660104712 & 0,213967137 & 0,489292303 & 0,044764173 & 0,773173416 & 0,008903289 \\
Rodapé & 0,959412270 & 0,014424010 & 0,885883299 & 0,007722831 & 0,434713927 & 0,066302841 \\
Conteúdo & 0,242629703 & 0,142284351 & 0,505617638 & 0,060779196 & 0,445764724 & 0,087254783 \\
\hline
\end{tabular}

Gama, Beta, Weibull, Log-normal e Rayleigh. A fim de determinar qual função densidade de probabilidade melhor se ajusta aos dados, foi utilizado um teste de hipótese não-paramétrico. Dentre os possíveis testes não-paramétricos da literatura, foi escolhido o teste qui-quadrado apresentado na Seção 4.2 .3

Para a característica referente ao posicionamento do link em relação à margem esquerda da página, o melhor resultado foi para a distribuição Beta. Os resultados gráficos com os ajustes do teste qui-quadrado para cada distribuição são apresentados na Figura 17.

Novamente, o teste qui-quadrado apresentou o melhor ajuste com a distribuição Beta, para a característica referente ao posicionamento do link em relação ao topo da página, como apresentado na Figura 18 .

Por fim, a distribuição que teve o melhor ajuste no teste qui-quadrado, para a característica referente à repetição do link, foi a distribuição Normal, como apresentado na Figura 19. 


\subsubsection{Construção do Classificador}

Como apresentado na Seção 4.3.4 o teste de hipótese resultou nas distribuições Beta para as características referentes ao posicionamento, e na distribuição Normal para a característica referente a repetição. Assim, é necessário definir a regra de decisão para estas duas distribuições. A regra de decisão para o classificador Naïve Bayes Normal é baseada na Equação (4.12)

$$
p\left(x_{k}=x \mid C_{j}\right)=\frac{1}{\sqrt{2 \pi \sigma_{k j}^{2}}} \exp \left(\frac{-\left(x-\mu_{k j}\right)^{2}}{2 \sigma_{k j}^{2}}\right), x \in \Re, \mu_{k j} \in \mathfrak{R}, \sigma_{k j}^{2}>0,
$$

em que $\mu_{k j}$ é a média e $\sigma_{k j}^{2}$ é a variância.
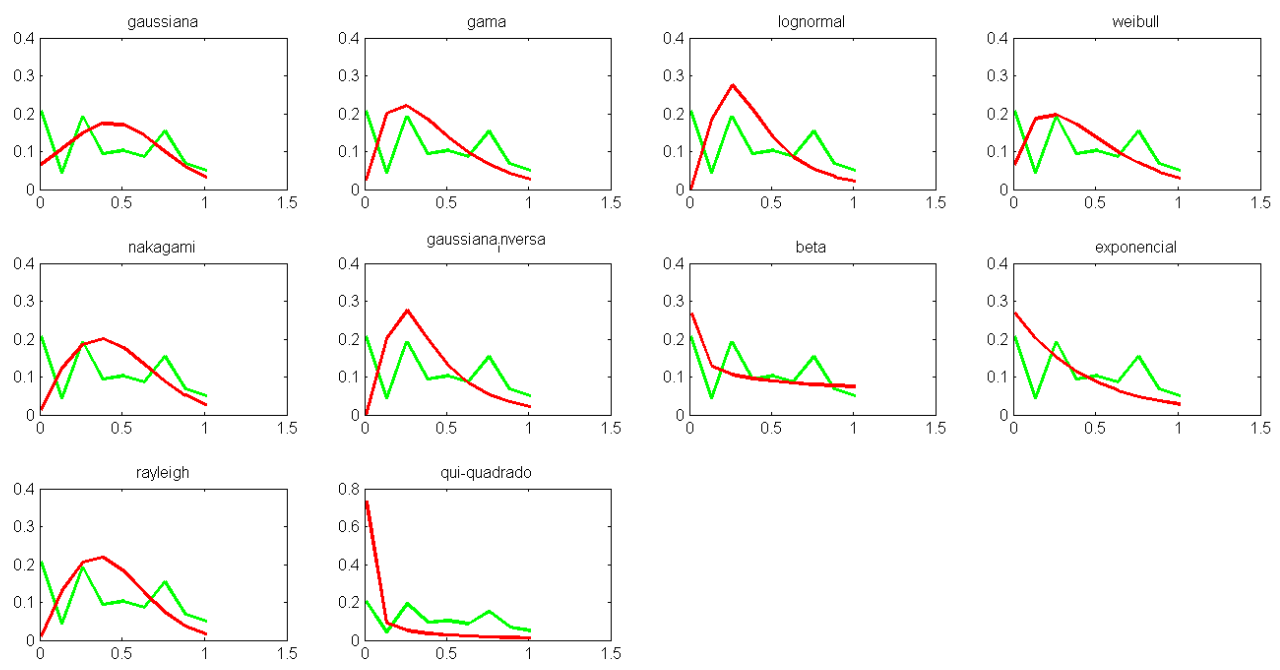

Figura 17 - Ajustes para cada distribuição resultantes do teste qui-quadrado para as amostras referentes ao posicionamento do link em relação a margem esquerda da página.
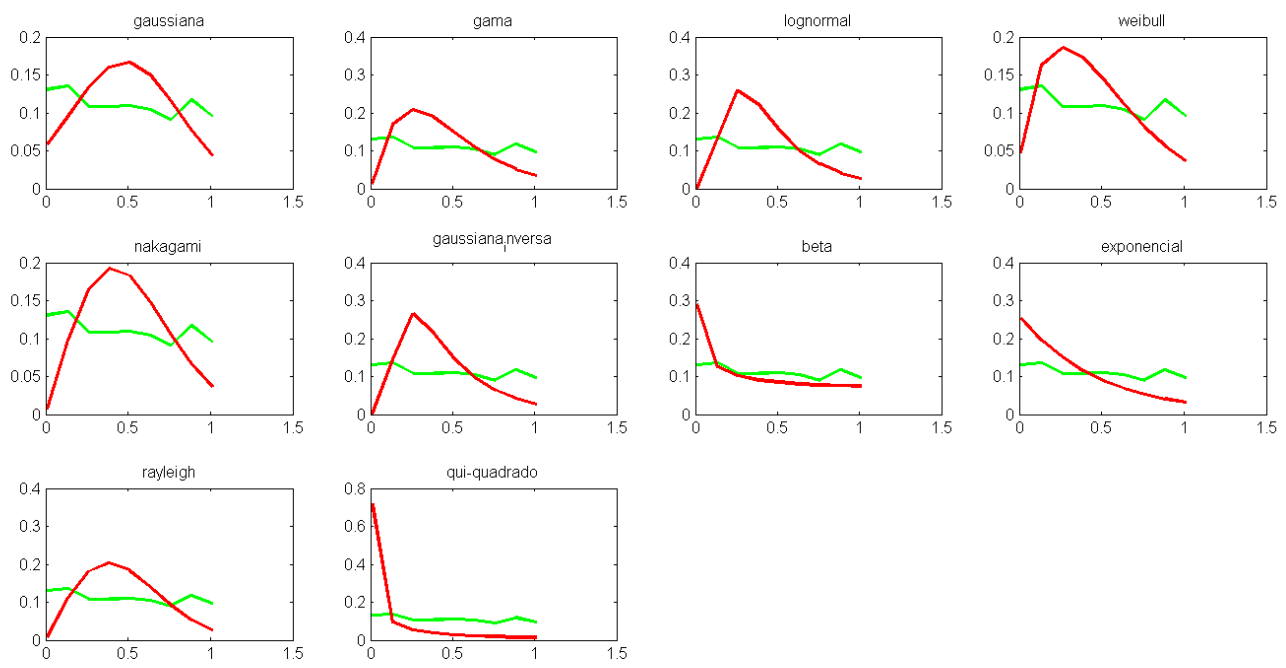

Figura 18 - Ajustes para cada distribuição resultantes do teste qui-quadrado para as amostras referentes ao posicionamento do link em relação ao topo da página. 


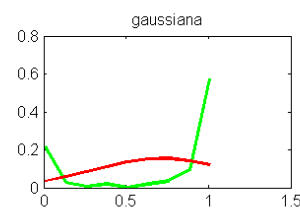

nakagami

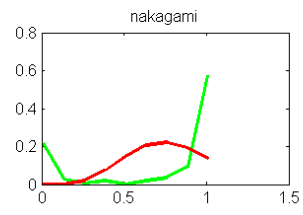

rayleigh

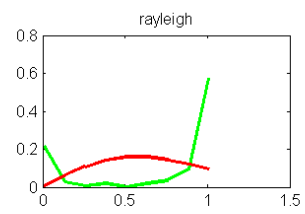

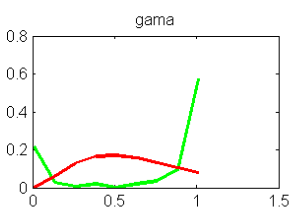

gaussiana,iversa

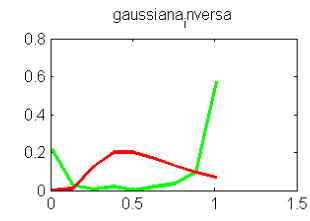

qui-quadrado

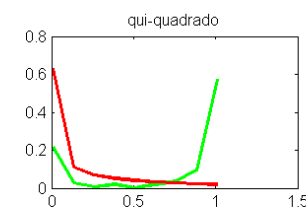

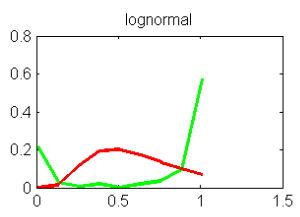

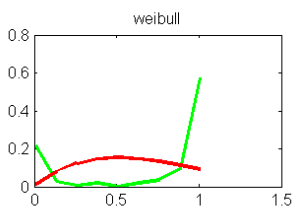

beta
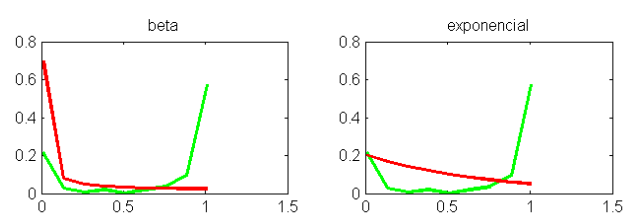

Figura 19 - Ajustes para cada distribuição resultantes do teste qui-quadrado para as amostras referentes a taxa de repetição do link no domínio.

Similarmente, a regra de decisão para o classificador Naïve Bayes Beta é baseado em (4.13)

$$
p\left(x_{k}=x \mid C_{j}\right)=\frac{1}{B\left(\alpha_{k j}, \beta_{k j}\right)} x^{\alpha_{k j}-1}(1-x)^{\beta_{k j}-1}, \quad 0<x<1, \alpha_{k j}, \beta_{k j}>0,
$$

em que $\alpha_{k j}, \beta_{k j}$ são os parâmetros de forma e $B(\cdot)$ é a função beta.

Os parâmetros $\mu_{k j}, \sigma_{k j}^{2}, \alpha_{k j}$ and $\beta_{k j}$ são estimados usando o método dos momentos apresentado na Seção 4.2.2. Assim, os estimadores dos parâmetros obtidos pelo método dos momentos para as distribuições Normal e Beta são dados pelas Equações (4.14) e (4.15), respectivamente.

$$
\begin{gathered}
\hat{\mu}_{k j}=m_{A}, \quad \hat{\sigma}_{k j}^{2}=v, \\
\hat{\alpha}_{k j}=\frac{m_{A}^{2}}{v}-m_{A}-\frac{m_{A}^{3}}{v}, \quad \hat{\beta}_{k j}=m_{A}+\frac{m_{A}\left(m_{A}-1\right)^{2}}{v}-1,
\end{gathered}
$$

em que $m_{A}$ é a média amostral e $v$ é a variância amostral.

Os valores da média e da variância amostral das amostras de treinamento associados a cada classe são apresentados na Tabela 2 .

\subsection{Avaliação e Resultados Obtidos}

Para avaliar os resultados do classificador proposto, foram utilizados 5 sites governamentais, diferentes dos utilizados na fase de treinamento. Os valores das características foram obtidos da mesma maneira descrita na Seção 4.3.3. 
Novamente, apenas as páginas iniciais de cada site foram consideradas. A Tabela 3 apresenta um resumo dos resultados obtidos pelo classificador proposto. As tabelas com os dados completos referentes a essa avaliação são apresentadas no Apêndice A.

Tabela 3 - Resultados experimentais do classificador proposto.

\begin{tabular}{|c|c|c|c|}
\hline Site & Porcentagem de Acerto & Classes de Links & Taxa de Acertos por Classe \\
\hline \multirow{5}{*}{ previdencia.gov.br } & \multirow{5}{*}{$95 \%$} & Menu Superior & $8 / 8$ \\
\hline & & Menu Lateral Esquerdo & $33 / 33$ \\
\hline & & Menu Lateral Direito & - \\
\hline & & Rodapé & $14 / 14$ \\
\hline & & Conteúdo & $11 / 14$ \\
\hline \multirow{5}{*}{ inmetro.gov.br } & \multirow{5}{*}{$15 \%$} & Menu Superior & $5 / 5$ \\
\hline & & Menu Lateral Esquerdo & $0 / 23$ \\
\hline & & Menu Lateral Direito & $0 / 30$ \\
\hline & & Rodapé & $0 / 2$ \\
\hline & & Conteúdo & $5 / 5$ \\
\hline \multirow{5}{*}{ secom.gov.br } & \multirow{5}{*}{$96 \%$} & Menu Superior & $9 / 10$ \\
\hline & & Menu Lateral Esquerdo & $20 / 22$ \\
\hline & & Menu Lateral Direito & - \\
\hline & & Rodapé & $24 / 24$ \\
\hline & & Conteúdo & $20 / 20$ \\
\hline \multirow{5}{*}{ fundacentro.gov.br } & \multirow{5}{*}{$65,4 \%$} & Menu Superior & $10 / 10$ \\
\hline & & Menu Lateral Esquerdo & - \\
\hline & & Menu Lateral Direito & $3 / 9$ \\
\hline & & Rodapé & $99 / 145$ \\
\hline & & Conteúdo & $11 / 24$ \\
\hline \multirow{5}{*}{ usa.gov } & \multirow{5}{*}{$88 \%$} & Menu Superior & $11 / 11$ \\
\hline & & Menu Lateral Esquerdo & - \\
\hline & & Menu Lateral Direito & - \\
\hline & & Rodapé & $10 / 10$ \\
\hline & & Conteúdo & $32 / 39$ \\
\hline
\end{tabular}

\subsection{Discussão dos Resultados}

Os resultados obtidos pelo classificador, apresentados na Tabela 3 , necessitam de uma análise minuciosa, com intuito de melhor compreender os resultados do classificador e o comportamento dos menus nas páginas Web. Percebe-se que uma análise simples e indiscriminada dos resultados pode levar a conclusões errôneas sobre a capacidade de classificação do método proposto.

Para demonstrar essa afirmação, pode-se inicialmente analisar os resultados em um contexto geral. Nas 5 páginas em que a avaliação do método foi conduzida, foram analisados um total de 458 links. Dentre os links avaliados, o método pôde classificar corretamente um total de 325 links, o que fornece uma taxa de acerto de aproximadamente $71 \%$.

Essa taxa de acerto pode ser considerada boa, dada a simplicidade das características visuais utilizadas para classificar algo tão complexo e heterogêneo quanto os links dos menus de 
navegação de uma página Web. Porém, ao analisar apenas esse resultado em um contexto geral, pode-se passar despercebido o real potencial do classificador.

Assim, para avaliar de maneira mais minuciosa os resultados obtidos, pode-se dividir os resultados em duas situações: sites em que o classificador se comportou como esperado e os sites em que o classificador teve um desempenho significativamente inferior. Ambos os casos fornecem informações valiosas de pesquisa, que podem contribuir tanto para a melhoria do classificador apresentado neste capítulo, quanto para o melhor entendimento do comportamento dos menus de navegação encontrados na Web.

Pode-se considerar os seguintes sites para os casos em que o classificador teve um bom desempenho: previdencia.gov.br, secom.gov.br e usa.gov. Os links corretamente classificados destes sites somam 192 links de um total de 205 links, resultando em uma taxa de acerto de aproximadamente $94 \%$, sendo essa muito superior à taxa de $71 \%$ encontrada no contexto geral. A justificativa para esse excelente desempenho está alinhado ao projeto de design utilizado nesses sites, que estão de acordo com os padrões de menu especificados na Seção 4.1 .

Já o mesmo não acorre para os outros 2 sites avaliados: fundacentro.gov.br e inmetro.gov.br. Com base nos resultados obtidos através do site da FUNDACENTRO, pôde-se notar as primeiras limitações do classificador desenvolvido. O método foi desenvolvido com base no classificador Naïve Bayes, que requer o conhecimento inicial das amostras de treinamento para calcular a probabilidade de uma dada amostra pertencer a uma classe. Assim, pela Tabela 3 e pela análise dos dados de treinamento, pode-se notar que, em média, os links de menus do Rodapé se encontram muito próximos da parte inferior da página, com uma proporção de aproximadamente 0,88 entre a distância do topo e a altura total da página. Porém, a página da FUNDACENTRO apresenta um rodapé extenso, com um total de 145 links, como pode ser visto na Figura 20.

Em contraste ao rodapé, o conteúdo da página é conciso, o que faz com que o início do extenso rodapé esteja posicionado pouco abaixo da metade da página, em termos de altura. Isso acarretou em probabilidades baixas para a classe Rodapé, e fez com que os links da parte superior do rodapé fossem erroneamente classificados como Menu Lateral Esquerdo ou Menu Lateral Direito. Outra limitação que pôde-se perceber a partir disso, vem do fato de que o método proposto não analisa o código da página. Pode-se notar pela Figura 20, que os links compartilham um mesmo nó pai na árvore DOM do documento HTML, além de compartilhar as mesmas características de estilo visual (cor, fonte, tamanho, entre outras). Se essas informações fossem incorporadas ao método proposto neste capítulo, é provável que a alta taxa de erro encontrada na avaliação do rodapé deste site fosse minimizada.

Por fim, deve-se analisar o site do Inmetro, que apresentou a pior taxa de acerto dentre os sites avaliados. O classificador desenvolvido errou na classificação de todos os link contidos nos Menus Laterais (Esquerdo e Direito) e no Rodapé. Para entender melhor os motivos que levaram a esse mal desempenho do classificador, é necessário retomar os fundamentos sobre uma das características consideradas pelo método: a repetição do mesmo link entre as páginas do 


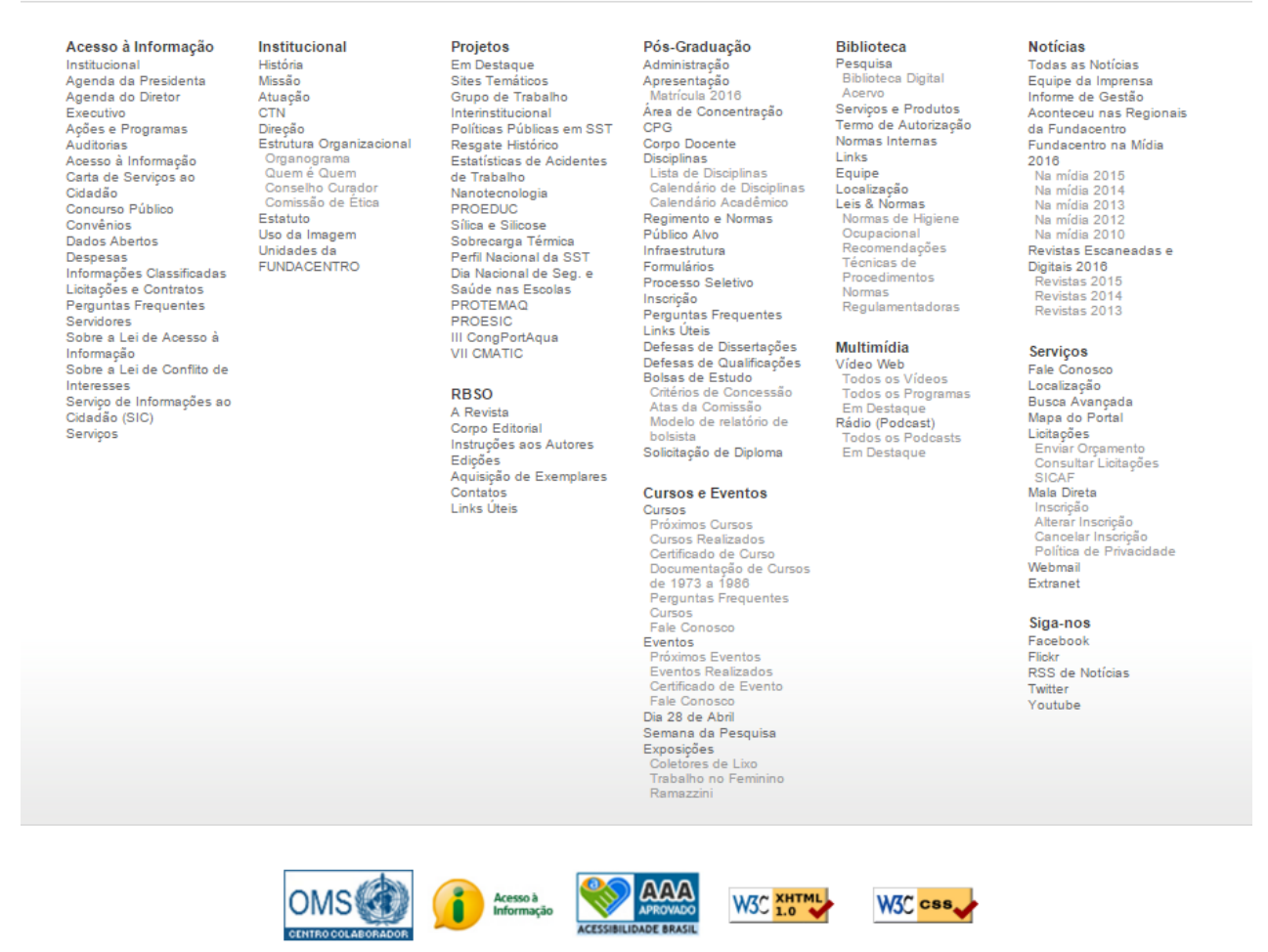

Figura 20 - Menus contidos no Rodapé do site Fundacentro.

site. Ao propor a metodologia do classificador, esperava-se que os menus de navegação fossem consistentes entre a maioria das páginas do site, proporcionando uma navegação global que se repetisse em quase todas as páginas. Após realizar o treinamento, essa hipótese foi comprovada. Os links classificados como Menu possuem uma proporção média de repetição do link acima de 0,9, com exceção do Menu Lateral Direito que ficou em torno de 0,67. Porém, ao avaliar o site do Inmetro, percebeu-se que os menus de navegação laterais não eram consistentes entre as diversas páginas do domínio. Por exemplo, a Figura 21 demonstra essa característica do site. Na parte superior da Figura 21, é apresentando um trecho dos menus laterais encontrados na página inicial do site do Inmetro. Ao clicar no link "Acesso à Informação"apresentado no início do menu lateral esquerdo, o site é redirecionado para uma nova página, que por sua vez, apresenta menus com links completamente distintos da página anterior, como pode ser visto na parte inferior da Figura 21. Isso fez com que a média da proporção referente à repetição do link entre as páginas do site ficasse em torno de 0,04, classificando todos esses links como conteúdo, em vez de menus.

O site do Inmetro sequer mantém a consistência do layout entre as diferentes páginas do domínio, o que fez com que, mesmo os links do rodapé tivessem uma proporção de repetição em torno de 0,5 , inviabilizando a classificação correta do mesmo. Entende-se que por critérios de usabilidade, o site do Inmetro possui alguns problemas que dificultariam o acesso e interação dos usuários. Porém, dada a heterogeneidade das páginas Web, é necessário pensar em estratégias para aprimorar o classificador, com intuito de detectar esses problemas e melhorar a taxa de 


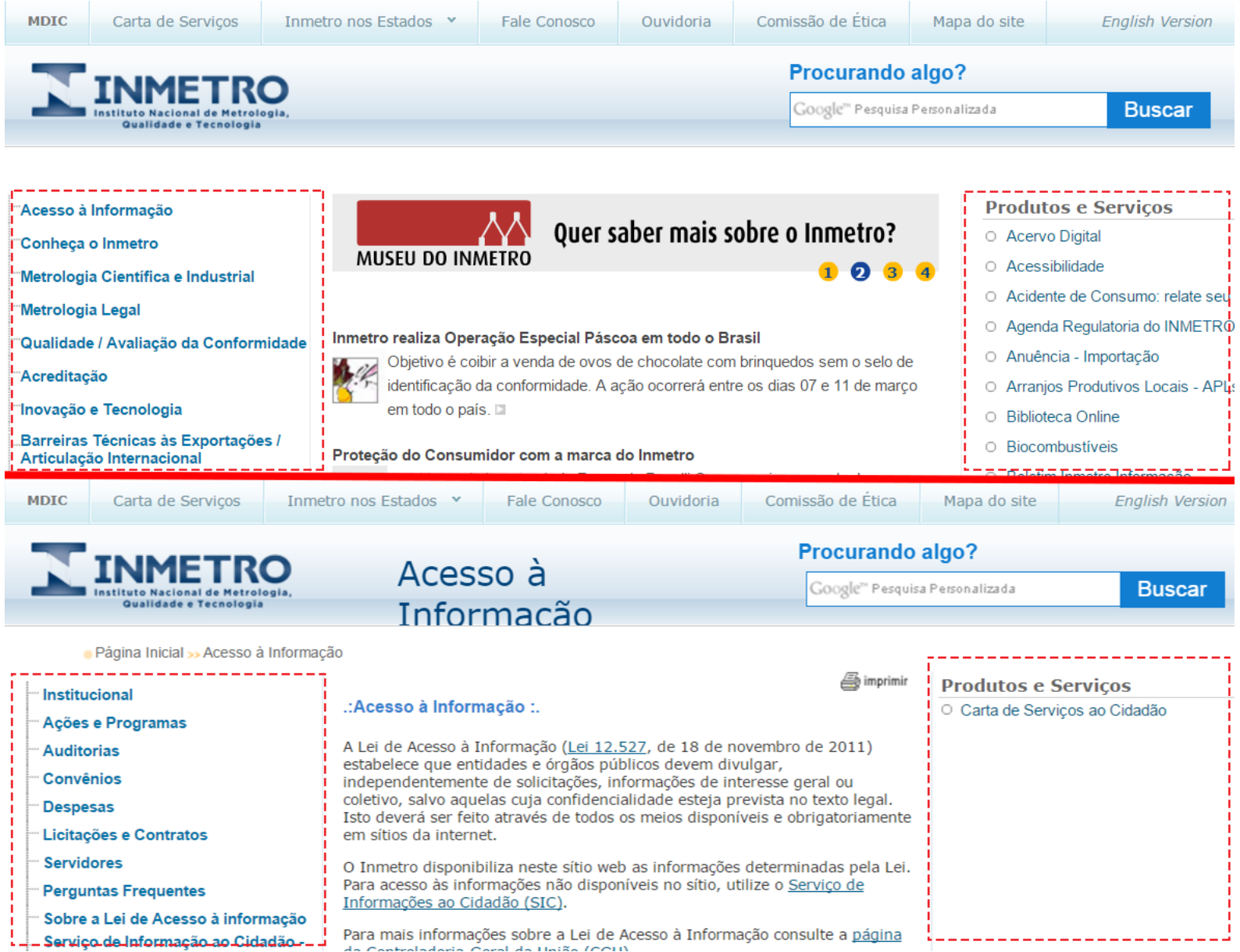

Figura 21 - Links considerados menus laterais no portal do Inmetro

acerto do classificador.

\subsection{Considerações Finais}

Este capítulo apresentou a abordagem e o desenvolvimento de um método para automaticamente classificar os links de navegação encontrados em uma página Web. O classificador, baseado no método Naïve Bayes, considera apenas características visuais dos links: o posicionamento do link em relação à margem esquerda da página, o posicionamento do link em relação ao topo da página e a repetição do mesmo entre as páginas do site.

Com base nessas características, foram propostas 5 classes de interesse: "menu de navegação superior", "menu de navegação lateral esquerdo", "menu de navegação lateral direito", "menu de navegação no rodapé" e "conteúdo". Feito isso, foi realizado um treinamento em sites governamentais, obtendo-se amostras relativas a cada classe de interesse.

A avaliação do classificador apresentou um bom desempenho do método proposto, principalmente para o caso dos sites desenvolvidos de acordo com os padrões de menu apresentados na Seção 4.1. Já para os sites com estruturas de menus menos usuais, o método não apresentou 
o mesmo desempenho. Uma possível estratégia para aprimorar o classificador proposto é a integração do conhecimento refente ao documento DOM do site ao método, visto que o mesmo pode conter informações valiosas a respeito da estrutura da página Web. 


\section{INTERFACE E NAVEGAÇÃO WEB OTIMIZADAS PARA USUÁRIOS CEGOS}

\subsection{Introdução}

Idealmente, as interfaces Web devem ser projetadas de acordo com diretrizes ou especificações técnicas que visam melhorar a acessibilidade para todos os indivíduos, que apresentem qualquer tipo de deficiência ou que utilizem qualquer tipo de dispositivo para interagir com essa interface. Porém, esse tipo de abordagem universal para acessibilidade tem se mostrado ineficiente para o caso dos usuários cegos.

Alguns estudos da literatura (POWER et al., 2012),(PETRIE; HAMILTON; KING, 2004) mostram a incompatibilidade entre as propostas de soluções para alguns dos problemas enfrentados pelos usuários cegos e algumas práticas que visam a acessibilidade universal para páginas Web. Além disso, outros trabalhos mostram que apesar de existirem especificações técnicas com o objetivo de minimizar problemas enfrentados pelos usuários de tecnologias assistivas, as mesmas ainda são pouco utilizadas (WATANABE; GERALDO; FORTES, 2015)(WATANABE; GERALDO; FORTES, 2014)(LEE; HENSCHEN, 2015).

Como apresentado na Seção 1.3, um tipo de abordagem encontrada na literatura, envolve a adaptação do conteúdo de uma página Web de maneira automática, com intuito de adequar esse conteúdo às necessidades dos usuários cegos.

Assim como o classificador proposto no Capítulo 4, existem diversos trabalhos na literatura que abordam a mineração de dados na Web. Esses estudos mostram que é possível extrair informações relevantes das páginas Web, que vão desde a estrutura da página Web até o seu conteúdo, com uma performance aceitável (SINGH; SINGH, 2010).

Nesse contexto, propõe-se um sistema, denominado NavAux, que tem como objetivo extrair conteúdos de páginas Web de maneira semi-supervisionada, e reorganizar esses conteúdos 
de uma forma otimizada aos leitores de tela, com o intuito de minimizar diversos dos problemas de navegação enfrentados pelos usuários cegos ao interagir com a Web.

Dado o classificador apresentado no Capitulo 4, é proposta uma abordagem para automaticamente transformar os links de navegação classificados pelo método, em um padrão de navegação otimizado aos leitores de tela, integrando os resultados obtidos ao NavAux.

Espera-se validar a hipótese de que a extração automática de conteúdos de uma página Web, e a transformação desse conteúdo em um modelo de interface elaborada com base nas necessidades dos usuários cegos, pode auxiliar a minimizar diversos dos problemas apresentados no Capítulo 3, possibilitando uma acessibilidade mais efetiva.

A Seção 5.2 apresenta os conceitos básicos referentes à estrutura comum de uma página Web, e as regiões pré-definidas segundo a linguagem HTML5 e a especificação ARIA. A Seção 5.3 apresenta o modelo de interface proposto, denominado NavAux, assim como a metodologia utilizada para transformar os dados de navegação extraídos a partir do classificador proposto no Capítulo 4 em um novo menu de navegação otimizado aos usuários cegos e leitores de tela. A avaliação do protótipo desenvolvido é apresentada na Seção 5.4 e uma discussão dos resultados é apresentada na Seção 5.5.

\subsection{Estrutura de uma página Web}

Inicialmente, é necessário compreender a estrutura básica de uma página Web, que é composta por certas regiões comuns, como menus de navegação, conteúdo principal, cabeçalho e rodapé (W3C, 2015b). A Figura 22 apresenta uma visão simplificada com alguns exemplos de estruturas de página Web comumente encontradas, assim como seus principais conteúdos e seções.

Como citado no Capítulo 4, tanto o HTML5 quanto a especificação ARIA, fornecem mecanismos para indicar tais regiões de forma significativa: o HTML5 define elementos específicos para esse tipos comuns de regiões encontradas nas páginas Web, como por exemplo, o $<$ header $>$ e o <nav>. A especificação ARIA utiliza o atributo role para adicionar esse tipo de informação.

Alguns elementos do HTML5 também possuem por padrão atributos ARIA role implícitos, como apresentado a seguir.

Cabeçalho: Presente na maioria dos sites, o cabeçalho é uma região localizada no topo da página Web. Nessa região, encontram-se normalmente o logo do site e outros tipos de informações, como opções de navegação e caixas de pesquisa. O cabeçalho principal da página é indicado pelo elemento <header> do HTML5, que por padrão possui o atributo role=banner, desde que o <header $>$ não tenha sido utilizado dentro de elementos do tipo $<$ section $>$ ou $<$ article $>$. 

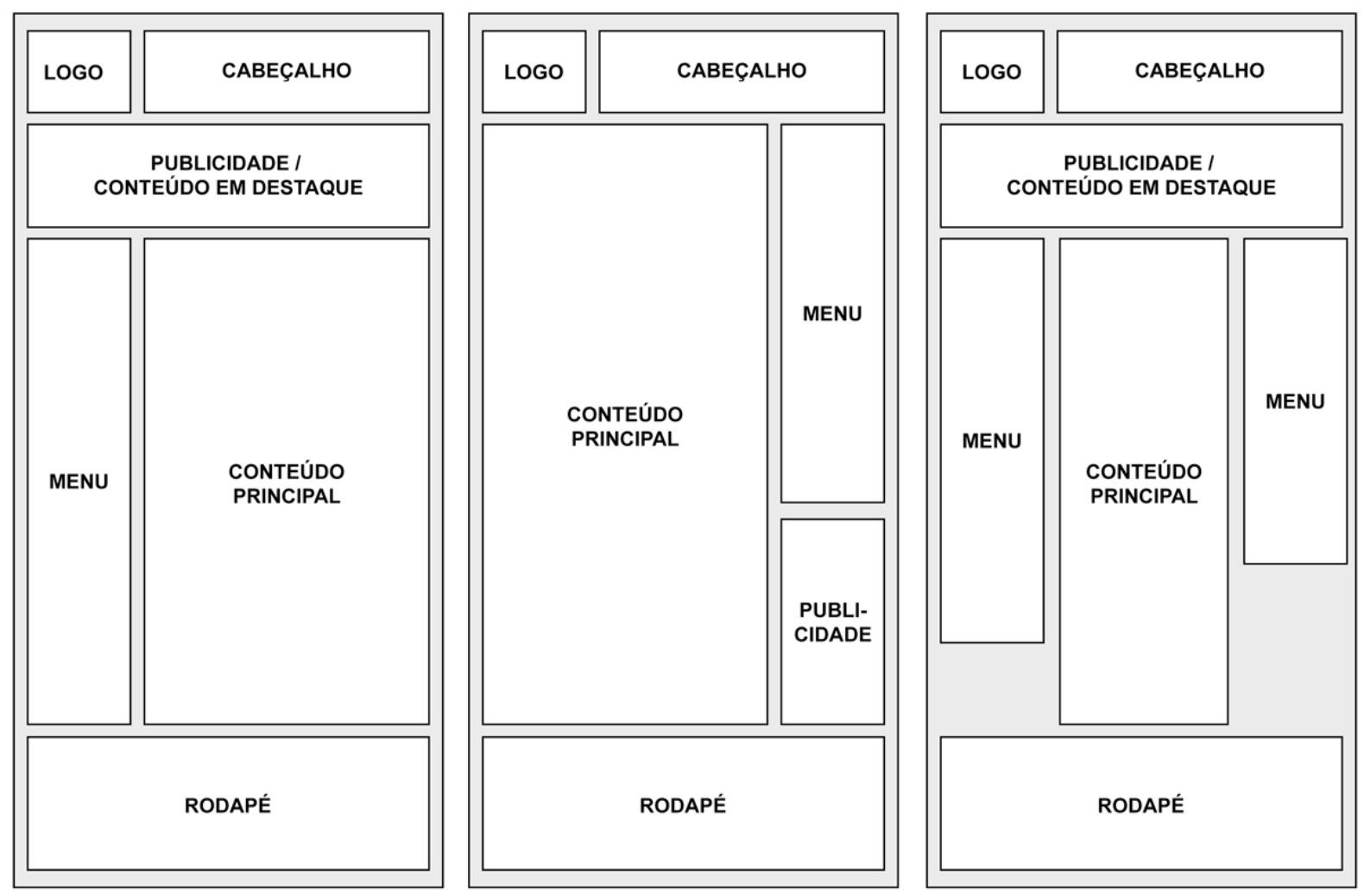

Figura 22 - Exemplos simplificados de estruturas comuns encontradas em páginas Web.

Código-fonte 1: Trecho de código HTML utilizado para representar ao cabeçalho da página Web.

$1<$ header $>$

$2<$ ! -- Logo, opções de navegação ou outras informações -->

$3</$ header $>$

Navegação: Essa seção é normalmente posicionada no cabeçalho e nas laterais da página Web. Utilizado para representar os menus de navegação, o elemento <nav> agrupa uma coleção de links e os torna disponíveis às tecnologias assistivas, através de seu atributo ARIA padrão role=navigation.

Código-fonte 2: Trecho de código HTML utilizado para representar a navegação em uma página Web.

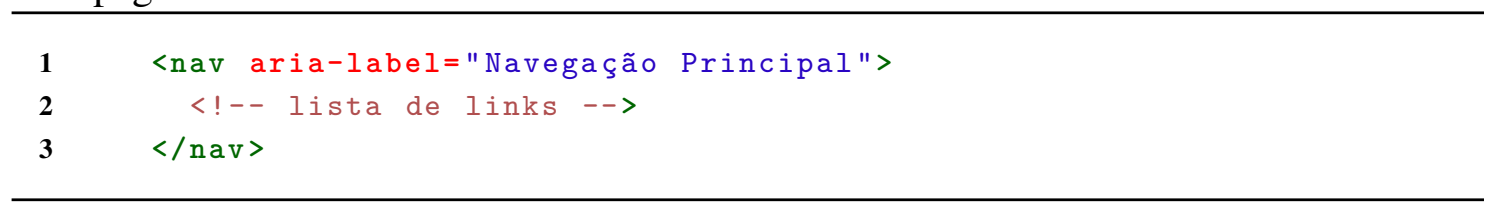

Conteúdo Principal: O conteúdo principal da página Web deve utilizar o elemento de marcação $<$ main>. Apenas um elemento main deve ser utilizado por página, permitindo que as tecnologias assistivas reconheçam esse conteúdo. 
Código-fonte 3: Trecho de código HTML utilizado para representar o conteúdo principal em uma página Web.

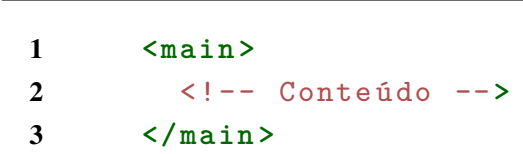

Ainda, para auxiliar a especificação do conteúdo, pode-se utilizar os elementos section e article. Esses elementos podem aparecer mais de uma vez ao longo da página Web.

- <section> - Esse elemento é utilizado para delimitar uma região genérica na página Web. Ele é usado para o agrupamento de conteúdos semelhantes. Por padrão, esse elemento possui o atributo role=region da especificação ARIA.

- <article> - Utilizado para representar uma seção do conteúdo de um site, que consiste de uma composição independente na página. Dentre os possíveis usos desse elemento estão: notícias, produtos em uma loja, postagens em fóruns, entre outros. Por padrão, esse elemento possui o atributo role=article da especificação ARIA.

Rodapé: Como o nome sugere, essa região é posicionada na parte inferior da página Web, e geralmente contém informações suplementares, como direitos autorais, política de privacidade ou menus repetidos (WELIE, 2007b). Esta região deve estar contida por um elemento <footer>. Por padrão, esse elemento possui o atributo da especificação ARIA role=contentinfo, desde que o <footer $>$ não tenha sido utilizado dentro de elementos do tipo <section $>$ ou $<$ article $>$.

Código-fonte 4: Trecho de código HTML utilizado para representar o rodapé em uma página Web.

$1<$ footer $>$

$2<$ !-- Informações de Rodapé -->

$3</$ footer $>$

Conteúdos Complementares: Essa seção é utilizada para conteúdos importantes que agregam informações ao conteúdo principal. O elemento utilizado para marcar essas regiões é o <aside>, que pode ser utilizado para representar barras laterais, publicidade, blocos de navegação e qualquer outro conteúdo separado do conteúdo principal. $\mathrm{O}$ atributo ARIA padrão para esse elemento é o role=complementary.

Código-fonte 5: Trecho de código HTML utilizado para representar conteúdos complementares em uma página Web.

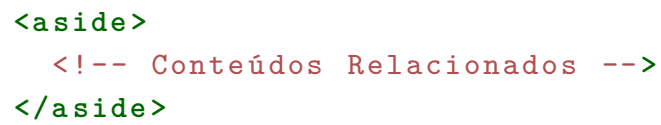


Pesquisa: A região de pesquisa apresenta a "ferramenta de busca"de um site. Não há nenhum elemento HTML5 dedicado para representar essa região, porém, pode-se utilizar o atributo ARIA role=search. A seguir, é apresentado um exemplo que utiliza o atributo role=search em um elemento $<$ div $>$ :

Código-fonte 6: Trecho de código HTML utilizado para representar a região de pesquisa em uma página Web.

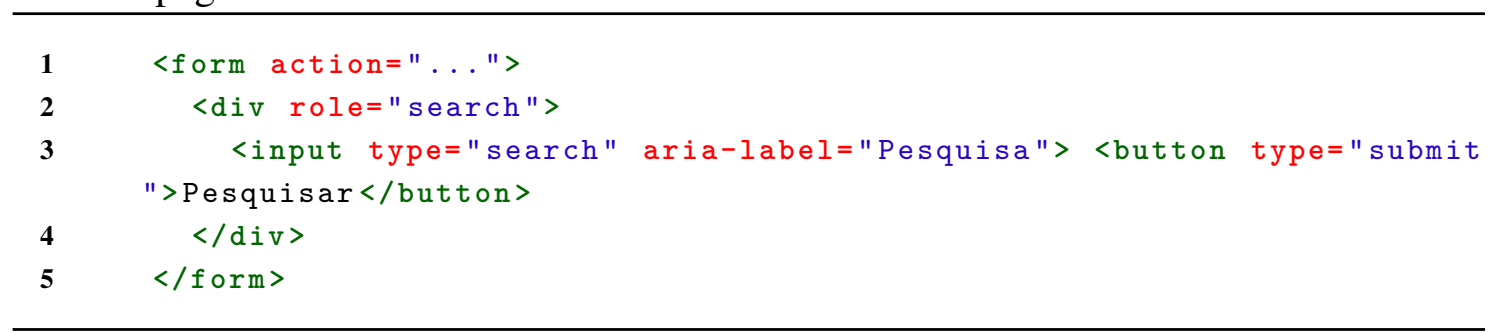

Os navegadores Web e tecnologias assistivas atuais fornecem um bom suporte à integração entre HTML5 e ARIA, porém, algumas versões mais antigas podem apresentar incompatibilidade com as novas especificações. O site html5accessibility [ $_{1}$ apresenta um resumo sobre o suporte oferecido pelos navegadores em relação à integração entre HTML5 e ARIA.

Para garantir que as tecnologias assistivas serão capazes de interpretar corretamente a marcação HTML5, pode-se inserir os atributos ARIA de maneira redundante, como apresentado abaixo.

Código-fonte 7: Exemplos de redundância na marcação ARIA e HTML5.

$1<$ header role="banner" $\rangle\langle/$ header $\rangle$

$2<$ main role="main" $></$ main $>$

$3<$ nav role="navigation" $>\langle/$ main $>$

$4<$ footer role=" contentinfo" $\rangle\langle/$ footer $\rangle$

Assim, mesmo que uma versão antiga do navegador não suporte os atributos padrões ARIA para os elementos HTML5, essa informação estará declarada diretamente na marcação. Com o avanço da compatibilidade, essa técnica não deve mais ser utilizada.

\subsection{NavAux}

Essa seção apresenta a abordagem proposta para o desenvolvimento do NavAux. A Seção 5.3.1 apresenta os detalhes sobre a estrutura da interface proposta. As Seções 5.3.2 e 5.3.3 apresentam, respectivamente, informações sobre as regiões do cabeçalho e conteúdos principal e complementar. Por fim, a Seção 5.3.4 apresenta detalhes sobre a região de navegação do protótipo, assim como a abordagem proposta para transformar os links oriundos da classificador em um novo modelo de navegação otimizado aos usuários cegos.

1 http://www.html5accessibility.com/ 


\subsubsection{Estrutura Geral}

A interface proposta é composta por 4 regiões principais: cabeçalho $(<$ header $>)$, conteúdo principal(<main>), conteúdo complementar(<aside>) e navegação (<nav>).

O objetivo com o uso de regiões fixas e pré-estabelecidas é minimizar alguns dos problemas enfrentados pelos usuários cegos apresentados na Seção 3.3. Essa abordagem possibilita, por exemplo, evitar alterações na estrutura do layout, evitar conteúdos irrelevantes por meio de atalhos e simplificar layouts muito complexos.

Como visto, as opções de navegação são recorrentes nas diferentes páginas, o que pode tornar esse conteúdo irrelevante aos usuários cegos após algumas interações (POWER et al. 2012) (BAVANI; JAAFAR; YATIM, 2010). Assim, optou-se por posicionar a região de navegação no fim da página, ao contrário do que ocorre nas interfaces visuais. Sendo assim, no cabeçalho da interface proposta deverá conter apenas alguns atalhos e o formulário de busca.

A segunda região consiste do conteúdo principal, visto que deve ser rapidamente acessado após a primeira interação na página. Na terceira região, encontram-se todos os conteúdos complementares da página, como anúncios e conteúdos relacionados ao principal. O Códigofonte 8 apresenta a estrutura HTML5 básica do NavAux. Optou-se por utilizar redundância com os respectivos atributos ARIA para garantir a compatibilidade com navegadores um pouco mais antigos. A Figura 23 apresenta uma ideia visual da organização dessas regiões.

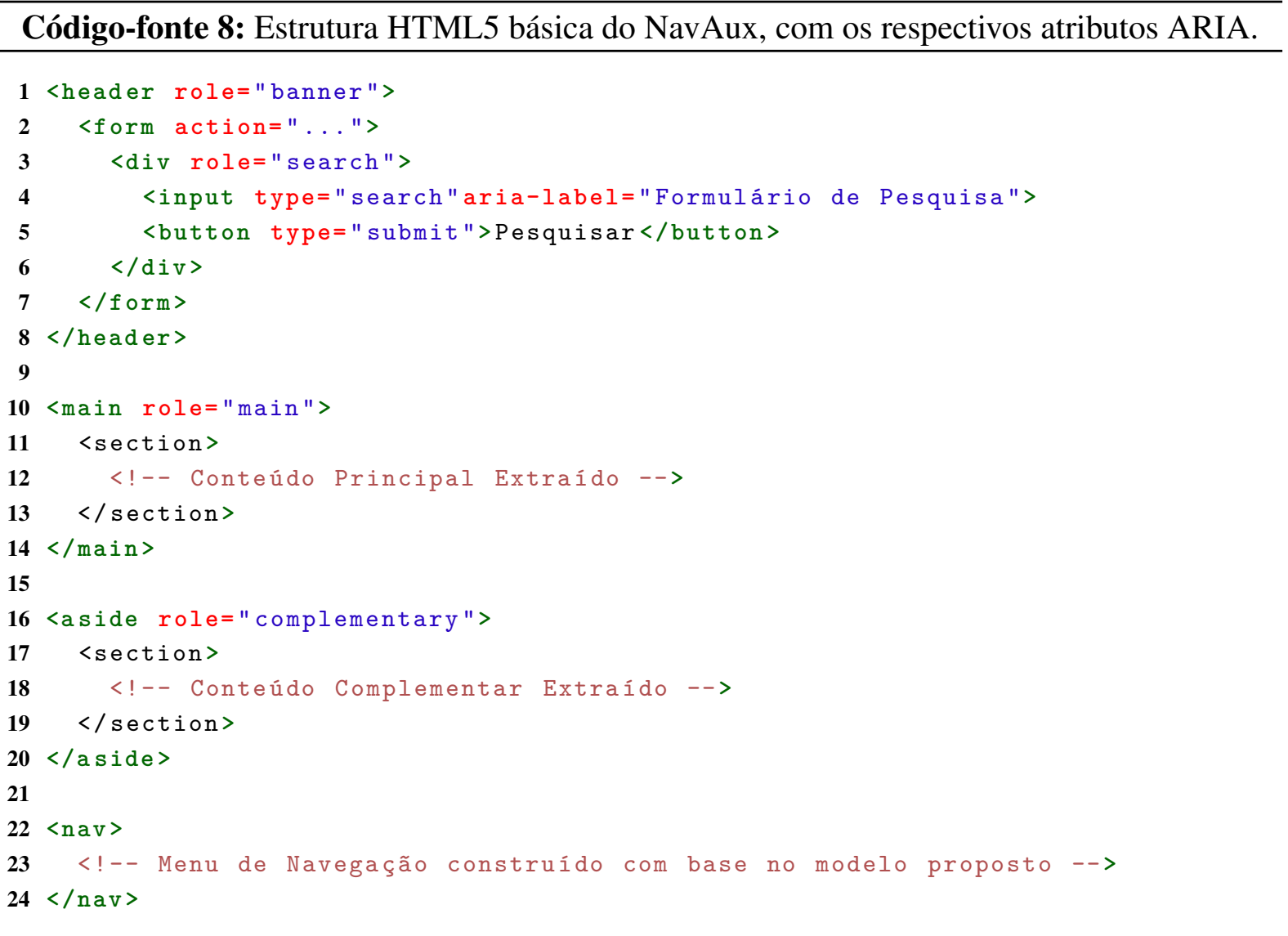


Vale ressaltar que a organização visual dessas regiões não impacta na acessibilidade do conteúdo Web para os usuários de leitores de tela. O posicionamento apresentando na Figura 23 , foi utilizado apenas para ilustrar o modelo de interface proposto.

Com intuito de possibilitar um acesso mais rápido entre as regiões, é proposto o uso de teclas de atalho que permitam navegar entre as 4 regiões estabelecidas. A adoção do padrão ARIA para definir essas regiões permite utilizar os próprios atalhos fornecidos pelos leitores de tela para essa navegação, o que pode auxiliar a diminuir a carga cognitiva do usuário cego durante o processo de aprendizado deste modelo de interface proposto, evitando sobrecarregar o usuário com novas informações. Assim, as teclas para navegar entre as regiões da interface ficam definidas de acordo com o leitor de tela utilizado pelo usuário. Os leitores de tela JAWS e NVDA, comumente utilizados pelos usuários cegos, apresentam as seguintes teclas de atalho:

- JAWS: tecla $(\mathbf{R})$ para pular para próxima região, ou Shift + $\mathbf{R}$ para voltar para a região anterior.

- NVDA: tecla D para pular para a próxima região, ou Shift + D para retroceder para região anterior.

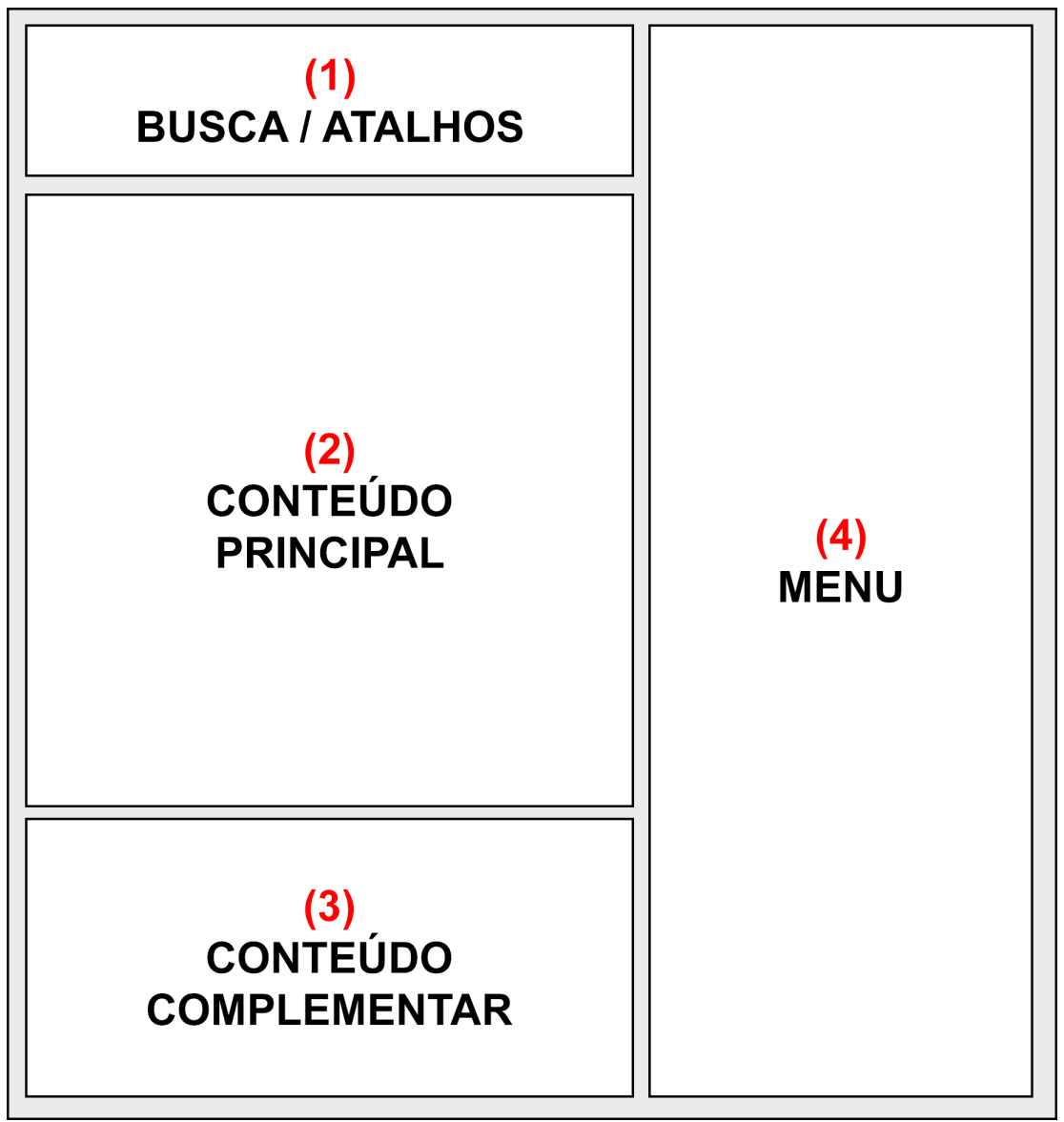

Figura 23 - Proposta para a estrutura da página Web voltada aos usuários cegos. 
Por fim, o usuário deve ter a possibilidade de a qualquer momento pedir informações sobre o seu estado atual, atalhos disponíveis e sobre as possíveis ações que podem ser tomadas a partir daquele ponto na página. Para isso, é fornecido um pop-up de ajuda, que pode ser invocado a qualquer momento pelas teclas de atalho Shift + ?, desde que o foco não esteja em uma caixa de texto. Como o pop-up altera o foco atual da aplicação, foi utilizada a biblioteca jQuery ${ }^{2}$ para controlar o foco da aplicação, permitindo que, ao fechar o pop-up, o foco seja retornado para a sua posição original.

As Seções 5.3.2, 5.3.3 e 5.3.4 apresentam mais informações sobre, respectivamente, as regiões de cabeçalho, contéudos e navegação.

\subsubsection{Cabeçalho - Atalhos/Busca}

Com objetivo de não sobrecarregar o cabeçalho da interface, na região do Cabeçalho são oferecidos apenas dois elementos: um link e um campo de pesquisa. Como o próprio leitor de telas permite a navegação entre a regiões, optou-se por não utilizar âncoras com objetivo de pular conteúdos irrelevantes, evitando poluir a interface proposta. Caso as âncoras fossem utilizadas, as mesmas poderiam se tornar irrelevantes ao aumentar a experiência de uso do usuário na nova interface, causando o efeito contrário do esperado.

Porém, é necessário informar o usuário sobre as teclas de atalho que o auxiliarão a utilizar a interface. Assim, foi proposto um link no cabeçalho para invocar um pop-up de ajuda, que descreve o funcionamento da interface, assim como as suas opções de atalho.

Logo após o link de ajuda, foi posicionado o campo de pesquisa devidamente rotulado pelo uso dos atributos ARIA. Dada a importância dos formulários de pesquisa, posicioná-los no topo faz com que eles sejam rapidamente acessados (LEPORINI; ANDRONICO; BUZZI, 2004)(HAANPERä; NIEMINEN, 2013).

Como o foco dessa pesquisa não envolveu a descoberta destes elementos de pesquisa, essa adaptação foi realizada de forma supervisionada no protótipo desenvolvido. Porém, vale ressaltar que existem trabalhos na literatura relacionados a descoberta dos elementos de pesquisa para variados tipos de aplicações (BHATIA; DIXIT et al., 2015)(ZHANG; HE; CHANG, 2004).

\subsubsection{Conteúdo Principal e Complementar}

A segunda região da interface proposta é composta pelo conteúdo principal da página Web. Outros tipos de conteúdos, que não são classificados como conteúdo principal ou referentes à navegação, são considerados conteúdos complementares, sendo assim, incluídos na terceira região do protótipo. Anúncios, notícias relacionadas e avisos sobre direitos autorais são exemplos de conteúdos considerados complementares.

2 https://jquery.com/ 
Dado que o foco desta pesquisa é voltado aos menus de navegação, novamente o conteúdo dessas regiões foi obtido de maneira supervisionada. Esses conteúdos não passaram por transformações, sendo assim, possíveis problemas de acessibilidade no conteúdo foram mantidos, como por exemplo, falta de texto alternativo em imagens ou links quebrados.

A identificação e a extração dos conteúdos principal e complementar possuem uma ampla gama de pesquisas relacionadas (SINGH; SINGH, 2010) (CHANDRAN; VIJENDRAN, 2015) (SONG; SUN; LIAO, 2015), possibilitando que seja feita uma investigação futura sobre o tema.

\subsubsection{Navegação}

Essa região da página contém todos os mecanismos referentes à navegação da página. A abordagem proposta para criação dos menus de navegação, consiste basicamente na transformação dos itens de menus classificados pelo método apresentado no Capítulo $4 \mathrm{em}$ um novo modelo otimizado para leitores de tela.

Esse novo modelo de navegação proposto segue a especificação ARIA (W3C, 2014a) para o desenvolvimento de menus acessíveis. As teclas de atalho para a navegação do menu são descritas em dois casos, de acordo com o foco do usuário:

Teclas de atalho caso o foco da aplicação esteja na barra de menu

- Seta Esquerda: Seleciona o item anterior do menu;

- Seta Direita: Seleciona o próximo item do menu;

- Seta para Cima: Expande o menu suspenso e seleciona o primeiro item;

- Seta para Baixo: Expande o menu suspenso e seleciona o primeiro item;

- Enter: Expande ou fecha o menu. Ao expandir, seleciona o primeiro item do menu;

- Barra de Espaço: Expande ou fecha o menu. Ao expandir, seleciona o primeiro item do menu;

Teclas de atalho caso o foco da aplicação esteja em um item de menu

- Seta Esquerda: Abre o item anterior do menu suspenso e seleciona o primeiro link desse menu;

- Seta Direita: Abre o próximo item do menu suspenso e seleciona o primeiro link desse menu;

- Seta para Cima: Seleciona o item de menu anterior;

- Seta para Baixo: Seleciona o próximo item de menu; 
- Enter: Aciona o link selecionado e fecha o menu;

- Barra de Espaço: Aciona o link selecionado e fecha o menu;

Quando um usuário atingir o último item de um menu, um aviso sonoro deve ser acionado para indicar que não existem próximos itens, com intuito de melhorar a compreensão do usuário sobre o seu estado atual durante a interação. O processo para transformação automática dos links de uma página Web para o modelo proposto, é apresentado a seguir.

\section{Processo de Transformação da Navegação}

A primeira etapa deste processo consiste em extrair os valores das características referentes à posição e a repetição de todos links da página Web, da mesma forma discutida na Seção 4.3.3 e submetê-los ao classificador proposto no Capitulo 4. Dentre os resultados oriundos do classificador, deve-se selecionar os links classificados como Menu Superior, Menu Lateral

Esquerdo e Menu Lateral Direito, como base para o novo menu de navegação a ser construído. Optou-se por utilizar essas classes de links com base na relevância desses menus em relação ao Rodapé, que em geral apenas apresenta links menos relevantes ou mesmo a repetição dos menus superior ou laterais. Após essa seleção, deve-se remover os links redundantes, dando prioridade para remover as duplicatas com a menor taxa de repetição.

Feito isso, é necessário dividir esses links, de modo a reduzir a quantidade de links de navegação sob um mesmo item de menu, com o objetivo de evitar menus muito complexos. Para isso, propõe-se agrupar os links selecionados em dois grupos, de acordo com a característica desses links refentes a sua taxa de repetição. Esse agrupamento pode ser realizado através do uso de técnicas simples de clusterização, como o k-means ou o Método Hierárquico (JAIN, 2010).

Com base nos resultados observados durante a elaboração do classificador proposto no Capítulo 4, essa abordagem proposta para separação dos links foi concebida considerando-se a seguinte hipótese: a alta taxa de repetição de um link reflete o fato de que esse link é consistente entre as diferentes páginas de um site. Caso esse link com alta taxa de repetição também seja classificado como um link pertencente a uma classe do tipo Menu, existe uma possibilidade maior de que esse link pertença a um menu de navegação referente a organização do conteúdo do site como um todo, como por exemplo, links para possíveis classificações do conteúdo encontradas no site a ser analisado. $\mathrm{O}$ mesmo não se repete para o caso dos links pertencentes a menus específicos para algumas páginas do site, que aparecem apenas nas páginas relacionadas a um determinado tema.

Para ilustrar esse conceito, pode se imaginar um portal de notícias que possua um menu de navegação consistente entre todas as páginas. Nesse menu encontram-se links para "Política", "Esportes"e "Tecnologia". Ao clicar no link "Esportes", o usuário é redirecionado para uma página do site relacionado a esse tema específico. Nessa página, assim como em outras páginas relacionadas ao tema esporte, encontra-se um segundo menu específico, que apresenta links para 
as diferentes modalidades de esporte, como "Futebol"e "Atletismo". Nessa ilustração, os links encontrados no menu consistente entre todas as páginas deverá apresentar uma taxa de repetição alta, próxima a 1, enquanto que o menu específico, apresentará uma taxa de repetição menor, de acordo com a quantidade de páginas relacionadas ao tema, em relação ao total de páginas do domínio.

Após a classificação desses links em 2 grupos, esses links devem ser reestruturados em dois níveis, sendo eles:

- Links de Navegação: Esse nível contém os links resultantes do agrupamento realizado, representados pela classe com maior taxa média de repetição. Espera-se que esses links estejam mais relacionados à navegação do site.

- Links Relacionados: Esse nível contém os links referentes a classe com menor taxa média de repetição. Acredita-se que existe uma possibilidade maior de que os links desse nível sejam mais relacionados ao conteúdo atual da página.

Após esse processo, os links inicialmente classificados como Menu de Navegação Superior, Lateral Direito ou Lateral Esquerdo, devem se encontrar distribuídos de acordo nos dois níveis apresentados acima: Navegação e Relacionados. Por fim, deve-se integrar os links classificados como Rodapé a esse menu reestruturado. Para isso, serão selecionados apenas os links que não sejam redundantes ao novo menu reestruturado. Assim, após excluir as duplicatas, os links de Rodapé restantes serão incorporados ao nível Relacionados do novo menu, por acreditar-se que os mesmos tem menor importância em relação aos itens agrupados como Navegação.

Por fim, os links deverão ser organizados em ordem alfabética e deve ser adicionada uma contagem do número total de itens em cada menu, para auxiliar o usuário a navegar pelos itens do menu.

Estudo de Caso - www.brasil.gov.br

Para demonstrar o método proposto na Seção 5.3.4, foi realizado um estudo de caso com base no site Portal Brasil. Assim, inicialmente foram extraídos os links de acordo com a abordagem apresentada na Seção 4.3.3, e essa amostras foram classificadas pelo método Naïve Bayes proposto no Capítulo 4. Os valores das amostras obtidas, assim como os resultados da classificação, são apresentados na Tabela 4.

Após coletar os valores das amostras, foi realizada a clusterização com o algoritmo $k$-means, com base nas taxas de repetição dos links classificados como Menu Superior e Menu Lateral Esquerdo. Após o agrupamento, foram removidos os links redundantes, e os resultados desse processo são apresentados na Figura 24. 
Tabela 4 - Links extraídos do Portal Brasil e classificados pelo método desenvolvido.

\begin{tabular}{|c|c|c|c|}
\hline URL & Label & Taxa de Repetição & Classificação \\
\hline /acessibilidade & Acessibilidade & 0,998596 & Menu Superior \\
\hline /mapadosite & Mapa do Site & 0,998596 & Menu Superior \\
\hline /servicos/perguntas-frequentes-1 & Perguntas Frequentes & 0,998596 & Menu Superior \\
\hline /servicos/fale-com-o-governo & Fale com o Governo & 0,998596 & Menu Superior \\
\hline /servicos/fale-com-a-presidenta & Fale com o Presidenta & 0,998596 & Menu Superior \\
\hline /home/ultimas-noticias & Últimas notícias & 0,998596 & Lateral Esquerdo \\
\hline /estados & Navegue por Estados & 0,998596 & Lateral Esquerdo \\
\hline /socialhub/socialhub & Social Hub & 0,359298 & Lateral Esquerdo \\
\hline /cidadania-e-justica & Cidadania e Justiça & 0,998596 & Lateral Esquerdo \\
\hline /ciencia-e-tecnologia & Ciência e Tecnologia & 0,998596 & Lateral Esquerdo \\
\hline /cultura & Cultura & 0,998596 & Lateral Esquerdo \\
\hline /defesa-e-seguranca & Defesa e Segurança & 0,998596 & Lateral Esquerdo \\
\hline /economia-e-emprego & Economia e Emprego & 0,998596 & Lateral Esquerdo \\
\hline /educacao & Educação & 0,998596 & Lateral Esquerdo \\
\hline /esporte & Esporte & 0,998596 & Lateral Esquerdo \\
\hline /governo & Governo & 0,998596 & Lateral Esquerdo \\
\hline /infraestrutura & Infraestrutura & 0,998596 & Lateral Esquerdo \\
\hline /meio-ambiente & Meio Ambiente & 0,998596 & Lateral Esquerdo \\
\hline /saude & Saúde & 0,998596 & Lateral Esquerdo \\
\hline /turismo & Turismo & 0,998596 & Lateral Esquerdo \\
\hline /centrais-de-conteudo/videos & Vídeos & 0,359298 & Lateral Esquerdo \\
\hline /centrais-de-conteudo/audios & Áudios & 0,359298 & Lateral Esquerdo \\
\hline /centrais-de-conteudo/infograficos & Infográficos & 0,359298 & Lateral Esquerdo \\
\hline /centrais-de-conteudo/imagens & Imagens & 0,359298 & Lateral Esquerdo \\
\hline /cidadania-e-justica & Cidadania e Justiça & 0,998596 & Rodapé \\
\hline /ciencia-e-tecnologia & Ciência e Tecnologia & 0,998596 & Rodapé \\
\hline /cultura & Cultura & 0,998596 & Rodapé \\
\hline /defesa-e-seguranca & Defesa e Segurança & 0,998596 & Rodapé \\
\hline /economia-e-emprego & Economia e Emprego & 0,998596 & Rodapé \\
\hline /educacao & Educação & 0,998596 & Rodapé \\
\hline /esporte & Esporte & 0,998596 & Rodapé \\
\hline /governo & Governo & 0,998596 & Rodapé \\
\hline /infraestrutura & Infraestrutura & 0,998596 & Rodapé \\
\hline /meio-ambiente & Meio Ambiente & 0,998596 & Rodapé \\
\hline /saude & Saúde & 0,998596 & Rodapé \\
\hline /turismo & Turismo & 0,998596 & Rodapé \\
\hline /servicos/contato-1 & Fale com o Governo & 0,998596 & Rodapé \\
\hline /servicos/perguntas-frequentes-1 & Perguntas Frequentes & 0,998596 & Rodapé \\
\hline /acessibilidade & Acessibilidade & 0,998596 & Rodapé \\
\hline /mapadosite & Mapa do Site & 0,998596 & Rodapé \\
\hline /lancamento & Sobre o Portal Brasil & 0,998596 & Rodapé \\
\hline$/$ rss & Assine & 0,998596 & Rodapé \\
\hline
\end{tabular}




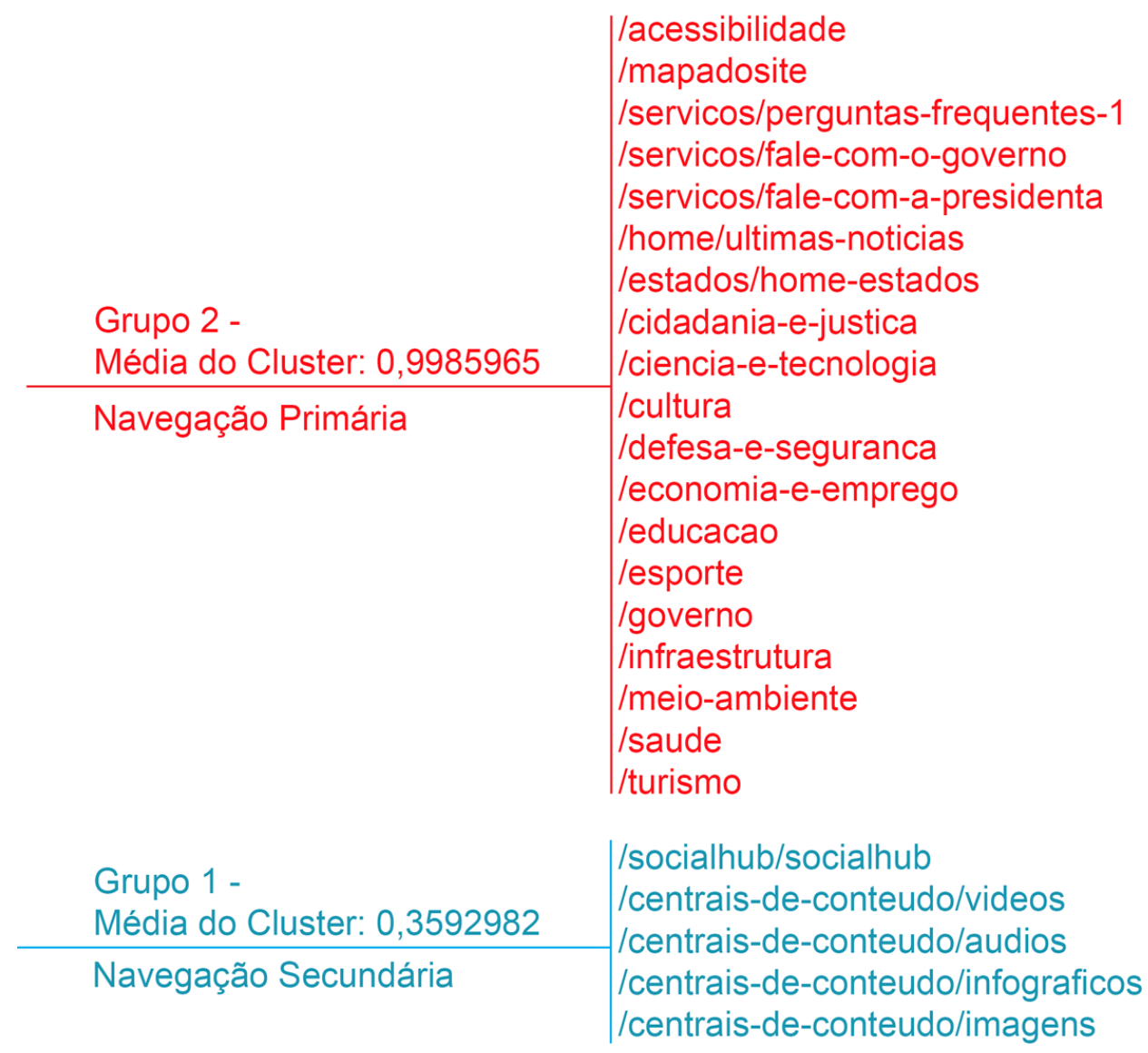

Figura 24 - Exemplo de agrupamento para os links do Portal Brasil.

Com base no agrupamento obtido, os links foram reestruturados segundo o padrão apresentado: links de Navegação e Relacionados. Os links previamente classificados como Rodapé que eram distintos aos já agrupados, foram incorporados ao menu Relacionados.

Feito isso, os itens foram organizados em ordem alfabética e as contagens dos links para cada item de menu foram adicionadas. $\mathrm{O}$ menu de navegação resultante desse processo é apresentado na Figura 25 .

\subsection{Avaliação do Protótipo}

Optou-se por não realizar a avaliação da interface com um usuário cego, com o objetivo inicial de validar se a interface proposta se comporta como esperado. A validação da interface com usuários cegos é fundamental, mas essa avaliação deve ser realizada apenas após se ter a certeza do funcionamento correto do protótipo. Isso é necessário visto que os usuários cegos podem não ser capazes de reconhecer quando o conteúdo não é acessível a eles, o que comprometeria esse tipo de avaliação caso a interface apresentasse problemas técnicos.

Optou-se então por realizar a avaliação do protótipo por meio de um percurso cognitivo (POLSON et al., 1992), com apoio de um leitor de tela. Para isso, foi utilizado o JAWS, que é o 


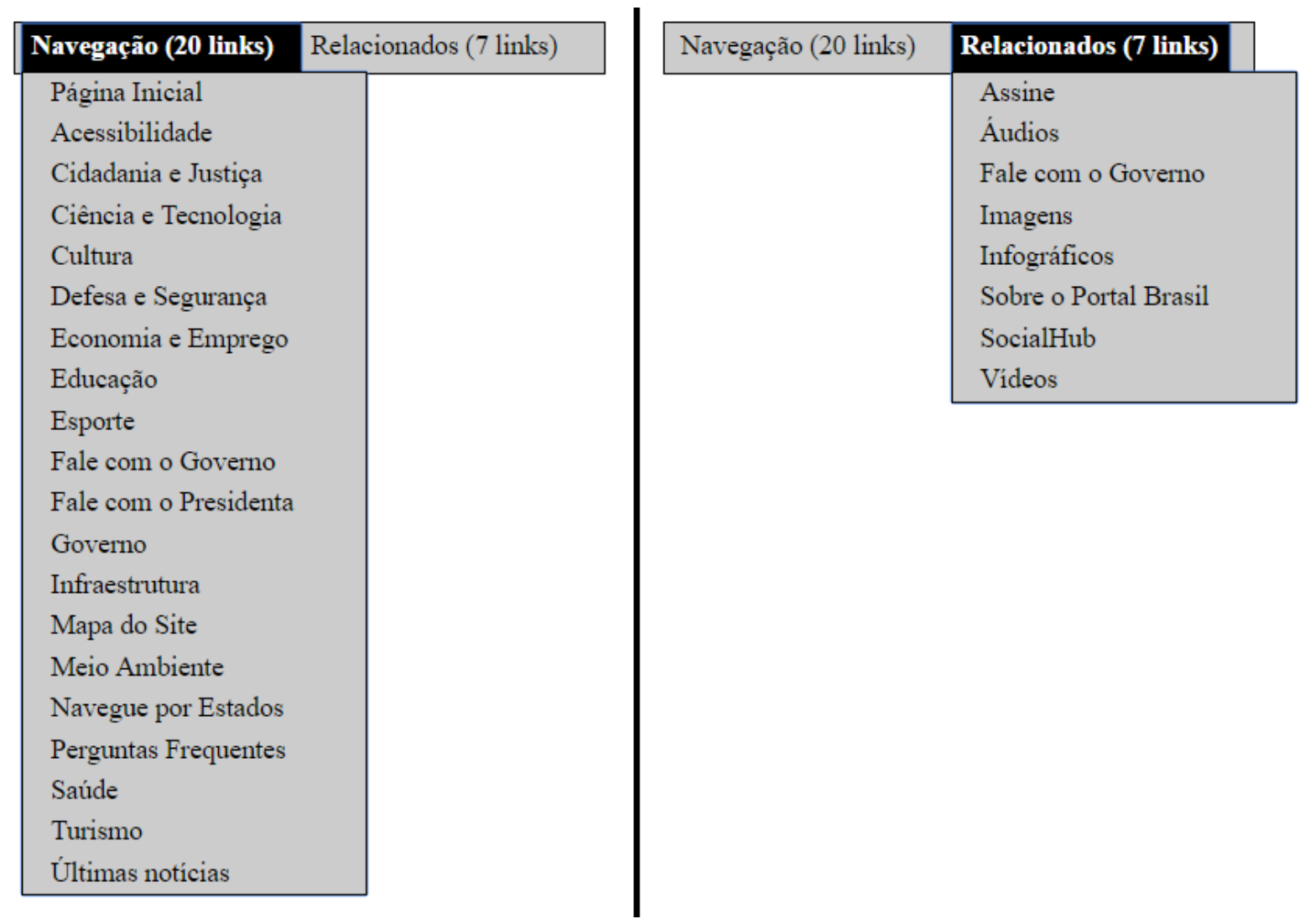

Figura 25 - Exemplo de novo modelo de navegação construído com base na abordagem proposta.

leitor de tela mais popular atualmente, embora o ZoomText, Window-Eyes e o NVDA, e estejam se tornando mais popular devido às suas características e seu custo mais baixo. As atividades do percurso cognitivo são apresentadas nas Seções 5.4.1- 5.4.3

\subsubsection{Preparação}

O objetivo deste percurso cognitivo foi avaliar a interface do protótipo apresentado na Seção 5.3. Foram considerados como usuários típicos desse sistema as pessoas cegas que navegam na Web com apoio de um leitor de tela e que já possuem um conhecimento mínimo sobre o funcionamento desses leitores. Considera-se que o usuário cego tenha também um conhecimento mínimo sobre a estrutura do protótipo e sobre sua estratégia de navegação.

O percurso cognitivo foi realizado por um especialista em acessibilidade e usabilidade para cegos, com base em perguntas e tarefas pré-definidas. Assim, foram elaboradas 4 tarefas para o percurso cognitivo, apresentadas a seguir com as respectivas sequências corretas de ações:

Tarefa 1. Acesso ao pop-up de ajuda: Deve-se acessar o pop-up de ajuda, que é o primeiro elemento apresentado. Após o acesso, deve-se ler o conteúdo do pop-up e conhecer as teclas de atalho fornecidas na interface. Feito isso, deve-se fechar o pop-up e retomar o foco na interface. 


\section{Sequência correta de ações:}

1. Acessar o pop-up de ajuda

2. Ler o conteúdo

3. Fechar o pop-up

Tarefa 2. Navegar pelas 4 regiões da interface: A segunda tarefa consiste em navegar pelas 4 regiões apresentadas na interface, através do uso das teclas de atalho do leitor JAWS.

\section{Sequência correta de ações:}

1. Navegar pelas 4 regiões do protótipo

Tarefa 3. Percorrer todo o conteúdo principal: A terceira tarefa consiste em navegar até a região do conteúdo principal por meio das teclas de atalho do JAWS e ler todo o conteúdo dessa região até o início da região com o conteúdo complementar.

\section{Sequência correta de ações:}

1. Navegar até a região "conteúdo principal"

2. Percorrer todo conteúdo desta região

Tarefa 4. Acessar o link de navegação "Sobre o Portal Brasil": A quarta tarefa consiste em explorar os itens contidos no menu de navegação. Feito isso, deve-se encontrar e acessar o link de navegação "Sobre o Portal Brasil".

\section{Sequência correta de ações:}

1. Navegar até a região de navegação

2. Selecionar o menu de navegação

3. Navegar até o item "Relacionados"

4. Percorrer os links até encontrar o item "Sobre o Portal Brasil"

\subsubsection{Análise e Coleta de Dados}

As tarefas apresentadas na Seção 5.4.1 foram analisadas com base nas seguintes questões:

Q1. O usuário saberá o que fazer?

Q2. O usuário vai notar que o elemento de interação está disponível?

Q3. Quando uma ação for executada, o usuário vai receber feedback do sistema informando se a ação estava correta ou não?

Considerando-se esses critérios, o percurso cognitivo para as tarefas propostas é apresentado a seguir: 
Tarefa 1. Acessar o pop-up de ajuda

Q1. Resposta: Sim, o usuário sabe que deve acessar o pop-up de ajuda.

Q2. Resposta: Sim, o botão é o primeiro elemento da interface a receber foco.

Q3. Resposta: Sim, o usuário recebe feedback adequado.

Tarefa 1. Ler o conteúdo

Q1. Resposta: Sim, o usuário sabe que deve ler o conteúdo para conhecer as teclas de atalho.

Q2. Resposta: Sim, o texto encontra-se na sequência de leitura correta.

Q3. Resposta: Sim, a própria leitura do conteúdo auxilia o usuário a acompanhar a ação.

Tarefa 1. Fechar o pop-up

Q1. Resposta: Não, não fica claro ao usuário que a interação com o botão "fechar" encerra o pop-up e retoma o foco para a interface.

Q2. Resposta: Sim, o botão se encontra logo ao final do conteúdo.

Q3. Resposta: Não, o leitor de tela apenas informa ao usuário que o foco voltou ao botão "ajuda", o que pode gerar confusão sobre a ação executada.

Tarefa 2. Navegar pelas 4 regiões do protótipo

Q1. Resposta: Sim, o usuário conhece a estrutura do protótipo e sabe que precisa navegar pelas regiões do mesmo em busca do conteúdo.

Q2. Resposta: Sim, caso o usuário conheça as teclas de atalho necessárias para a interação.

Q3. Resposta: Sim, cada região possui atributos ARIA que fornece as informações necessárias ao leitor de tela.

Tarefa 3. Navegar até a região "conteúdo principal”

Q1. Resposta: Sim, o usuário sabe que deve navegar até essa região para ler o conteúdo do site.

Q2. Resposta: Sim, o usuário irá notar a região graças aos atributos ARIA e HTML corretamente definidos.

Q3. Resposta: Sim, o leitor de tela informa que o foco se encontra na região principal.

Tarefa 3. Percorrer todo conteúdo desta região

Q1. Resposta: Sim, o usuário sabe que deve ler o conteúdo. 
Q2. Resposta: Sim, o texto encontra-se na sequência de leitura correta.

Q3. Resposta: Sim, a própria leitura do conteúdo auxilia o usuário a acompanhar a ação.

Tarefa 4. Navegar até a região de navegação

Q1. Resposta: Sim, o usuário sabe que deve navegar até essa região para encontrar os menus de navegação.

Q2. Resposta: Sim, caso o usuário conheça as teclas de atalho necessárias para a interação.

Q3. Resposta: Sim, o leitor de tela informa que o foco se encontra na região de navegação.

Tarefa 4. Selecionar o menu de navegação

Q1. Resposta: Não, apesar do foco chegar ao menu, não fica claro ao usuário que o mesmo deve pressionar a tecla TAB para iniciar a interação.

Q2. Resposta: Sim, como o menu segue a especificação ARIA, o leitor de tela é informado sobre esse componente.

Q3. Resposta: Sim, apenas caso o usuário tenha sucesso na ação.

Tarefa 4. Navegar até o item "Relacionados"

Q1. Resposta: Não, o leitor de tela não informa ao usuário que o mesmo deve usar as setas para esquerda e direita para navegar entre os tópicos do menu.

Q2. Resposta: Não, visto que o usuário não é informado sobre as teclas de atalho.

Q3. Resposta: Sim, para o caso em que o usuário executa a ação correta.

Tarefa 4. Percorrer os links até encontrar o item "Sobre o Portal Brasil"

Q1. Resposta: Sim, o leitor de tela informa como interagir com o menu.

Q2. Resposta: Sim, a implementação da especificação ARIA garante a comunicação da interação com o leitor de tela.

Q3. Resposta: Sim, a própria leitura do conteúdo auxilia o usuário a acompanhar a ação.

\subsubsection{Relato dos Resultados}

A uso da interface mostrou-se satisfatório, porém o percurso cognitivo realçou algumas correções necessárias na interface, como a alteração dos labels dos atributos ARIA das regiões, com o intuito de facilitar a interpretação dos usuários, a melhoria do texto apresentando no pop-up de ajuda, a melhoria do feedback ao fechar o pop-up e recuperar o foco na interface e a melhoria do feedback para interagir com o menu. 


\subsection{Considerações Finais}

Nesse capítulo, foi apresentada a proposta para um modelo de interface voltado especificamente para os usuários cegos que navegam na Web com apoio de um leitor de tela. Para complementar a interface, foi proposta uma abordagem para automaticamente coletar os itens de navegação de uma página Web e transformá-los em um padrão mais acessível, seguindo as especificações ARIA.

Algumas vantagens podem ser citadas no uso da abordagem proposta. A primeira vantagem que pode ser mencionada está no fato da interface resultante possuir um estrutura bem definida, que pode auxiliar os usuários cegos na compreensão dessa estrutura. Além disso, o uso correto da linguagem HTML5 e da especificação ARIA, permite uma boa integração da interface com as tecnologias assistivas, como o leitor de tela. Outra vantagem está relacionada à navegação. Além de apresentar um modelo de acordo com as especificações ARIA, esse modelo simplifica a navegação, eliminando diversos links redundantes da página original. Como exemplo, pode-se citar o estudo de caso realizado na Seção 5.3.4, que reduziu 42 links na página original para 27 no modelo de navegação proposto, obtendo uma redução de $36 \%$. Essa redução, assim como as regiões bem definidas, podem auxiliar a diminuir a carga cognitiva necessária para navegar pela interface.

O uso do pop-up de ajuda também pode-se tornar muito vantajoso para o usuário, que pode facilmente ter acesso às teclas de atalho disponíveis, assim como o estado atual do foco na interface, e as ações que podem ser tomadas a partir daquele ponto.

Algumas vantagens, como a diminuição da redundância dos links, não puderam ser estendidas às outras regiões do site, visto que não foi realizada uma extração automática desse conteúdo. Sendo assim, optou-se por não alterar os conteúdos originais dessas outras regiões.

Uma das principais desvantagens dessa abordagem está relacionada ao fato de que os métodos para extração automática do conteúdo, como o método apresentado no Capítulo 4, podem não classificar corretamente todos os elementos de todas as diversas possíveis páginas na Web, o que acarretaria em um mal funcionamento desse tipo de abordagem.

Além disso, é necessário realizar mais estudos de caso para verificar o comportamento da transformação automática dos menus, e avaliar com usuários reais o impacto gerado devido à alteração da relação original entre os links.

Considera-se que a abordagem proposta apresenta uma linha de pesquisa promissora, e que com os avanços nos métodos para extração de conteúdo, as vantagens apresentadas superem os possíveis erros de classificação. 
Pela análise da literatura, pode-se notar a necessidade de pesquisas relacionadas a acessibilidade na Web, com uma tendência em trabalhos relacionados a tipos específicos de deficiências ou barreiras tecnológicas.

Conceitos básicos e pesquisas sobre auxílios a usuários cegos na interação com a Web foram descritos para contextualizar as iniciativas que mais se destacam no cenário das pesquisas nos últimos anos sobre a questão de acessibilidade. Nessas pesquisas, foi apontado o fato de que as pessoas cegas ainda apresentam grande dificuldade ao interagir com a Web, principalmente devido a falta de acesso às sugestões visuais encontradas nas páginas, que auxiliam a compreender melhor o conteúdo apresentado nestas páginas.

Apesar de diversos esforços do W3C em promover diretrizes e especificações para minimizar os problemas de acessibilidade, estudos apresentam indícios de que o conceito de acessibilidade universal pode não ser suficiente para o caso dos usuários cegos.

Sendo assim, essa tese propôs um abordagem para extrair automaticamente informações sobre as estruturas de navegação que, em geral encontram-se apenas implícitas na apresentação visual das páginas Web, e alterar o design dessa navegação de uma maneira otimizada aos usuários cegos que utilizam leitores de tela, com o objetivo de minimizar essa barreira tecnológica.

Para isso, optou-se por fazer um levantamento das principais dificuldades encontradas pelos usuários cegos ao navegar na Web, assim como as recomendações para minimizar esses problemas, por meio de um mapeamento sistemático da literatura.

Após a identificação dessas dificuldades, foram coletadas informações sobre as possíveis diretrizes de acessibilidade e usabilidade na Web que visam minimizar os problemas encontrados pelos usuários cegos que interagem e navegam na Web utilizando um leitor de tela. Assim, o Capítulo 3 apresentou os principais resultados do mapeamento sistemático sobre as dificuldades enfrentadas pelos usuários cegos ao navegar na Web e as diretrizes recomendadas para minimizar 
esses problemas.

Uma análise minuciosa foi realizada sobre os resultados encontrados, que foram agrupados em 3 categorias: técnicos, semânticos e cognitivos, e na navegação das páginas Web. Em resumo, foram identificadas 40 dificuldades, das quais 16 se enquadram em problemas técnicos, 17 como problemas semânticos e cognitivos e, 7 como problemas na navegação. Quanto às principais diretrizes de acessibilidade e usabilidade encontradas, que visam minimizar alguns dos problemas enfrentados por usuários cegos, elas totalizaram 40 diretrizes, sendo que 11 delas se enquadram nas que prescrevem orientação para redução de problemas técnicos, 21 das diretrizes são para reduzir problemas semânticos e cognitivos e, 8 diretrizes são para reduzir problemas na navegação. Por fim, o mapeamento sistemático resultou em uma discussão que analisa os resultados obtidos e destaca as tendências sobre os trabalhos na área.

Os problemas semânticos e cognitivos são os mais abordados pelos artigos, o que aparentemente demonstra uma carência maior de soluções para suas questões. Os artigos que discutem sobre os problemas técnicos, fazem isso de uma forma introdutória e sem maiores detalhes. Além disso, as discussões técnicas costumam aparecer seguidas de referências aos conjuntos de diretrizes WCAG 2.0 (W3C, 2008) e ARIA (W3C, 2016d), que são bem abrangentes neste aspecto técnico. Por outro lado, os artigos que discutem sobre os problemas de navegação enfrentados pelos cegos apresentam indícios de que essas questões necessitam de mais pesquisas e propostas sistematizadas.

Sendo assim, a segunda etapa dessa pesquisa propôs uma abordagem baseada no método Naïve Bayes, com o objetivo de classificar automaticamente os links contidos em uma página web em diferentes classes referentes às suas estruturas de navegação. Para isso, foram consideradas características comumente encontradas nos padrões de design de menus de navegação: o posicionamento do link e a sua consistência entre as diferentes páginas do domínio. Essas características foram mensuradas por meio das distâncias do link em relação às margens superior e esquerda da página, e da repetição de um link entre as diferentes páginas.

Após definir as classes de interesse e as características a serem mensuradas, foi realizado um treinamento supervisionado em páginas iniciais de sites governamentais, com o objetivo de obter amostras de treinamento. Após o treinamento, foi realizado um teste de hipótese para escolher a melhor distribuição que representa cada característica, e os parâmetros para o classificador foram calculados com base nas médias e variâncias amostrais de cada classe e característica.

Para avaliar o método, novamente foi realizado um treinamento supervisionado, em que, as amostras foram comparadas aos resultados oriundos do classificador proposto. Em geral, o classificador apresentou bons resultados, mas mostra-se necessária uma integração dos dados referentes ao documento DOM, possibilitando contornar alguns problemas referentes às estruturas de menus pouco usuais. Mesmo assim, o classificador apresenta indícios de que pode automaticamente extrair e fornecer informações semânticas referentes a estrutura de navegação 
de uma página a outros sistemas.

Com base no classificador desenvolvido, foi apresentada uma abordagem para organizar os links classificados em um padrão de navegação otimizado aos leitores de tela. Essa abordagem sugere utilizar um método de clusterização para agrupar os resultados em duas classes de importância, denominadas Links de Navegação e Links Relacionados, de acordo com a taxa de repetição dos links de menu.

O padrão de navegação proposto segue a especificação ARIA, possibilitando que o leitor de tela compreenda a sua estrutura. Também possui teclas de atalho, links organizados em ordem alfabética e a contagem total de links para cada item do menu.

Por fim, esse padrão de navegação foi integrado a um modelo de interface proposto, próprio aos usuários cegos. Essa abordagem utiliza regiões para organizar o conteúdo, que seguem as especificações ARIA, facilitando a navegação por meio de um leitor de tela. Além disso, telas de ajuda também são fornecidas, com informações sobre os atalhos disponíveis, informações sobre o estado atual do usuário na interface e as possíveis ações que podem ser tomadas a partir daquele ponto.

Com exceção da navegação, o conteúdo do protótipo foi adicionado de modo supervisionado, visto que esse trabalho não abordou métodos para extração automática desse tipo de conteúdo. Esse protótipo foi avaliado através de um percurso cognitivo, com apoio do leitor de tela JAWS. Os resultados dos testes mostraram-se satisfatórios, apresentando indícios de que a abordagem proposta pode ser considerada uma alternativa viável para minimizar os problemas de acessibilidade enfrentados pelos usuários cegos ao navegar na Web.

\subsection{Limitações dos Estudos Realizados}

Foram identificadas algumas limitações das abordagens propostas nesse trabalho:

- Os problemas e diretrizes encontrados pelo mapeamento sistemático foram classificados em 3 categorias: Técnicos, Semânticos ou Cognitivos, e de Navegação. Porém, em alguns casos, pode ocorrer uma certa intersecção dessas categorias. Por exemplo, uma página com layout complexo gera um problema cognitivo ao usuário, pois dificulta que a pessoa cega tenha uma melhor compreensão da página. Porém, esse mesmo problema influencia diretamente na navegação do usuário cego, o que pode causar confusão na classificação proposta.

- As diretrizes resultantes do mapeamento sistemático estão organizadas nas mesmas categorias propostas para os problemas. Porém, elas não estão diretamente conectadas a cada problema específico, o que pode inviabilizar uma avaliação de acessibilidade por meio dessas diretrizes. 
- O classificador desenvolvido apresenta problemas nos casos em que o menu não apresenta o padrão de projeto esperado, como nos casos em que não ocorre a consistência do menu entre diferentes páginas, ou quando se utiliza novos menus no rodapé da página, sendo que em geral espera-se apenas por menus de repetição (WELIE, 2007b). Além disso, como foi utilizado JavaScript para extração dos valores referentes ao posicionamento dos links, os menus do tipo dropdown não podem ser classificados, pois em geral, apresentam valores negativos para a sua posição.

- O treinamento para o desenvolvimento do classificador, assim como a avaliação, foram realizados considerando-se apenas as páginas iniciais de cada site. Apesar da taxa de repetição de um link envolver a análise de diversas páginas de um mesmo domínio, os testes não avaliaram a performance do classificador nessas outras páginas.

- O padrão de navegação proposto apresentou um bom desempenho durante a interação com apoio do leitor de tela, porém, visto que nem sempre o classificador fornece resultados $100 \%$ corretos, é necessário uma análise mais minuciosa sobre os impactos gerados pela transformação automática do conteúdo. Além disso, torna-se necessário investigar qual o impacto cognitivo dessa transformação com base na interação de usuários reais.

- A abordagem para o modelo de interface proposto sugere a investigação de mecanismos para a extração automática de diferentes tipos de conteúdos, como o conteúdo principal e os formulários de busca de uma página. Porém, é necessário avaliar de maneira mais minuciosa as técnicas existentes, assim como os problemas que poderiam surgir devido ao uso destas técnicas.

\subsection{Trabalhos Futuros}

- Com base no mapeamento sistemático apresentado, pode-se pensar em elaborar categorias mais flexíveis para a organização do conteúdo encontrado. Nesse contexto, pode ser considerada uma abordagem com base na organização desse conteúdo segundo princípios de usabilidade.

- A elaboração de relações entre os problemas e diretrizes para usuários cegos pode contribuir para a compreensão dos conteúdos apresentados no mapeamento sistemático. A integração desse conteúdo com alguns exemplos práticos, encontrados em páginas Web, também se mostra interessante.

- Uma possível melhoria para o classificador desenvolvido seria integrar a árvore DOM gerada pelo navegador ao método proposto. Assim, uma análise posterior poderia refinar os resultados ao comparar os links de acordo com seu caminho na árvore. Por exemplo, 10 links classificados como Rodapé compartilhando o mesmo nó pai de outro link classificado como Conteúdo. Isso poderia ser mensurado de alguma forma para otimizar os resultados. 
- Pode-se integrar o classificador proposto com abordagens para automaticamente identificar menus dropdown, que atualmente não podem ser medidos devido a problemas na obtenção dos valores referentes à sua posição.

- A alteração na estrutura e agrupamento dos menus gera uma alteração na proposta inicial do desenvolvedor da página. Itens originalmente relacionados não necessariamente estarão aninhados no mesmo menu. É necessário investigar o impacto dessas mudanças do ponto de vista do usuário cego, através da interação com diversos exemplos de casos reais.

- O protótipo apresenta o comportamento esperado no leitor de tela, porém, o mesmo deve ser avaliado por usuários reais, visto que os cegos apresentam uma maneira própria de interpretar o conteúdo da página, e isso deve ser levado em consideração. 



\section{REFERÊNCIAS}

AIZPURUA, A.; ARRUE, M.; VIGO, M. Prejudices, memories, expectations and confidence influence experienced accessibility on the web. Computers in Human Behavior, v. 51, Part A, p. 152 - 160, 2015. ISSN 0747-5632. Disponível em: <http://www.sciencedirect.com/science/ article/pii/S0747563215003222>. Citado 2 vezes nas páginas 62 e 69.

AL-MOUH, N.; AL-KHALIFA, H. S.; TANIAR, D.; PARDEDE, E. Enhancing web accessibility by implementing context aware proxy. International Journal of Web Information Systems, Emerald Group Publishing Limited, v. 12, n. 2, 2016. Citado na página 29.

ALONSO, F.; FUERTES, J.; GONZÁLEZ, Á.; MARTÍNEZ, L. On the testability of wcag 2.0 for beginners. In: ACM. Proceedings of the 2010 International Cross Disciplinary Conference on Web Accessibility (W4A). [S.1.], 2010. p. 9. Citado 2 vezes nas páginas 26 e 43.

ANTONELLI, H. L.; FORTES, R. P. d. M. A support for developers implement the accessibility guidelines regarding to web menus. In: ACM. Proceedings of the 21st Brazilian Symposium on Multimedia and the Web. [S.1.], 2015. p. 33-40. Citado na página 72.

ASAKAWA, C.; LEPORINI, B. Screen readers. In: STEPHANIDIS, C. (Ed.). The Universal Access Handbook. [S.1.]: CRC Press, 2009. cap. 28, p. 1-17. Citado na página 48.

BABU, R.; SINGH, R. Evaluation of web accessibility and usability from blind user's perspective: The context of online assessment. AMCIS 2009 Proceedings, p. 623, 2009. Citado na página 48 .

BAVANI, R.; JAAFAR, A.; YATIM, N. A study on web experience among visually impaired users in malaysia. In: User Science and Engineering (i-USEr), 2010 International Conference on. [S.1.: s.n.], 2010. p. 11 -15. Citado 3 vezes nas páginas 60, 62 e 98 .

BÉLANGER, F.; CARTER, L. Trust and risk in e-government adoption. The Journal of Strategic Information Systems, Elsevier, v. 17, n. 2, p. 165-176, 2008. Citado na página 76.

BENAVÍDEZ, C.; FUERTES, J.; GUTIÉRREZ, E.; MARTÍNEZ, L. Semi-automatic evaluation of web accessibility with hera 2.0. Computers Helping People with Special Needs, Springer, p. 199-206, 2006. Citado na página 23 .

BHATIA, K. K.; DIXIT, A. et al. A novel design of hidden web crawler using ontology. arXiv preprint arXiv:1508.02127, 2015. Citado na página 100 .

BIGHAM, J.; LADNER, R. Accessmonkey: a collaborative scripting framework for web users and developers. In: ACM. Proceedings of the 2007 international cross-disciplinary conference on Web accessibility (W4A). [S.1.], 2007. p. 25-34. Citado na página 23.

BIGHAM, J. P.; CAVENDER, A. C. Evaluating existing audio captchas and an interface optimized for non-visual use. In: ACM. Proceedings of the SIGCHI Conference on Human Factors in Computing Systems. [S.1.], 2009. p. 1829-1838. Citado na página 59. 
BORODIN, Y.; BIGHAM, J. P.; DAUSCH, G.; RAMAKRISHNAN, I. More than meets the eye: a survey of screen-reader browsing strategies. In: ACM. Proceedings of the 2010 International Cross Disciplinary Conference on Web Accessibility (W4A). [S.1.], 2010. p. 13. Citado na página 68

BRAJNIK, G. Barrier walkthrough: Heuristic evaluation guided by accessibility barriers. [S.l.]: Tech. rept. Universita Degli Studi di Udine, Dipartimento di Matematica e Informatica, Via delle Scienze, 206, Rizzi 33100 Udine, Italy. http://users. dimi. uniud. it/ giorgio. brajnik/projects/bw/bw. html. Last Accessed 26th June, 2009. Citado 5 vezes nas páginas 58, 59, 61, 62 e 63.

BRAJNIK, G.; YESILADA, Y.; HARPER, S. Testability and validity of wcag 2.0: the expertise effect. In: ACM. Proceedings of the 12th international ACM SIGACCESS conference on Computers and accessibility. [S.1.], 2010. p. 43-50. Citado na página 43 .

BROWN, A.; JAY, C.; HARPER, S. Tailored presentation of dynamic web content for audio browsers. International Journal of Human-Computer Studies, v. 70, n. 3, p. 179 196, 2012. ISSN 1071-5819. Disponível em: <http://www.sciencedirect.com/science/article/pii/ S1071581911001443>. Citado na página 65.

BRUDVIK, J. T.; BIGHAM, J. P.; CAVENDER, A. C.; LADNER, R. E. Hunting for headings: sighted labeling vs. automatic classification of headings. In: Proceedings of the 10th international ACM SIGACCESS conference on Computers and accessibility. New York, NY, USA: ACM, 2008. (Assets '08), p. 201-208. ISBN 978-1-59593-976-0. Disponível em: <http://doi.acm.org/10.1145/1414471.1414508>. Citado na página 66

BURGET, R.; RUDOLFOVA, I. Web page element classification based on visual features. In: IEEE. Intelligent Information and Database Systems, 2009. ACIIDS 2009. First Asian Conference on. [S.1.], 2009. p. 67-72. Citado na página 75 .

BUZZI, M.; LEPORINI, B. Is wikipedia usable for the blind? In: Proceedings of the 2008 international cross-disciplinary conference on Web accessibility (W4A). New York, NY, USA: ACM, 2008. (W4A '08), p. 15-22. ISBN 978-1-60558-153-8. Disponível em: <http: //doi.acm.org/10.1145/1368044.1368049>. Citado 2 vezes nas páginas 64 e 65 .

BUZZI, M. C.; BUZZI, M.; LEPORINI, B.; AKHTER, F. Usability and accessibility of ebay by screen reader. Springer, 2009. Citado na página 62 .

BUZZI, M. C.; BUZZI, M.; LEPORINI, B.; MORI, G.; PENICHET, V. M. R. Accessing google docs via screen reader. In: Proceedings of the 12th international conference on Computers helping people with special needs: Part I. Berlin, Heidelberg: Springer-Verlag, 2010. (ICCHP'10), p. 92-99. ISBN 3-642-14096-3, 978-3-642-14096-9. Disponível em: $<$ http://dl.acm.org/citation.cfm?id=1886667.1886686> C Citado 3 vezes nas páginas 60, 65 e66

CALDWELL, B.; COOPER, M.; REID, L.; VANDERHEIDEN, G. Web content accessibility guidelines 2.0. W3C Recommendation, v. 11, 2008. Citado 3 vezes nas páginas 24, 26 e 67.

CALVO, R.; IGLESIAS, A.; MORENO, L. Accessibility barriers for users of screen readers in the moodle learning content management system. Univers. Access Inf. Soc., Springer-Verlag, Berlin, Heidelberg, v. 13, n. 3, p. 315-327, ago. 2014. ISSN 1615-5289. Disponível em: $<$ http: //dx.doi.org/10.1007/s10209-013-0314-3>. Citado 3 vezes nas páginas 60, 61 e 64. 
CANDAN, K. S.; DöNDERLER, M. E.; HEDGPETH, T.; KIM, J. W.; LI, Q.; SAPINO, M. L. Sea: Segment-enrich-annotate paradigm for adapting dialog-based content for improved accessibility. ACM Trans. Inf. Syst., ACM, New York, NY, USA, v. 27, n. 3, p. 15:1-15:45, maio 2009. ISSN 1046-8188. Disponível em: <http://doi.acm.org/10.1145/1508850.1508853>. Citado 3 vezes nas páginas 60,61 e 64 .

CASELLA, G.; BERGER, R. L. Statistical inference. [S.1.]: Duxbury Pacific Grove, CA, 2002. v. 2. Citado na página 78 .

CHAKRABARTI, D.; KUMAR, R.; PUNERA, K. A graph-theoretic approach to webpage segmentation. In: ACM. Proceedings of the 17th international conference on World Wide Web. [S.1.], 2008. p. 377-386. Citado na página 75.

CHANDRAN, D.; VIJENDRAN, A. S. A layout based detachment approach for extracting content from webpages. American Journal of Applied Sciences, Science Publications, v. 12, n. 6, p. 411, 2015. Citado na página 101.

CHISHOLM, W.; VANDERHEIDEN, G.; JACOBS, I. Web content accessibility guidelines 1.0. interactions, ACM, v. 8, n. 4, p. 35-54, 2001. Citado na página 24.

CIPOLLA-FICARRA, F. V. Quality and Communicability for Interactive Hypermedia Systems: Concepts and Practices for Design: Concepts and Practices for Design. [S.1.]: IGI Global, 2010. Citado 2 vezes nas páginas 27 e 48 .

COMMISSION, D. R. et al. The web: Access and inclusion for disabled people. London: TSO, 2004. Citado 2 vezes nas páginas 24 e 38.

CONNOR, J. O. Pro html5 accessibility: Building an inclusive web. Berkeley, CA: Apress, 2012. Citado 3 vezes nas páginas 35,44 e 46.

CRAIG, J.; SCHWERDTFEGER, I. R.; SEEMAN, L. Accessible rich internet applications (wai-aria) 1.0. 2008. Citado na página 67.

ENCELLE, B.; OLLAGNIER-BELDAME, M.; POUCHOT, S.; PRIÉ, Y. Annotation-based video enrichment for blind people: a pilot study on the use of earcons and speech synthesis. In: The proceedings of the 13th international ACM SIGACCESS conference on Computers and accessibility. New York, NY, USA: ACM, 2011. (ASSETS '11), p. 123-130. ISBN 978-14503-0920-2. Disponível em: <http://doi.acm.org/10.1145/2049536.2049560>. Citado 4 vezes nas páginas 28, $59,64 \mathrm{e} 66$.

FAYZRAKHMANOV, R.; GÖBEL, M.; HOLZINGER, W.; KRÜPL, B.; MAGER, A.; BAUMGARTNER, R. Modelling web navigation with the user in mind. In: ACM. Proceedings of the 2010 International Cross Disciplinary Conference on Web Accessibility (W4A). [S.1.], 2010. p. 14. Citado na página 28 .

FERATI, M.; RAUFI, B.; KURTI, A.; VOGEL, B. Accessibility requirements for blind and visually impaired in a regional context: An exploratory study. In: Usability and Accessibility Focused Requirements Engineering (UsARE), 2014 IEEE 2nd International Workshop on. [S.1.: s.n.], 2014. p. 13-16. Citado na página 69.

FERREIRA, S. B. L.; LEITE, J. C. S. d. P. Avaliação da usabilidade em sistemas de informação: o caso do sistema submarino. Revista de Administração Contemporânea, SciELO Brasil, v. 7, n. 2, p. 115-136, 2003. Citado na página 65. 
FERREIRA, S. B. L.; NUNES, R. R.; SILVEIRA, D. S. da. Aligning usability requirements with the accessibility guidelines focusing on the visually-impaired. Procedia Computer Science, v. 14, n. 0, p. $263-273,2012$. ISSN 1877-0509. <ce:title>Proceedings of the 4th International Conference on Software Development for Enhancing Accessibility and Fighting Info-exclusion (DSAI 2012)</ce:title> . Disponível em: <http://www.sciencedirect.com/science/ article/pii/S1877050912007922>. Citado 8 vezes nas páginas 58, 59, 60, 61, 63, 64, 65, e 66.

FOLEY, J. D. Computer Graphics: Principles and Practice. [S.1.]: Addison-Wesley Professional, 1996. v. 12110. Citado na página 64.

FRANCIS, H.; AL-JUMEILY, D.; LUND, T. O. A framework to support e-commerce development for people with visual impairment. In: IEEE. Developments in eSystems Engineering (DeSE), 2013 Sixth International Conference on. [S.1.], 2013. p. 335-341. Citado na página 66 .

FREIRE, A. P.; LINHALIS, F.; BIANCHINI, S. L.; FORTES, R. P.; PIMENTEL, M. da G. C. Revealing the whiteboard to blind students: An inclusive approach to provide mediation in synchronous e-learning activities. Computers \& Education, v. 54, n. 4, p. 866-876, 2010. ISSN 03601315. Disponível em: <http://www.sciencedirect.com/science/article/pii/S0360131509002565>. Citado na página 24.

FUGLERUD, K. S.; TJØSTHEIM, I.; GUNNARSSON, B. R.; TOLLEFSEN, M. Use of social media by people with visual impairments: usage levels, attitudes and barriers. In: Proceedings of the 13th international conference on Computers Helping People with Special Needs Volume Part I. Berlin, Heidelberg: Springer-Verlag, 2012. (ICCHP'12), p. 565-572. ISBN 9783-642-31521-3. Disponível em: <http://dx.doi.org/10.1007/978-3-642-31522-0_85>. Citado 2 vezes nas páginas $59 \mathrm{e} 63$.

GALLAGHER, B.; PETRIE, H. Initial results from a critical review of research on technology for older and disabled people. In: Proceedings of the 15th International ACM SIGACCESS Conference on Computers and Accessibility. New York, NY, USA: ACM, 2013. (ASSETS '13), p. 53:1-53:2. ISBN 978-1-4503-2405-2. Disponível em: <http://doi.acm.org/10.1145/ 2513383.2513417>. Citado 2 vezes nas páginas $23 \mathrm{e} 24$.

GHAHARI, R. R.; FERATI, M.; YANG, T.; BOLCHINI, D. Back navigation shortcuts for screen reader users. In: Proceedings of the 14th international ACM SIGACCESS conference on Computers and accessibility. New York, NY, USA: ACM, 2012. (ASSETS '12), p. 1-8. ISBN 978-1-4503-1321-6. Disponível em: <http://doi.acm.org/10.1145/2384916.2384918>. Citado 3 vezes nas páginas 63,67 e 68 .

GIRAUD, S.; COLOMBI, T.; RUSSO, A.; THÉROUANNE, P. Accessibility of rich internet applications for blind people: a study to identify the main problems and solutions. In: Proceedings of the 9th ACM SIGCHI Italian Chapter International Conference on Computer-Human Interaction: Facing Complexity. New York, NY, USA: ACM, 2011. (CHItaly), p. 163-166. ISBN 978-1-4503-0876-2. Disponível em: <http://doi.acm.org/10.1145/2037296.2037335>. Citado 4 vezes nas páginas 62, 63, 65, e66.

GIRAUD, S.; THÉROUANNE, P.; STEINER, D. D. Conceptualization of a technical solution for web navigation of visually impaired people. In: ACM. Proceedings of the 27th Conference on l'Interaction Homme-Machine. [S.1.], 2015. p. 24. Citado na página 29 
GOBLE, C.; HARPER, S.; STEVENS, R. The travails of visually impaired web travellers. In: ACM. Proceedings of the eleventh ACM on Hypertext and hypermedia. [S.1.], 2000. p. 1-10. Citado 2 vezes nas páginas $27 \mathrm{e} 50$.

GUERCIO, A.; STIRBENS, K.; WILLIAMS, J.; HAIBER, C. Addressing challenges in web accessibility for the blind and visually impaired. International Journal of Distance Education Technologies (IJDET), IGI Global, v. 9, n. 4, p. 1-13, 2011. Citado na página 29.

GUPTA, S.; KAISER, G.; NEISTADT, D.; GRIMM, P. Dom-based content extraction of html documents. In: ACM. Proceedings of the 12th international conference on World Wide Web. [S.1.], 2003. p. 207-214. Citado na página 75.

HAANPERä, T.; NIEMINEN, M. Usability of web search interfaces for blind users - a review of digital academic library user interfaces. In: Proceedings of the 7th International Conference on Universal Access in Human-Computer Interaction: Applications and Services for Quality of Life - Volume Part III. Berlin, Heidelberg: Springer-Verlag, 2013. (UAHCI'13), p. 321330. ISBN 978-3-642-39193-4. Disponível em: <http://dx.doi.org/10.1007/978-3-642-39194-1_ 38>. Citado 2 vezes nas páginas $70 \mathrm{e} 100$.

HANSON, V. L.; RICHARDS, J. T. Progress on website accessibility? ACM Transactions on the Web (TWEB), ACM, v. 7, n. 1, p. 2, 2013. Citado na página 23.

HARRISON, C.; PETRIE, H. Impact of usability and accessibility problems in e-commerce and e-government websites. In: Proceedings of HCI. [S.1.: s.n.], 2006. v. 1. Citado na página 50.

HOCHHEISER, H.; LAZAR, J. Revisiting breadth vs. depth in menu structures for blind users of screen readers. Interacting with Computers, v. 22, n. 5, p. 389 - 398, 2010. ISSN 0953-5438. $<$ ce:title $>$ Modelling user experience - An agenda for research and practice $</$ ce:title $>$. Disponível em: $<$ http://www.sciencedirect.com/science/article/pii/S0953543810000123>. Citado na página 68 .

ISLAM, M.; AHMED, F.; BORODIN, Y.; MAHMUD, J.; RAMAKRISHNAN, I. Improving accessibility of transaction-centric web objects. SDM, 2010. Citado na página 62 .

JAIN, A. K. Data clustering: 50 years beyond k-means. Pattern recognition letters, Elsevier, v. 31, n. 8, p. 651-666, 2010. Citado na página 102.

JEON, M.; WALKER, B. N. Spindex (speech index) improves auditory menu acceptance and navigation performance. ACM Trans. Access. Comput., ACM, New York, NY, USA, v. 3, n. 3, p. 10:1-10:26, abr. 2011. ISSN 1936-7228. Disponível em: <http://doi.acm.org/10.1145/ 1952383.1952385>. Citado 3 vezes nas páginas 66, 68, e 72 .

KANE, S.; SHULMAN, J.; SHOCKLEY, T.; LADNER, R. A web accessibility report card for top international university web sites. In: ACM. Proceedings of the 2007 international cross-disciplinary conference on Web accessibility (W4A). [S.1.], 2007. p. 148-156. Citado 2 vezes nas páginas $23 \mathrm{e} 24$.

KIRSCH, N.; SHENTON, M.; SPIRL, E.; ROWAN, J.; SIMPSON, R.; SCHRECKENGHOST, D.; LOPRESTI, E. Web-based assistive technology interventions for cognitive impairments after traumatic brain injury: A selective review and two case studies. Rehabilitation psychology, Educational Publishing Foundation, v. 49, n. 3, p. 200, 2004. Citado na página 23. 
KITCHENHAM, B. A.; CHARTERS, S. Guidelines for performing systematic literature reviews in software engineering. 2007. Citado na página 53 .

KRASNER, G. E.; POPE, S. T. et al. A description of the model-view-controller user interface paradigm in the smalltalk- 80 system. Journal of object oriented programming, v. 1, n. 3, p. 26-49, 1988. Citado na página 45.

KUBER, R. Developing an assistive haptic framework for improving non-visual access to the web. ACM SIGACCESS Accessibility and Computing, ACM, n. 86, p. 16-19, 2006. Citado na página 23 .

LAZAR, J.; ALLEN, A.; KLEINMAN, J.; MALARKEY, C. What frustrates screen reader users on the web: A study of 100 blind users. International Journal of human-computer interaction, Taylor \& Francis, v. 22, n. 3, p. 247-269, 2007. Citado na página 48.

LEAVITT, M. O.; SHNEIDERMAN, B. Research-based web design \& usability guidelines. US Department of Health and Human Services, 2006. Citado na página 26.

LEE, J. C.; HENSCHEN, L. J. On the need for assistance in html5 web authoring systems. In: Universal Access in Human-Computer Interaction. Access to Today's Technologies. [S.1.]: Springer, 2015. p. 213-220. Citado 2 vezes nas páginas 72 e 93.

LEPORINI, B.; ANDRONICO, P.; BUZZI, M. Designing search engine user interfaces for the visually impaired. In: ACM. Proceedings of the 2004 international cross-disciplinary workshop on Web accessibility (W4A). [S.1.], 2004. p. 57-66. Citado na página 100.

LEPORINI, B.; PATERNÒ, F. Applying web usability criteria for vision-impaired users: does it really improve task performance? Intl. Journal of Human-Computer Interaction, Taylor \& Francis, v. 24, n. 1, p. 17-47, 2008. Citado 4 vezes nas páginas 26, 44, 61 e 65.

LEUTHOLD, S.; BARGAS-AVILA, J. A.; OPWIS, K. Beyond web content accessibility guidelines: Design of enhanced text user interfaces for blind internet users. International Journal of Human-Computer Studies, v. 66, n. 4, p. 257 - 270, 2008. ISSN 1071-5819. Disponível em: $<$ http://www.sciencedirect.com/science/article/pii/S1071581907001413>. Citado 8 vezes nas páginas 26, 28, 44, 60, 62, 64, 66, e 72.

LIN, S.-H.; HO, J.-M. Discovering informative content blocks from web documents. In: ACM. Proceedings of the eighth ACM SIGKDD international conference on Knowledge discovery and data mining. [S.1.], 2002. p. 588-593. Citado na página 75.

LOPES, R.; GOMES, D.; CARRIÇO, L. Web not for all: A large scale study of web accessibility. In: ACM. Proceedings of the 2010 International Cross Disciplinary Conference on Web Accessibility (W4A). [S.1.], 2010. p. 10. Citado 3 vezes nas páginas 24, 26 e 43.

LUNN, D.; HARPER, S.; BECHHOFER, S. Identifying behavioral strategies of visually impaired users to improve access to web content. ACM Trans. Access. Comput., ACM, New York, NY, USA, v. 3, n. 4, p. 13:1-13:35, abr. 2011. ISSN 1936-7228. Disponível em: <http://doi.acm.org/ 10.1145/1952388.1952390>, Citado 3 vezes nas páginas 62, 66 e 72 .

MELO, A. R.; SOARES, M. M.; CAMPOS, F.; CORREIA, W. Ergonomic evaluation of websites focusing on the human-computer interface so as to improve access to the web especially by people with visual disabilities. In: Design, User Experience, and Usability. Web, Mobile, and Product Design. [S.1.]: Springer, 2013. p. 257-264. Citado na página 65. 
MILLER, G. A. The magical number seven, plus or minus two: some limits on our capacity for processing information. Psychological review, American Psychological Association, v. 63, n. 2, p. 81,1956 . Citado na página 66 .

MORASH, V. S.; SIU, Y.-T.; MIELE, J. A.; HASTY, L.; LANDAU, S. Guiding novice web workers in making image descriptions using templates. ACM Transactions on Accessible Computing (TACCESS), ACM, v. 7, n. 4, p. 12, 2015. Citado na página 59.

PEREIRA, L. S.; FERREIRA, S. B. L.; ARCHAMBAULT, D. Preliminary web accessibility evaluation method through the identification of critical items with the participation of visually impaired users. Procedia Computer Science, Elsevier, v. 67, p. 77-86, 2015. Citado 4 vezes nas páginas 59, 60, $63, \mathrm{e} 64$.

PEREIRA, L. S.; FERREIRA, S. B. L.; BRAGA, H.; SALGADO, L. C. de C.; NUNES, R. R. Using cultural viewpoint metaphors to provide web accessibility for the visually impaired users. Procedia Computer Science, Elsevier, v. 27, p. 186-196, 2014. Citado 2 vezes nas páginas 59 e 60.

PETRIE, H.; HAMILTON, F.; KING, N. Tension, what tension?: Website accessibility and visual design. In: ACM. Proceedings of the 2004 international cross-disciplinary workshop on Web accessibility (W4A). [S.1.], 2004. p. 13-18. Citado 4 vezes nas páginas 26, 28, 53 e 93

PETRIE, H.; KHEIR, O. The relationship between accessibility and usability of websites. In: Proceedings of the SIGCHI Conference on Human Factors in Computing Systems. New York, NY, USA: ACM, 2007. (CHI '07), p. 397-406. ISBN 978-1-59593-593-9. Disponível em: <http://doi.acm.org/10.1145/1240624.1240688>. Citado na página 38.

PETRIE, H.; KING, N.; VELASCO, C.; GAPPA, H.; NORDBROCK, G. The usability of accessibility evaluation tools. Universal Access in Human-Computer Interaction. Applications and Services, Springer, p. 124-132, 2007. Citado na página 23.

PETRIE, H.; POWER, C.; SWALLOW, D.; VELASCO, C.; GALLAGHER, B.; MAGENNIS, M.; MURPHY, E.; COLLIN, S.; DOWN, K. The value chain for web accessibility: challenges and opportunities. Proceedings of the Workshop on Accessible Design in the Digital World 2011, 2011. Citado na página 43 .

POLSON, P. G.; LEWIS, C.; RIEMAN, J.; WHARTON, C. Cognitive walkthroughs: a method for theory-based evaluation of user interfaces. International Journal of man-machine studies, Elsevier, v. 36, n. 5, p. 741-773, 1992. Citado na página 105.

PORTA, M.; RAVELLI, A. Weyeb, an eye-controlled web browser for hands-free navigation. In: IEEE. Human System Interactions, 2009. HSI'09. 2nd Conference on. [S.1.], 2009. p. 210-215. Citado na página 23.

POWER, C.; FREIRE, A.; PETRIE, H.; SWALLOW, D. Guidelines are only half of the story: accessibility problems encountered by blind users on the web. In: Proceedings of the SIGCHI Conference on Human Factors in Computing Systems. New York, NY, USA: ACM, 2012. (CHI '12), p. 433-442. ISBN 978-1-4503-1015-4. Disponível em: <http://doi.acm.org/10.1145/ 2207676.2207736>. Citado 12 vezes nas páginas 24, 26, 28, 50, 51, 53, 60, 61, 62, 68, 93 e 98 ,

PUZIS, Y.; BORODIN, E.; AHMED, F.; MELNYK, V.; RAMAKRISHNAN, I. V. Guidelines for an accessible web automation interface. In: The proceedings of the 13th international ACM SIGACCESS conference on Computers and accessibility. New York, NY, USA: ACM, 2011. 
(ASSETS '11), p. 249-250. ISBN 978-1-4503-0920-2. Disponível em: <http://doi.acm.org/10. 1145/2049536.2049591>. Citado na página 62 .

RØMEN, D.; SVANÆS, D. Evaluating web site accessibility: validating the wai guidelines through usability testing with disabled users. In: ACM. Proceedings of the 5th Nordic conference on Human-computer interaction: building bridges. [S.1.], 2008. p. 535-538. Citado na página 50 .

RUTH-JANNECK, D. An integrative accessibility engineering approach using multidimensional classifications of barriers in the web. In: Proceedings of the International Cross-Disciplinary Conference on Web Accessibility. New York, NY, USA: ACM, 2011. (W4A '11), p. 10:1-10:7. ISBN 978-1-4503-0476-4. Disponível em: <http://doi.acm.org/10.1145/1969289.1969303>. Citado na página 61 .

SANTOS, E. P. dos; LARA, S. M. de; WATANABE, W. M.; FILHO, M. C.; FORTES, R. P. Usability evaluation of horizontal navigation bar with drop-down menus by middle aged adults. In: Proceedings of the 29th ACM international conference on Design of communication. New York, NY, USA: ACM, 2011. (SIGDOC '11), p. 145-150. ISBN 978-1-4503-0936-3. Disponível em: <http://doi.acm.org/10.1145/2038476.2038504>. Citado na página 24.

SARIDIS, G. Parameter estimation: Principles and problems. Automatic Control, IEEE Transactions on, IEEE, v. 28, n. 5, p. 634-635, 1983. Citado na página 78.

SAVIDIS, A.; STEPHANIDIS, C. The homer uims for dual user interface development: Fusing visual and non-visual interactions. Interacting with Computers, Elsevier, v. 11, n. 2, p. 173209, 1998. Citado na página 24.

SERVICES, H.; ADMINISTRATION, U. S. G. S. Research-based web design \& usability guidelines. [S.1.]: United States Govt Printing Office, 2006. Citado na página 43.

SINGH, B.; SINGH, H. K. Web data mining research: a survey. In: IEEE. Computational Intelligence and Computing Research (ICCIC), 2010 IEEE International Conference on. [S.1.], 2010. p. 1-10. Citado 2 vezes nas páginas 93 e 101.

SNEDEGOR, G.; COCHRAN, W. G. Statistical methods. Statistical methods., Ames: Iowa State University Press., n. 8th ed, 1989. Citado na página 79.

SONG, D.; SUN, F.; LIAO, L. A hybrid approach for content extraction with text density and visual importance of dom nodes. Knowledge and Information Systems, Springer, v. 42, n. 1, p. 75-96, 2015. Citado 2 vezes nas páginas $75 \mathrm{e} 101$.

THATCHER, J.; WADDELL, C. Constructing accessible websites. [S.1.]: APress LP, 2003. Citado na página 23.

TRIPP, D. Pesquisa-ação: uma introdução metodológica. Educação e pesquisa, SciELO Brasil, v. 31, n. 3, p. 443-466, 2005. Citado na página 29.

VIGO, M.; HARPER, S. Coping tactics employed by visually disabled users on the web. International Journal of Human-Computer Studies, v. 71, n. 11, p. 1013 - 1025, 2013. ISSN 10715819. Disponível em: <http://www.sciencedirect.com/science/article/pii/S1071581913001006>. Citado 4 vezes nas páginas 27, 28, 53, e 69. 
VOYKINSKA, V.; AZENKOT, S.; WU, S.; LESHED, G. How blind people interact with visual content on social networking services. Proceedings of CSCW 2016 (to appear), 2016. Citado na página 28 .

W3C. Web Content Accessibility Guidelines 1.0. 1999. Disponível em: <https://www.w3.org/ TR/WCAG10/>. Acesso em: 13 fev. 2013. Citado 2 vezes nas páginas 34 e 36.

. Authoring Tool Accessibility Guidelines 1.0. 2000. Disponível em: $<$ https://www.w3. org/TR/2000/REC-ATAG10-20000203/>. Acesso em: 06 jan. 2016. Citado na página 34.

User Agent Accessibility Guidelines 1.0. 2002. Disponível em: <https://www.w3.org/ TR/UAAG10/>. Acesso em: 06 jan. 2016. Citado na página 34.

Introduction to Web Accessibility. 2005. Disponível em: <https://www.w3.org/WAI/ intro/accessibility.php>. Acesso em: 28 mai. 2014. Citado na página 33 .

Web Content Accessibility Guidelines 2.0. 2008. Disponível em: <https://www.w3.org/ TR/WCAG20/>. Acesso em: 08 mar. 2016. Citado 3 vezes nas páginas 34, 39 e 112.

How People with Disabilities Use the Web: Overview. 2012. Disponível em: $<$ https: //www.w3.org/WAI/intro/people-use-web/>. Acesso em: 17 set. 2014. Citado na página 50.

. HTML Microdata. 2013. Disponível em: <https://www.w3.org/TR/microdata/>. Acesso em: 18 mar. 2015. Citado na página 72 .

Accessible Rich Internet Applications (WAI-ARIA) 1.0. 2014. Disponível em: $<$ https: //Www.w3.org/TR/wai-aria/>. Acesso em: 18 mar. 2015. Citado 3 vezes nas páginas 34,72 $\mathrm{e} 101$

HTML5. 2014. Disponível em: <https://www.w3.org/TR/html/>, Acesso em: 18 mar. 2015. Citado na página 71

Authoring Tool Accessibility Guidelines 2.0. 2015. Disponível em: $<$ https://www.w3. org/TR/ATAG20/>. Acesso em: 06 jan. 2016. Citado na página 34 .

Page Sections - Page Structure - WAI Web Accessibility Tutorials. 2015. Disponível em: <https://www.w3.org/TR/html/>, Acesso em: 03 ago. 2015. Citado na página 94.

. User Agent Accessibility Guidelines 2.0. 2015. Disponível em: <https://www.w3.org/ TR/UAAG20/>. Acesso em: 06 jan. 2016. Citado na página 34.

WAI Guidelines and Techniques. 2015. Disponível em: <https://www.w3.org/WAI/ guid-tech.html>. Acesso em: 24 mar. 2016. Citado na página 33.

. Accessible Rich Internet Applications (WAI-ARIA) 1.1. 2016. Disponível em: <https: //www.w3.org/TR/wai-aria-1.1/>. Acesso em: 5 abr. 2016. Citado na página 47.

Assistive Technologies - Accessible Rich Internet Applications (WAI-ARIA) 1.1. 2016. Disponível em: <https://www.w3.org/TR/wai-aria-1.1/\#dfn-assistive-technologies $>$. Acesso em: 15 abr. 2016. Citado na página 35.

Introduction I Accessible Rich Internet Applications (WAI-ARIA) 1.0. 2016. Dispo-

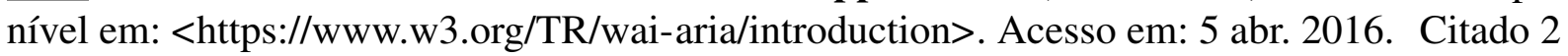
vezes nas páginas $45 \mathrm{e} 46$. 
. WAI-ARIA Overview. 2016. Disponível em: <https://www.w3.org/WAI/intro/aria.php $>$. Acesso em: 18 fev. 2016. Citado 3 vezes nas páginas 34,44 e 112.

Web Accessibility Initiative (WAI). 2016. Disponível em: <https://www.w3.org/WAI/>. Acesso em: 08 abr. 2016. Citado na página 33.

WATANABE, W.; JUNIOR, A.; UZÊDA, V.; FORTES, R.; PARDO, T.; ALUÍSIO, S. Facilita: reading assistance for low-literacy readers. In: ACM. Proceedings of the 27th ACM international conference on Design of communication. [S.1.], 2009. p. 29-36. Citado na página 24.

WATANABE, W. M.; CANDIDO, J. A.; AMÂNCIO, M. A.; de Oliveira, M.; PARDO, T. A. S.; FORTES, R. P. M.; ALUÍSIO, S. M. Adapting web content for low-literacy readers by using lexical elaboration and named entities labeling. In: Proceedings of the 2010 International Cross Disciplinary Conference on Web Accessibility (W4A). New York, NY, USA: ACM, 2010. (W4A '10), p. 8:1-8:9. ISBN 978-1-4503-0045-2. Disponível em: $<$ http://doi.acm.org/10. 1145/1805986.1805998>, Citado na página 24.

WATANABE, W. M.; GERALDO, R. J.; FORTES, R. P. D. M. Keyboard navigation mechanisms in widgets: an investigation on aria's implementations. Journal of Web Engineering, Rinton Press, Incorporated, v. 14, n. 1-2, p. 41-62, 2015. Citado 2 vezes nas páginas 72 e 93.

WATANABE, W. M.; GERALDO, R. J.; FORTES, R. P. de M. Keyboard navigation mechanisms in tab widgets: an investigation on aria's conformance. In: ACM. Proceedings of the 29th Annual ACM Symposium on Applied Computing. [S.1.], 2014. p. 721-726. Citado na página 93.

WELIE, M. van. Main Navigation - Interaction Design Pattern Library. 2007. Disponível em: <http://www.welie.com/patterns/showPattern.php?patternID=main-navigation/>. Acesso em: 20 fev. 2014. Citado 2 vezes nas páginas 73 e 74.

Repeated Menu - Interaction Design Pattern Library. 2007. Disponível em: $<\mathrm{http:}$ //www.welie.com/patterns/showPattern.php?patternID=repeated-menu>. Acesso em: $20 \mathrm{fev}$. 2014. Citado 2 vezes nas páginas 96 e 114.

YALLA, P.; WALKER, B. N. Advanced auditory menus: design and evaluation of auditory scroll bars. In: Proceedings of the 10th international ACM SIGACCESS conference on Computers and accessibility. New York, NY, USA: ACM, 2008. (Assets '08), p. 105-112. ISBN 978-1-59593-976-0. Disponível em: <http://doi.acm.org/10.1145/1414471.1414492>. Citado 2 vezes nas páginas $68 \mathrm{e} 72$.

YANG, Y.; ZHANG, H. Html page analysis based on visual cues. In: IEEE. Document Analysis and Recognition, 2001. Proceedings. Sixth International Conference on. [S.1.], 2001. p. 859864. Citado na página 71 .

YESILADA, Y.; HARPER, S.; GOBLE, C.; STEVENS, R. Screen readers cannot see. In: Web Engineering. [S.1.]: Springer, 2004. p. 445-458. Citado 2 vezes nas páginas 27 e 51.

YI, L.; LIU, B.; LI, X. Eliminating noisy information in web pages for data mining. In: ACM. Proceedings of the ninth ACM SIGKDD international conference on Knowledge discovery and data mining. [S.1.], 2003. p. 296-305. Citado na página 75.

ZHANG, H. The optimality of naive bayes. AA, v. 1, n. 2, p. 3, 2004. Citado na página 77 
ZHANG, X.; ZHANG, Y.; HE, J.; COBIA, F. Vision-based web page block segmentation and informative block detection. In: IEEE. Web Intelligence (WI) and Intelligent Agent Technologies (IAT), 2013 IEEE/WIC/ACM International Joint Conferences on. [S.1.], 2013. v. 3, p. 265-269. Citado na página 75 .

ZHANG, Z.; HE, B.; CHANG, K. C.-C. Understanding web query interfaces: Best-effort parsing with hidden syntax. In: ACM. Proceedings of the 2004 ACM SIGMOD international conference on Management of data. [S.1.], 2004. p. 107-118. Citado na página 100.

ZHAO, H.; PLAISANT, C.; SHNEIDERMAN, B.; LAZAR, J. Data sonification for users with visual impairment: A case study with georeferenced data. ACM Trans. Comput.-Hum. Interact., ACM, New York, NY, USA, v. 15, n. 1, p. 4:1-4:28, maio 2008. ISSN 1073-0516. Disponível em: <http://doi.acm.org/10.1145/1352782.1352786>. Citado 4 vezes nas páginas $28,61,64,66$. 

APÊNDICE

\section{A}

\section{TESTES CLASSIFICADOR}

\section{A.1 Resultados da Avaliação do Classificador}

\section{A.1.1 previdencia.gov.br}

\begin{tabular}{lllll}
\hline Repetição & Dist. Topo & Dist. Esquerda & Classe & Resultado \\
\hline 0.846153846 & 0.06725030 & 0.40886203 & MenuSuperior & MenuSuperior \\
0.838461538 & 0.02586550 & 0.68882175 & MenuSuperior & MenuSuperior \\
0.838461538 & 0.02586550 & 0.90634441 & MenuSuperior & MenuSuperior \\
0.838461538 & 0.06725030 & 0.49345418 & MenuSuperior & MenuSuperior \\
0.838461538 & 0.06725030 & 0.58710977 & MenuSuperior & MenuSuperior \\
0.838461538 & 0.06725030 & 0.73514602 & MenuSuperior & MenuSuperior \\
0.838461538 & 0.06725030 & 0.80362538 & MenuSuperior & MenuSuperior \\
0.846153846 & 0.06725030 & 0.91238671 & MenuSuperior & MenuSuperior \\
0.838461538 & 0.10465579 & 0.01611279 & LateralEsquerdo & LateralEsquerdo \\
0.846153846 & 0.11818544 & 0.01611279 & LateralEsquerdo & LateralEsquerdo \\
0.846153846 & 0.13131715 & 0.01611279 & LateralEsquerdo & LateralEsquerdo \\
0.838461538 & 0.14484680 & 0.01611279 & LateralEsquerdo & LateralEsquerdo \\
0.846153846 & 0.16593713 & 0.01611279 & LateralEsquerdo & LateralEsquerdo \\
0.846153846 & 0.17906884 & 0.01611279 & LateralEsquerdo & LateralEsquerdo \\
0.838461538 & 0.20015917 & 0.01611279 & LateralEsquerdo & LateralEsquerdo \\
0.846153846 & 0.22881019 & 0.01611279 & LateralEsquerdo & LateralEsquerdo
\end{tabular}




\begin{tabular}{|c|c|c|c|c|}
\hline Repetição & Dist. Topo & Dist. Esquerda & Classe & Resultado \\
\hline 0.846153846 & 0.24194190 & 0.01611279 & LateralEsquerdo & LateralEsquerdo \\
\hline 0.846153846 & 0.25547155 & 0.01611279 & LateralEsquerdo & LateralEsquerdo \\
\hline 0.846153846 & 0.25547155 & 0.01611279 & LateralEsquerdo & LateralEsquerdo \\
\hline 0.846153846 & 0.33306805 & 0.01611279 & LateralEsquerdo & LateralEsquerdo \\
\hline 0.846153846 & 0.33306805 & 0.01611279 & LateralEsquerdo & LateralEsquerdo \\
\hline 0.838461538 & 0.34659769 & 0.01611279 & LateralEsquerdo & LateralEsquerdo \\
\hline 0.846153846 & 0.36012734 & 0.01611279 & LateralEsquerdo & LateralEsquerdo \\
\hline 0.838461538 & 0.38081974 & 0.01611279 & LateralEsquerdo & LateralEsquerdo \\
\hline 0.846153846 & 0.42339833 & 0.01611279 & LateralEsquerdo & LateralEsquerdo \\
\hline 0.838461538 & 0.44409073 & 0.01611279 & LateralEsquerdo & LateralEsquerdo \\
\hline 0.846153846 & 0.47274174 & 0.01611279 & LateralEsquerdo & LateralEsquerdo \\
\hline 0.838461538 & & 0.01611279 & LateralEsquerdo & LateralEsquerdo \\
\hline 0.846153846 & 0.51452447 & 0.01611279 & LateralEsquerdo & LateralEsquerdo \\
\hline 0.846153846 & 0.53561480 & 0.01611279 & LateralEsquerdo & LateralEsquerdo \\
\hline 0.838461538 & 0.60604855 & 0.01611279 & LateralEsquerdo & LateralEsquerdo \\
\hline 0.838461538 & 0.60604855 & 0.016 & LateralEsquerdo & LateralEsquerdo \\
\hline 0.838461538 & 0.62674095 & 0.01611279 & LateralEsquerdo & LateralEsquerdo \\
\hline 0.838461538 & 0.64027059 & 0.01611279 & LateralEsquerdo & LateralEsquerdo \\
\hline 0.838461538 & 0.65340231 & 0.01611279 & LateralEsquerdo & LateralEsquerdo \\
\hline 0.838461538 & 0.66693195 & 0.01611279 & LateralEsquerdo & LateralEsquerdo \\
\hline 0.838461538 & 0.68802228 & 0.01611279 & LateralEsquerdo & LateralEsquerdo \\
\hline 0.838461538 & 0.70115400 & 0.01611279 & LateralEsquerdo & LateralEsquerdo \\
\hline 0.838461538 & 0.72224433 & 0.01611279 & LateralEsquerdo & LateralEsquerdo \\
\hline 0.838461538 & 0.73537604 & 0.01611279 & LateralEsquerdo & LateralEsquerdo \\
\hline 0.838461538 & 0.75646638 & 0.01611279 & LateralEsquerdo & LateralEsquerdo \\
\hline 0.007692308 & 0.78790291 & 0.22759315 & Conteudo & Conteudo \\
\hline 0.007692308 & 0.86748906 & 0.22759315 & Conteudo & Conteudo \\
\hline 0.007692308 & 0.86748906 & 0.48942598 & Conteudo & Conteudo \\
\hline 0.007692308 & 0.86748906 & 0.75125881 & Conteudo & Conteudo \\
\hline 0.846153846 & 0.07799443 & 0.86706949 & Conteudo & MenuSuperior \\
\hline 0.838461538 & 0.08873856 & 0.75125881 & Conteudo & MenuSuperior \\
\hline
\end{tabular}




\begin{tabular}{lllll}
\hline Repetição & Dist. Topo & Dist. Esquerda & Classe & Resultado \\
\hline 0.030769231 & 0.39076801 & 0.23464250 & Conteudo & Conteudo \\
0.030769231 & 0.43454039 & 0.23464250 & Conteudo & Conteudo \\
0.030769231 & 0.46836450 & 0.23464250 & Conteudo & Conteudo \\
0.030769231 & 0.50258655 & 0.23464250 & Conteudo & Conteudo \\
0.030769231 & 0.53680859 & 0.23464250 & Conteudo & Conteudo \\
0.046153846 & 0.57103064 & 0.23464250 & Conteudo & Conteudo \\
0.030769231 & 0.60525269 & 0.23464250 & Conteudo & Conteudo \\
0.723076923 & 0.62554716 & 0.22759315 & Conteudo & LateralEsquerdo \\
0.846153846 & 0.92837246 & 0.02719033 & Rodape & Rodape \\
0.846153846 & 0.93752487 & 0.02719033 & Rodape & Rodape \\
0.838461538 & 0.94707521 & 0.02719033 & Rodape & Rodape \\
0.846153846 & 0.95662555 & 0.02719033 & Rodape & Rodape \\
0.846153846 & 0.96577795 & 0.02719033 & Rodape & Rodape \\
0.738461538 & 0.92837246 & 0.25780463 & Rodape & Rodape \\
0.838461538 & 0.93752487 & 0.25780463 & Rodape & Rodape \\
0.846153846 & 0.94707521 & 0.25780463 & Rodape & Rodape \\
0.838461538 & 0.95662555 & 0.25780463 & Rodape & Rodape \\
0.838461538 & 0.96577795 & 0.25780463 & Rodape & Rodape \\
0.723076923 & 0.97532829 & 0.25780463 & Rodape & Rodape \\
0.730769231 & 0.92837246 & 0.71802618 & Rodape & Rodape \\
0.738461538 & 0.95503382 & 0.71802618 & Rodape & Rodape \\
0.838461538 & 0.96458416 & 0.71802618 & Rodape & Rodape \\
\hline
\end{tabular}

\section{A.1.2 fundacentro.gov.br}

\begin{tabular}{lllll}
\hline Repetição & Dist. Topo & Dist. Esquerda & Classe & Resultado \\
\hline 0.885558583 & 0.05752004 & 0.07014218 & MenuSuperior & MenuSuperior \\
0.885558583 & 0.05752004 & 0.23222749 & MenuSuperior & MenuSuperior \\
0.885558583 & 0.05752004 & 0.33744076 & MenuSuperior & MenuSuperior \\
0.885558583 & 0.05752004 & 0.41706161 & MenuSuperior & MenuSuperior \\
0.885558583 & 0.05752004 & 0.48056872 & MenuSuperior & MenuSuperior \\
0.885558583 & 0.05752004 & 0.60758294 & MenuSuperior & MenuSuperior \\
0.885558583 & 0.05752004 & 0.74881517 & MenuSuperior & MenuSuperior \\
0.885558583 & 0.05752004 & 0.83791469 & MenuSuperior & MenuSuperior
\end{tabular}




\begin{tabular}{lllll}
\hline Repetição & Dist. Topo & Dist. Esquerda & Classe & Resultado \\
\hline 0.005449591 & 0.10372466 & 0.73459716 & LateralDireito & Conteudo \\
0.005449591 & 0.14285714 & 0.73459716 & LateralDireito & Conteudo \\
0.888283379 & 0.12305516 & 0.73459716 & LateralDireito & MenuSuperior \\
0.885558583 & 0.19519095 & 0.01895735 & Conteudo & LateralEsquerdo \\
0.005449591 & 0.22489392 & 0.33175355 & Conteudo & Conteudo \\
0.005449591 & 0.25601132 & 0.33175355 & Conteudo & Conteudo \\
0.005449591 & 0.28712871 & 0.33175355 & Conteudo & Conteudo \\
0.885558583 & 0.21829326 & 0.74407583 & LateralDireito & MenuSuperior \\
0.002724796 & 0.19613390 & 0.71090047 & LateralDireito & Conteudo \\
0.885558583 & 0.23102310 & 0.74407583 & LateralDireito & LateralDireito \\
0.002724796 & 0.25365394 & 0.71090047 & LateralDireito & Conteudo \\
0.885558583 & 0.27581330 & 0.74407583 & LateralDireito & LateralDireito \\
0.885558583 & 0.28854314 & 0.74407583 & LateralDireito & LateralDireito \\
0.005449591 & 0.29278642 & 0.02369668 & Conteudo & Conteudo \\
0.002724796 & 0.32201792 & 0.01895735 & Conteudo & Conteudo \\
0.885558583 & 0.19519095 & 0.01895735 & Conteudo & LateralEsquerdo \\
0.885558583 & 0.39839698 & 0.01895735 & Conteudo & LateralEsquerdo \\
0.885558583 & 0.39839698 & 0.48720379 & Conteudo & Conteudo \\
0.008174387 & 0.41819896 & 0.16587678 & Conteudo & Conteudo \\
0.885558583 & 0.46440358 & 0.41516588 & Conteudo & LateralEsquerdo \\
0.885558583 & 0.47194719 & 0.87582938 & Conteudo & LateralDireito \\
0.885558583 & 0.50966525 & 0.01895735 & Conteudo & LateralEsquerdo \\
0.885558583 & 0.54031117 & 0.01895735 & Conteudo & LateralEsquerdo \\
0.002724796 & 0.50966525 & 0.25308057 & Conteudo & Conteudo \\
0.888283379 & 0.54832626 & 0.25308057 & Conteudo & LateralEsquerdo \\
0.885558583 & 0.52805280 & 0.50142180 & Conteudo & Conteudo \\
0.885558583 & 0.54219708 & 0.50142180 & Conteudo & Conteudo \\
0.885558583 & 0.55634135 & 0.50142180 & Conteudo & Conteudo \\
0.885558583 & 0.52805280 & 0.64739336 & Conteudo & LateralDireito \\
0.885558583 & 0.55634135 & 0.64739336 & Conteudo & LateralDireito
\end{tabular}




\begin{tabular}{lllll}
\hline Repetição & Dist. Topo & Dist. Esquerda & Classe & Resultado \\
\hline 0.885558583 & 0.52522395 & 0.79336493 & Conteudo & LateralDireito \\
0.888283379 & 0.54691183 & 0.79336493 & Conteudo & LateralDireito \\
0.885558583 & 0.59783121 & 0.01895735 & Rodape & LateralEsquerdo \\
0.885558583 & 0.61150401 & 0.01990521 & Rodape & LateralEsquerdo \\
0.885558583 & 0.61810467 & 0.01990521 & Rodape & LateralEsquerdo \\
0.885558583 & 0.63083451 & 0.01990521 & Rodape & LateralEsquerdo \\
0.885558583 & 0.63743517 & 0.01990521 & Rodape & LateralEsquerdo \\
0.888283379 & 0.64356436 & 0.01990521 & Rodape & LateralEsquerdo \\
0.885558583 & 0.65016502 & 0.01990521 & Rodape & LateralEsquerdo \\
0.885558583 & 0.66289486 & 0.01990521 & Rodape & LateralEsquerdo \\
0.885558583 & 0.66949552 & 0.01990521 & Rodape & LateralEsquerdo \\
0.885558583 & 0.67562471 & 0.01990521 & Rodape & LateralEsquerdo \\
0.885558583 & 0.68222536 & 0.01990521 & Rodape & LateralEsquerdo \\
0.885558583 & 0.68882603 & 0.01990521 & Rodape & LateralEsquerdo \\
0.885558583 & 0.69495521 & 0.01990521 & Rodape & LateralEsquerdo \\
0.885558583 & 0.70155587 & 0.01990521 & Rodape & LateralEsquerdo \\
0.885558583 & 0.70815653 & 0.01990521 & Rodape & LateralEsquerdo \\
0.885558583 & 0.71428571 & 0.01990521 & Rodape & LateralEsquerdo \\
0.885558583 & 0.72701556 & 0.01990521 & Rodape & LateralEsquerdo \\
0.885558583 & 0.74021688 & 0.01990521 & Rodape & LateralEsquerdo \\
0.885558583 & 0.75294672 & 0.01990521 & Rodape & LateralEsquerdo \\
0.885558583 & 0.60490335 & 0.17156398 & Rodape & LateralEsquerdo \\
0.885558583 & 0.61150401 & 0.17156398 & Rodape & LateralEsquerdo \\
0.885558583 & 0.61810467 & 0.17156398 & Rodape & LateralEsquerdo \\
0.885558583 & 0.62423385 & 0.17156398 & Rodape & LateralEsquerdo \\
0.885558583 & 0.63083451 & 0.17156398 & Rodape & LateralEsquerdo \\
0.885558583 & 0.64262140 & 0.17156398 & Rodape & LateralEsquerdo \\
0.888283379 & 0.64875059 & 0.17156398 & Rodape & LateralEsquerdo \\
0.885558583 & 0.65487977 & 0.17156398 & Rodape & LateralEsquerdo \\
0.885558583 & 0.66100896 & 0.17156398 & Rodape & LateralEsquerdo \\
0.66713814 & 0.17156398 & Rodape & LateralEsquerdo
\end{tabular}




\begin{tabular}{lllll}
\hline Repetição & Dist. Topo & Dist. Esquerda & Classe & Resultado \\
\hline 0.885558583 & 0.67373880 & 0.17156398 & Rodape & LateralEsquerdo \\
0.885558583 & 0.67986799 & 0.17156398 & Rodape & LateralEsquerdo \\
0.885558583 & 0.59783121 & 0.32227488 & Rodape & LateralEsquerdo \\
0.888283379 & 0.60490335 & 0.32322275 & Rodape & LateralEsquerdo \\
0.885558583 & 0.61150401 & 0.32322275 & Rodape & LateralEsquerdo \\
0.885558583 & 0.61810467 & 0.32322275 & Rodape & LateralEsquerdo \\
0.885558583 & 0.63837812 & 0.34218010 & Rodape & Rodape \\
0.885558583 & 0.64497878 & 0.34218010 & Rodape & Rodape \\
0.885558583 & 0.65157944 & 0.34218010 & Rodape & Rodape \\
0.885558583 & 0.66430929 & 0.34218010 & Rodape & Rodape \\
0.885558583 & 0.67043847 & 0.34218010 & Rodape & Rodape \\
0.885558583 & 0.67703913 & 0.34218010 & Rodape & Rodape \\
0.885558583 & 0.68363979 & 0.34218010 & Rodape & Rodape \\
0.885558583 & 0.68976898 & 0.34218010 & Rodape & Rodape \\
0.885558583 & 0.69636964 & 0.34218010 & Rodape & Rodape \\
0.885558583 & 0.70909948 & 0.34218010 & Rodape & Rodape \\
0.885558583 & 0.71570014 & 0.34218010 & Rodape & Rodape \\
0.885558583 & 0.72230080 & 0.34218010 & Rodape & Rodape \\
0.885558583 & 0.72842999 & 0.34218010 & Rodape & Rodape \\
0.885558583 & 0.75153230 & 0.34218010 & Rodape & Rodape \\
0.885558583 & 0.75813296 & 0.34218010 & Rodape & Rodape \\
0.885558583 & 0.76473362 & 0.34218010 & Rodape & Rodape \\
0.885558583 & 0.77086280 & 0.34218010 & Rodape & Rodape \\
0.885558583 & 0.77746346 & 0.34218010 & Rodape & Rodape \\
0.885558583 & 0.78406412 & 0.34218010 & Rodape & Rodape \\
0.885558583 & 0.79019330 & 0.34218010 & Rodape & Rodape \\
0.885558583 & 0.60537482 & 0.49289099 & Rodape & Rodape \\
0.885558583 & 0.61291843 & 0.49383886 & Rodape & Rodape \\
0.885558583 & 0.61904762 & 0.49383886 & Rodape & Rodape \\
0.885558583 & 0.62517680 & 0.49383886 & Rodape & Rodape \\
0.885558583 & 0.63177746 & 0.49383886 & Rodape & Rodape \\
\hline
\end{tabular}




\begin{tabular}{|c|c|c|c|c|}
\hline Repetição & Dist. Topo & Dist. Esquerda & Classe & Resultado \\
\hline 0.885558583 & 0.63790665 & 0.49383886 & Rodape & Rodape \\
\hline 0.885558583 & 0.64450731 & 0.49383886 & Rodape & Rodape \\
\hline 0.885558583 & 0.65629420 & 0.49383886 & Rodape & Rodape \\
\hline 0.885558583 & 0.66242338 & 0.49383886 & Rodape & Rodape \\
\hline 0.885558583 & 0.66855257 & 0.49383886 & Rodape & Rodape \\
\hline 0.885558583 & 0.67515323 & 0.49383886 & Rodape & Rodape \\
\hline 0.885558583 & 0.68128241 & 0.49383886 & Rodape & Rodape \\
\hline 0.885558583 & 0.68788307 & 0.49383886 & Rodape & Rodape \\
\hline 0.885558583 & 0.69401226 & 0.49383886 & Rodape & Rodape \\
\hline 0.885558583 & 0.70061292 & 0.49383886 & Rodape & Rodape \\
\hline 0.885558583 & 0.70721358 & 0.49383886 & Rodape & Rodape \\
\hline 0.885558583 & 0.71334276 & 0.49383886 & Rodape & Rodape \\
\hline 0.885558583 & 0.71994342 & 0.49383886 & Rodape & Rodape \\
\hline 0.885558583 & 0.72654408 & 0.49383886 & Rodape & Rodape \\
\hline 0.885558583 & 0.73267327 & 0.49383886 & Rodape & Rodape \\
\hline 0.885558583 & 0.74493164 & 0.49383886 & Rodape & Rodape \\
\hline 0.885558583 & 0.75058934 & 0.49383886 & Rodape & Rodape \\
\hline 0.885558583 & 0.75671853 & 0.49383886 & Rodape & Rodape \\
\hline 0.885558583 & 0.76944837 & 0.49383886 & Rodape & Rodape \\
\hline 0.885558583 & 0.78500707 & 0.49289099 & Rodape & Rodape \\
\hline 0.885558583 & 0.79820839 & 0.49383886 & Rodape & Rodape \\
\hline 0.885558583 & 0.80386610 & 0.49383886 & Rodape & Rodape \\
\hline 0.885558583 & 0.80999528 & 0.49383886 & Rodape & Rodape \\
\hline 0.885558583 & 0.81612447 & 0.49383886 & Rodape & Rodape \\
\hline 0.885558583 & 0.82791136 & 0.49383886 & Rodape & Rodape \\
\hline 0.885558583 & 0.84016973 & 0.49383886 & Rodape & Rodape \\
\hline 0.885558583 & 0.85195662 & 0.49383886 & Rodape & Rodape \\
\hline 0.885558583 & 0.85195662 & 0.49383886 & Rodape & Rodape \\
\hline 0.885558583 & 0.85808581 & 0.49383886 & Rodape & Rodape \\
\hline 0.885558583 & 0.86421499 & 0.49383886 & Rodape & Rodape \\
\hline 0.885558583 & 0.86987270 & 0.49383886 & Rodape & Rodape \\
\hline
\end{tabular}




\begin{tabular}{lllll}
\hline Repetição & Dist. Topo & Dist. Esquerda & Classe & Resultado \\
\hline 0.88555883 & 0.88307402 & 0.49383886 & Rodape & Rodape \\
0.885558583 & 0.87647336 & 0.49383886 & Rodape & Rodape \\
0.88555853 & 0.88920321 & 0.49383886 & Rodape & Rodape \\
0.885558583 & 0.89533239 & 0.49383886 & Rodape & Rodape \\
0.885558583 & 0.90146158 & 0.49383886 & Rodape & Rodape \\
0.885558583 & 0.90711928 & 0.49383886 & Rodape & Rodape \\
0.885558583 & 0.60537482 & 0.64454976 & Rodape & Rodape \\
0.885558583 & 0.60537482 & 0.64454976 & Rodape & Rodape \\
0.885558583 & 0.61857614 & 0.64549763 & Rodape & Rodape \\
0.885558583 & 0.62423385 & 0.64549763 & Rodape & Rodape \\
0.885558583 & 0.63083451 & 0.64549763 & Rodape & Rodape \\
0.885558583 & 0.63743517 & 0.64549763 & Rodape & Rodape \\
0.885558583 & 0.64356436 & 0.64549763 & Rodape & Rodape \\
0.885558583 & 0.65016502 & 0.64549763 & Rodape & Rodape \\
0.885558583 & 0.65629420 & 0.64549763 & Rodape & Rodape \\
0.885558583 & 0.66289486 & 0.64549763 & Rodape & Rodape \\
0.885558583 & 0.67515323 & 0.64549763 & Rodape & Rodape \\
0.885558583 & 0.68694012 & 0.64549763 & Rodape & Rodape \\
0.885558583 & 0.72088637 & 0.64454976 & Rodape & Rodape \\
0.885558583 & 0.73361622 & 0.64549763 & Rodape & Rodape \\
0.885558583 & 0.73974540 & 0.64549763 & Rodape & Rodape \\
0.885558583 & 0.74587459 & 0.64549763 & Rodape & Rodape \\
0.885558583 & 0.74587459 & 0.64549763 & Rodape & Rodape \\
0.885558583 & 0.75766148 & 0.64549763 & Rodape & Rodape \\
0.885558583 & 0.76379067 & 0.64549763 & Rodape & Rodape \\
0.888283379 & 0.61291843 & 0.79715640 & Rodape & LateralDireito \\
0.885558583 & 0.61904762 & 0.79715640 & Rodape & LateralDireito \\
0.885558583 & 0.62564828 & 0.79715640 & Rodape & LateralDireito \\
0.885558583 & 0.63224894 & 0.79715640 & Rodape & LateralDireito \\
0.885558583 & 0.64497878 & 0.79715640 & Rodape & LateralDireito \\
\hline 0.65110797 & 0.79715640 & Rodape & LateralDireito
\end{tabular}




\begin{tabular}{lllll}
\hline Repetição & Dist. Topo & Dist. Esquerda & Classe & Resultado \\
\hline 0.885558583 & 0.65676568 & 0.79715640 & Rodape & LateralDireito \\
0.885558583 & 0.66289486 & 0.79715640 & Rodape & LateralDireito \\
0.885558583 & 0.66902405 & 0.79715640 & Rodape & LateralDireito \\
0.885558583 & 0.67515323 & 0.79715640 & Rodape & LateralDireito \\
0.885558583 & 0.68128241 & 0.79715640 & Rodape & LateralDireito \\
0.885558583 & 0.69401226 & 0.79715640 & Rodape & Rodape \\
0.885558583 & 0.69966997 & 0.79715640 & Rodape & Rodape \\
0.885558583 & 0.70579915 & 0.79715640 & Rodape & Rodape \\
0.888283379 & 0.72890146 & 0.79715640 & Rodape & Rodape \\
0.885558583 & 0.73550212 & 0.79715640 & Rodape & Rodape \\
0.885558583 & 0.74210278 & 0.79715640 & Rodape & Rodape \\
0.885558583 & 0.74823197 & 0.79715640 & Rodape & Rodape \\
0.885558583 & 0.75483263 & 0.79715640 & Rodape & Rodape \\
0.885558583 & 0.76096181 & 0.79715640 & Rodape & Rodape \\
0.885558583 & 0.76661952 & 0.79715640 & Rodape & Rodape \\
0.885558583 & 0.77274870 & 0.79715640 & Rodape & Rodape \\
0.885558583 & 0.78453560 & 0.79715640 & Rodape & Rodape \\
0.885558583 & 0.79066478 & 0.79715640 & Rodape & Rodape \\
0.885558583 & 0.79679396 & 0.79715640 & Rodape & Rodape \\
0.885558583 & 0.80292315 & 0.79715640 & Rodape & Rodape \\
0.885558583 & 0.83168317 & 0.79620853 & Rodape & Rodape \\
0.885558583 & 0.85148515 & 0.79715640 & Rodape & Rodape \\
0.888283379 & 0.94012258 & 0.32227488 & Rodape & Rodape \\
0.885558583 & 0.05752004 & 0.85687204 & MenuSuperior & MenuSuperior \\
0.885558583 & 0.05752004 & 0.76777251 & MenuSuperior & MenuSuperior \\
\hline & & & &
\end{tabular}

\section{A.1.3 inmetro.gov.br}

\begin{tabular}{lllll}
\hline Repetição & Dist. Topo & Dist. Esquerda & Classe & Resultado \\
\hline 0.516891892 & 0.01902017 & 0.370841487 & MenuSuperior & MenuSuperior \\
0.489864865 & 0.01902017 & 0.474559687 & MenuSuperior & MenuSuperior \\
0.486486486 & 0.01902017 & 0.560665362 & MenuSuperior & MenuSuperior \\
0.513513514 & 0.01902017 & 0.691780822 & MenuSuperior & MenuSuperior \\
0.554054054 & 0.01902017 & 0.840508806 & MenuSuperior & MenuSuperior
\end{tabular}




\begin{tabular}{lllll}
\hline Repetição & Dist. Topo & Dist. Esquerda & Classe & \multicolumn{1}{c}{ Resultado } \\
\hline 0.010135135 & 0.09567723 & 0.015655577 & LateralEsquerdo Conteudo \\
0.006756757 & 0.10835735 & 0.015655577 & LateralEsquerdo Conteudo \\
0.010135135 & 0.12103746 & 0.015655577 & LateralEsquerdo Conteudo \\
0.010135135 & 0.13371758 & 0.015655577 & LateralEsquerdo Conteudo \\
0.020270270 & 0.14582133 & 0.015655577 & LateralEsquerdo Conteudo \\
0.006756757 & 0.16599424 & 0.015655577 & LateralEsquerdo Conteudo \\
0.006756757 & 0.17867435 & 0.015655577 & LateralEsquerdo Conteudo \\
0.013513514 & 0.19135447 & 0.015655577 & LateralEsquerdo Conteudo \\
0.006756757 & 0.21095101 & 0.015655577 & LateralEsquerdo Conteudo \\
0.006756757 & 0.22363112 & 0.015655577 & LateralEsquerdo Conteudo \\
0.006756757 & 0.23631124 & 0.015655577 & LateralEsquerdo Conteudo \\
0.006756757 & 0.24899135 & 0.015655577 & LateralEsquerdo Conteudo \\
0.013513514 & 0.26109510 & 0.015655577 & LateralEsquerdo Conteudo \\
0.006756757 & 0.27377522 & 0.015655577 & LateralEsquerdo Conteudo \\
0.006756757 & 0.28645533 & 0.015655577 & LateralEsquerdo Conteudo \\
0.020270270 & 0.29913545 & 0.015655577 & LateralEsquerdo Conteudo \\
0.165540541 & 0.34755043 & 0.066536204 & LateralEsquerdo Conteudo \\
0.006756757 & 0.42651297 & 0.034246575 & LateralEsquerdo Conteudo \\
0.162162162 & 0.48011527 & 0.034246575 & LateralEsquerdo Conteudo \\
0.168918919 & 0.53314121 & 0.034246575 & LateralEsquerdo Conteudo \\
0.006756757 & 0.73948127 & 0.039138943 & LateralEsquerdo Conteudo \\
0.006756757 & 0.66916427 & 0.007827789 & LateralEsquerdo Conteudo \\
0.006756757 & 0.88126801 & 0.065557730 & LateralEsquerdo Conteudo \\
0.516891892 & 0.94466859 & 0.205479452 & Rodape & Conteudo \\
0.479729730 & 0.94236311 & 0.628180039 & Rodape & Conteudo \\
0.020270270 & 0.16368876 & 0.295499022 & Conteudo & Conteudo \\
0.020270270 & 0.20345821 & 0.295499022 & Conteudo & Conteudo \\
0.020270270 & 0.24322767 & 0.295499022 & Conteudo & Conteudo \\
0.020270270 & 0.28299712 & 0.295499022 & Conteudo & Conteudo \\
0.32276657 & 0.295499022 & Conteudo & Conteudo \\
0.10951009 & 0.760273973 & LateralDireito Conteudo
\end{tabular}




\begin{tabular}{|c|c|c|c|c|}
\hline Repetição & Dist. Topo & Dist. Esquerda & Classe & Resultado \\
\hline 0.118243243 & 0.12046110 & 0.760273973 & LateralDireito & Conteudo \\
\hline 0.118243243 & 0.13141210 & 0.760273973 & LateralDireito & Conteudo \\
\hline 0.023648649 & 0.14236311 & 0.760273973 & LateralDireito & Conteudo \\
\hline 0.131756757 & 0.15331412 & 0.760273973 & LateralDireito & Conteudo \\
\hline 0.010135135 & 0.16426513 & 0.760273973 & LateralDireito & Conteudo \\
\hline 0.101351351 & 0.17521614 & 0.760273973 & LateralDireito & Conteudo \\
\hline 0.108108108 & 0.18616715 & 0.760273973 & LateralDireito & Conteudo \\
\hline 0.037162162 & 0.19711816 & 0.760273973 & LateralDireito & Conteudo \\
\hline 0.010135135 & 0.20806916 & 0.760273973 & LateralDireito & Conteudo \\
\hline 0.006756757 & 0.21959654 & 0.760273973 & LateralDireito & Conteudo \\
\hline 0.027027027 & 0.23054755 & 0.760273973 & LateralDireito & Conteudo \\
\hline 0.010135135 & 0.24149856 & 0.760273973 & LateralDireito & Conteudo \\
\hline 0.010135135 & 0.25244957 & 0.760273973 & LateralDireito & Conteudo \\
\hline 0.010135135 & 0.26340058 & 0.760273973 & LateralDireito & Conteudo \\
\hline 0.118243243 & 0.27435159 & 0.760273973 & LateralDireito & Conteudo \\
\hline 0.010135135 & 0.29337176 & 0.760273973 & LateralDireito & Conteudo \\
\hline 0.027027027 & 0.30432277 & 0.760273973 & LateralDireito & Conteudo \\
\hline 0.027027027 & 0.31527377 & 0.760273973 & LateralDireito & Conteudo \\
\hline 0.010135135 & 0.32622478 & 0.760273973 & LateralDireito & Conteudo \\
\hline 0.108108108 & 0.33717579 & 0.760273973 & LateralDireito & Conteudo \\
\hline 0.030405405 & 0.34812680 & 0.760273973 & LateralDireito & Conteudo \\
\hline 0.010135135 & 0.35907781 & 0.760273973 & LateralDireito & Conteudo \\
\hline 0.152027027 & 0.37002882 & 0.760273973 & LateralDireito & Conteudo \\
\hline 0.037162162 & 0.40000000 & 0.760273973 & LateralDireito & Conteudo \\
\hline 0.037162162 & 0.41095101 & 0.760273973 & LateralDireito & Conteudo \\
\hline 0.037162162 & 0.42190202 & 0.760273973 & LateralDireito & Conteudo \\
\hline 0.010135135 & 0.43285303 & 0.760273973 & LateralDireito & Conteudo \\
\hline 0.023648649 & 0.44438040 & 0.760273973 & LateralDireito & Conteudo \\
\hline 0.168918919 & 0.38904899 & 0.760273973 & LateralDireito & Conteudo \\
\hline
\end{tabular}

\section{A.1.4 secom.gov.br}

\begin{tabular}{lllll}
\hline Repetição & Dist. Topo & Dist. Esquerda & Classe & Resultado \\
\hline 0.922169811 & 0.01324707 & 0.67701863 & MenuSuperior & MenuSuperior \\
0.922169811 & 0.01324707 & 0.78053830 & MenuSuperior & MenuSuperior
\end{tabular}




\begin{tabular}{lllll}
\hline Repetição & Dist. Topo & Dist. Esquerda & Classe & Resultado \\
\hline 0.922169811 & 0.01324707 & 0.90476190 & MenuSuperior MenuSuperior \\
0.922169811 & 0.01447936 & 0.30848861 & MenuSuperior $\quad$ MenuSuperior \\
0.922169811 & 0.01447936 & 0.21118012 & MenuSuperior $\quad$ MenuSuperior \\
0.922169811 & 0.01447936 & 0.11594203 & MenuSuperior $\quad$ MenuSuperior \\
0.922169811 & 0.01447936 & 0.00310559 & MenuSuperior LateralEsquerdo \\
0.922169811 & 0.05760937 & 0.68219462 & MenuSuperior MenuSuperior \\
0.922169811 & 0.05760937 & 0.81884058 & MenuSuperior MenuSuperior \\
0.922169811 & 0.05760937 & 0.88198758 & MenuSuperior MenuSuperior \\
0.705188679 & 0.08379544 & 0.00310559 & LateralEsquerdo LateralEsquerdo \\
0.922169811 & 0.13986445 & 0.00310559 & LateralEsquerdo LateralEsquerdo \\
0.922169811 & 0.15403574 & 0.00310559 & LateralEsquerdo LateralEsquerdo \\
0.922169811 & 0.16358595 & 0.00310559 & LateralEsquerdo LateralEsquerdo \\
0.922169811 & 0.17282810 & 0.00310559 & LateralEsquerdo LateralEsquerdo \\
0.922169811 & 0.18237831 & 0.00310559 & LateralEsquerdo LateralEsquerdo \\
0.922169811 & 0.19162046 & 0.00310559 & LateralEsquerdo LateralEsquerdo \\
0.922169811 & 0.20117067 & 0.00310559 & LateralEsquerdo LateralEsquerdo \\
0.922169811 & 0.21041282 & 0.00310559 & LateralEsquerdo LateralEsquerdo \\
0.922169811 & 0.21996303 & 0.00310559 & LateralEsquerdo LateralEsquerdo \\
0.922169811 & 0.26340111 & 0.00310559 & LateralEsquerdo LateralEsquerdo \\
0.922169811 & 0.27295133 & 0.00310559 & LateralEsquerdo LateralEsquerdo \\
0.922169811 & 0.28712261 & 0.00310559 & LateralEsquerdo LateralEsquerdo \\
0.922169811 & 0.29667283 & 0.00310559 & LateralEsquerdo LateralEsquerdo \\
0.554245283 & 0.30591497 & 0.00310559 & LateralEsquerdo LateralEsquerdo \\
0.922169811 & 0.31546519 & 0.00310559 & LateralEsquerdo LateralEsquerdo \\
0.922169811 & 0.32470733 & 0.00310559 & LateralEsquerdo LateralEsquerdo \\
0.922169811 & 0.33918669 & 0.00310559 & LateralEsquerdo LateralEsquerdo \\
0.556603774 & 0.34842883 & 0.00310559 & LateralEsquerdo LateralEsquerdo \\
0.554245283 & 0.36290819 & 0.00310559 & LateralEsquerdo LateralEsquerdo \\
0.551886792 & 0.41712877 & 0.00310559 & LateralEsquerdo Conteudo \\
0.014150943 & 0.20517560 & 0.23706004 & Conteudo & Conteudo
\end{tabular}




\begin{tabular}{|c|c|c|c|c|}
\hline Repetição & Dist. Topo & Dist. Esquerda & Classe & Resultado \\
\hline 0.014150943 & 0.20517560 & 0.49068323 & Conteudo & Conteudo \\
\hline 0.014150943 & 0.10936537 & 0.75879917 & Conteudo & Conteudo \\
\hline 0.004716981 & 0.17344424 & 0.75879917 & Conteudo & Conteudo \\
\hline 0.033018868 & 0.23074553 & 0.75879917 & Conteudo & Conteudo \\
\hline 0.004716981 & 0.23321011 & 0.51759834 & Conteudo & Conteudo \\
\hline 0.004716981 & 0.28773876 & 0.22049689 & Conteudo & Conteudo \\
\hline 0.033018868 & 0.33887862 & 0.22049689 & Conteudo & Conteudo \\
\hline 0.004716981 & 0.33703019 & 0.48964803 & Conteudo & Conteudo \\
\hline 0.033018868 & 0.33703019 & 0.75879917 & Conteudo & Conteudo \\
\hline 0.007075472 & 0.40819470 & 0.22049689 & Conteudo & Conteudo \\
\hline 0.007075472 & 0.40819470 & 0.75879917 & Conteudo & Conteudo \\
\hline 0.030660377 & 0.40819470 & 0.48964803 & Conteudo & Conteudo \\
\hline 0.007075472 & 0.47412200 & 0.22049689 & Conteudo & Conteudo \\
\hline 0.035377358 & 0.52834258 & 0.22049689 & Conteudo & Conteudo \\
\hline 0.030660377 & 0.52834258 & 0.48964803 & Conteudo & Conteudo \\
\hline 0.030660377 & 0.52834258 & 0.75879917 & Conteudo & Conteudo \\
\hline 0.028301887 & 0.59581023 & 0.22049689 & Conteudo & Conteudo \\
\hline 0.028301887 & 0.59581023 & 0.48964803 & Conteudo & Conteudo \\
\hline 0.030660377 & 0.59581023 & 0.75879917 & Conteudo & Conteudo \\
\hline 0.922169811 & 0.84849045 & 0.02380952 & Rodape & Rodape \\
\hline 0.922169811 & 0.85434381 & 0.02380952 & Rodape & Rodape \\
\hline 0.922169811 & 0.86019717 & 0.02380952 & Rodape & Rodape \\
\hline 0.922169811 & 0.86605052 & 0.02380952 & Rodape & Rodape \\
\hline 0.922169811 & 0.87190388 & 0.02380952 & Rodape & Rodape \\
\hline 0.922169811 & 0.87775724 & 0.02380952 & Rodape & Rodape \\
\hline 0.922169811 & 0.88361060 & 0.02380952 & Rodape & Rodape \\
\hline 0.922169811 & 0.88915588 & 0.02380952 & Rodape & Rodape \\
\hline 0.922169811 & 0.89500924 & 0.02380952 & Rodape & Rodape \\
\hline 0.922169811 & 0.84849045 & 0.26190476 & Rodape & Rodape \\
\hline 0.922169811 & 0.85434381 & 0.26190476 & Rodape & Rodape \\
\hline 0.922169811 & 0.86019717 & 0.26190476 & Rodape & Rodape \\
\hline
\end{tabular}




\begin{tabular}{lllll}
\hline Repetição & Dist. Topo & Dist. Esquerda & Classe & Resultado \\
\hline 0.922169811 & 0.86605052 & 0.26190476 & Rodape & Rodape \\
0.922169811 & 0.87190388 & 0.26190476 & Rodape & Rodape \\
0.922169811 & 0.87775724 & 0.26190476 & Rodape & Rodape \\
0.924528302 & 0.88361060 & 0.26190476 & Rodape & Rodape \\
0.922169811 & 0.88915588 & 0.26190476 & Rodape & Rodape \\
0.922169811 & 0.89500924 & 0.26190476 & Rodape & Rodape \\
0.922169811 & 0.80086260 & 0.26190476 & Rodape & Rodape \\
0.922169811 & 0.84849045 & 0.73602484 & Rodape & Rodape \\
0.922169811 & 0.85434381 & 0.73602484 & Rodape & Rodape \\
0.922169811 & 0.84849045 & 0.49896480 & Rodape & Rodape \\
0.924528302 & 0.85434381 & 0.49896480 & Rodape & Rodape \\
0.924528302 & 0.86019717 & 0.49896480 & Rodape & Rodape \\
\hline
\end{tabular}

\section{A.1.5 usa.gov}

\begin{tabular}{lllll}
\hline Repetição & Dist. Topo & Dist. Esquerda & Classe & Resultado \\
\hline 0.98125 & 0.005309735 & 0.03529412 & MenuSuperior & MenuSuperior \\
0.98125 & 0.004955752 & 0.86134454 & MenuSuperior & MenuSuperior \\
0.98125 & 0.056637168 & 0.07815126 & MenuSuperior & MenuSuperior \\
0.98250 & 0.056637168 & 0.21512605 & MenuSuperior & MenuSuperior \\
0.98250 & 0.056637168 & 0.48991597 & MenuSuperior & MenuSuperior \\
0.98125 & 0.056637168 & 0.35294118 & MenuSuperior & MenuSuperior \\
0.98125 & 0.056637168 & 0.62689076 & MenuSuperior & MenuSuperior \\
0.98125 & 0.056637168 & 0.76470588 & MenuSuperior & MenuSuperior \\
0.98125 & 0.056637168 & 0.90168067 & MenuSuperior & MenuSuperior \\
0.98125 & 0.130973451 & 0.80504202 & MenuSuperior & MenuSuperior \\
0.98125 & 0.130973451 & 0.89495798 & MenuSuperior & MenuSuperior \\
0.00750 & 0.275044248 & 0.06722689 & Conteudo & Conteudo \\
0.01125 & 0.282123894 & 0.06722689 & Conteudo & Conteudo \\
0.98125 & 0.296283186 & 0.06722689 & Conteudo & LateralEsquerdo \\
0.01500 & 0.313982301 & 0.30672269 & Conteudo & Conteudo \\
0.01000 & 0.321061947 & 0.30672269 & Conteudo & Conteudo \\
0.01625 & 0.328141593 & 0.30672269 & Conteudo & Conteudo
\end{tabular}




\begin{tabular}{|c|c|c|c|c|}
\hline Repetição & Dist. Topo & Dist. Esquerda & Classe & Resultado \\
\hline 0.01375 & 0.313982301 & 0.54621849 & Conteudo & Conteudo \\
\hline 0.01125 & 0.321061947 & 0.54621849 & Conteudo & Conteudo \\
\hline 0.00875 & 0.328141593 & 0.54621849 & Conteudo & Conteudo \\
\hline 0.98250 & 0.335221239 & 0.54621849 & Conteudo & Conteudo \\
\hline 0.01000 & 0.313982301 & 0.78571429 & Conteudo & Conteudo \\
\hline 0.01250 & 0.328141593 & 0.78571429 & Conteudo & Conteudo \\
\hline 0.46375 & 0.377345133 & 0.02100840 & Conteudo & Conteudo \\
\hline 0.01625 & 0.377345133 & 0.26638656 & Conteudo & Conteudo \\
\hline 0.98250 & 0.483539823 & 0.02100840 & Conteudo & LateralEsquerdo \\
\hline 0.98125 & 0.483539823 & 0.26638656 & Conteudo & LateralEsquerdo \\
\hline 0.98250 & 0.377345133 & 0.51260504 & Conteudo & LateralEsquerdo \\
\hline 0.98125 & 0.377345133 & 0.75798319 & Conteudo & LateralDireito \\
\hline 0.98125 & 0.483539823 & 0.51260504 & Conteudo & LateralEsquerdo \\
\hline 0.98125 & 0.483539823 & 0.75798319 & Conteudo & LateralDireito \\
\hline 0.46375 & 0.681415929 & 0.03361344 & Conteudo & Conteudo \\
\hline 0.45500 & 0.681415929 & 0.27058824 & Conteudo & Conteudo \\
\hline 0.46375 & 0.681415929 & 0.50756302 & Conteudo & Conteudo \\
\hline 0.08625 & 0.745486726 & 0.50756302 & Conteudo & Conteudo \\
\hline 0.01500 & 0.745486726 & 0.27058824 & Conteudo & Conteudo \\
\hline 0.09000 & 0.745486726 & 0.03361344 & Conteudo & Conteudo \\
\hline 0.03500 & 0.809203540 & 0.03361344 & Conteudo & Conteudo \\
\hline 0.08750 & 0.809203540 & 0.50756302 & Conteudo & Conteudo \\
\hline 0.46500 & 0.826902655 & 0.03361344 & Conteudo & Conteudo \\
\hline 0.54250 & 0.763185841 & 0.03361344 & Conteudo & Conteudo \\
\hline 0.46500 & 0.809203540 & 0.27058824 & Conteudo & Conteudo \\
\hline 0.98125 & 0.898053097 & 0.02100840 & Rodape & Rodape \\
\hline 0.98125 & 0.912920354 & 0.02100840 & Rodape & Rodape \\
\hline 0.98250 & 0.927079646 & 0.02100840 & Rodape & Rodape \\
\hline 0.98125 & 0.897345133 & 0.34873950 & Rodape & Rodape \\
\hline 0.98125 & 0.906548673 & 0.34873950 & Rodape & Rodape \\
\hline 0.98125 & 0.916106195 & 0.34873950 & Rodape & Rodape \\
\hline
\end{tabular}




\begin{tabular}{lllll}
\hline Repetição & Dist. Topo & Dist. Esquerda & Classe & Resultado \\
\hline 0.98125 & 0.925309735 & 0.34873950 & Rodape & Rodape \\
0.98125 & 0.944070796 & 0.34873950 & Rodape & Rodape \\
0.98125 & 0.953274336 & 0.34873950 & Rodape & Rodape \\
0.98125 & 0.962831858 & 0.34873950 & Rodape & Rodape \\
0.03500 & 0.660176991 & 0.75798319 & Conteudo & Conteudo \\
0.00625 & 0.678584071 & 0.75798319 & Conteudo & Conteudo \\
0.08625 & 0.812743363 & 0.75798319 & Conteudo & Conteudo \\
0.01500 & 0.789026549 & 0.75798319 & Conteudo & Conteudo \\
0.09000 & 0.770619469 & 0.75798319 & Conteudo & Conteudo \\
0.08750 & 0.733805310 & 0.75798319 & Conteudo & Conteudo \\
0.46375 & 0.715398230 & 0.75798319 & Conteudo & Conteudo \\
0.02000 & 0.696991150 & 0.75798319 & Conteudo & Conteudo \\
\hline
\end{tabular}

